UNIVERSIDADE DE SÃO PAULO

FACULDADE DE ECONOMIA, ADMINISTRAÇÃO E CONTABILIDADE DEPARTAMENTO DE ADMINISTRAÇÃO PROGRAMA DE PÓS-GRADUAÇÃo EM ADMINISTRAÇÃo

O EFEITO DE VALÊNCIA DA RECOMENDAÇÃO E MATURIDADE DE MARCA EM DECISÕES DE COMPRA QUE ENVOLVEM DIFERENTES NÍVEIS DE ESFORÇO COGNITIVO

Daniel Infante Ferreira Gonçalves

Orientador: Prof. Dr. José Afonso Mazzon 
Prof. Dr. Marco Antonio Zago Reitor da Universidade de São Paulo

Prof. Dr. Adalberto Américo Fischmann Diretor da Faculdade de Economia, Administração e Contabilidade

Prof. Dr. Roberto Sbragia

Chefe do Departamento de Administração

Prof. Dr. Moacir de Miranda Oliveira Júnior Coordenador do Programa de Pós-graduação em Administração 
DANIEL INFANTE FERREIRA GONÇALVES

\section{O EFEITO DE VALÊNCIA DA RECOMENDAÇÃO E MATURIDADE DE MARCA EM DECISÕES DE COMPRA QUE ENVOLVEM DIFERENTES NÍVEIS DE ESFORÇO COGNITIVO}

Dissertação apresentada ao Departamento de Administração da Faculdade de Economia, Administração e Contabilidade da Universidade de São Paulo como requisito para a obtenção do título de Mestre em Administração.

Orientador: Prof. Dr. José Afonso Mazzon

\section{SÃo PAULO}




\section{FICHA CATALOGRÁFICA}

Elaborada pela Seção de Processamento Técnico do SBD/FEA/USP

Gonçalves, Daniel Infante Ferreira.

$\mathrm{O}$ efeito de valência da recomendação e maturidade de marca em decisões de compra que envolvem diferentes níveis de esforço cognitivo. - São Paulo, 2015

$80 \mathrm{p}$.

Dissertação (Mestrado) - Universidade de São Paulo, 2015.

Orientador: José Afonso Mazzon.

1. Comportamento do consumidor. 2. Marcas. 3. Marketing. I. Universidade de São Paulo. Faculdade de Economia, Administração e Contabilidade. II. Título.

CDD -658.8342 
Aos meus pais 


\section{AGRADECIMENTOS}

Agradeço aos meus pais e família, que não deixaram de me apoiar e dar o suporte necessário para que concluísse este trabalho.

Agradeço ao amigo e "sócio", Luiz Filipe Trivelato, pelo apoio e incentivo dado à elaboração deste estudo.

Agradeço à empresa eCGlobal Solutions que, gentilmente, disponibilizou seu painel de respondentes para a aplicação da pesquisa.

Agradeço, especialmente, ao meu orientador, Prof. Dr. José Afonso Mazzon, pelos ensinamentos, caminhos sugeridos e, principalmente, por estar sempre disposto a ajudar em tudo o que foi necessário para a conclusão deste trabalho.

E, por fïm, agradeço à minha esposa, Tássia, pela dedicação, cumplicidade, amor e carinho desde o início desta jornada. 


\section{RESUMO}

Atualmente, a comunicação entre marcas e consumidores é um processo complexo. O excessivo volume de mensagens publicitárias leva à maior seletividade e menor sensibilidade a apelos persuasivos que, no passado, surtiam efeito. Assim, o monitoramento e uso de "boca a boca", considerado por consumidores um dos meios de comunicação mais confiável, tornase fundamental. O estudo sobre a relação entre marcas, recomendação e decisões de consumo não é algo novo na literatura de marketing, porém, muito pouco se sabe sobre como tais construtos se relacionam em decisões que exigem diferentes níveis de cognição. Este foi o elemento direcionador deste trabalho que procura investigar o papel que a valência da recomendação e o estágio de maturidade de marcas apresentam em decisões de compra que exigem diferentes níveis de esforço cognitivo, assumindo a visão apresentada pelas teorias de duplo processo cognitivo. Com este propósito, foi desenvolvido um experimento com desenho fatorial completo, considerando a manipulação de três fatores de tratamento (valência da recomendação, maturidade de marca e tipo de decisão) de dois níveis (positiva ou negativa, madura ou nova, urgente ou planejada, respectivamente) e a avaliação de seus efeitos em intenção de compra (variável dependente). O procedimento de coleta envolveu o desenvolvimento de estímulos para a representação da combinação dos níveis dos tratamentos em oito celas de teste independentes $\left(2^{3}\right)$ e de um questionário de autopreenchimento pela Internet. Para a análise dos resultados, aplicaram-se modelos lineares generalizados para teste de cada uma das hipóteses de pesquisa. Os resultados mostram que, em situações de decisão urgente, nas quais o esforço cognitivo é menor, o efeito da valência da recomendação em intenção de compra é superior ao efeito da maturidade de uma marca. Por outro lado, em situações de decisão planejada, nas quais o esforço cognitivo é maior, o efeito da maturidade de uma marca em intenção de compra é superior ao efeito de valência da recomendação. Uma marca nova, que ainda está em processo de construção de sua imagem, sofreu maior efeito da valência de recomendação e, portanto, teve sua intenção de compra mais sensível a situações de decisão urgente. Para uma marca madura, observou-se que sua intenção de compra não varia entre situações de decisão urgente e planejada quando ocorre uma recomendação positiva. Porém, quando ocorreu uma recomendação negativa, houve maior sensibilidade e a intenção de compra por uma marca madura foi mais afetada em situações de decisão urgente do que planejada. Por fim, encontrou-se efeito interativo significativo entre valência da recomendação, maturidade da marca e tipo de decisão, o que validou a existência de cenários nos quais uma marca nova pode ter intenção de compra párea a uma marca madura. Estes resultados podem auxiliar no desenvolvimento de estratégias de comunicação de marketing, principalmente no que se refere ao uso e monitoramento de ações de "boca a boca" para a experimentação de uma marca nova ou proteção de uma marca madura.

Palavras-chave: comportamento do consumidor, marcas, marketing. 


\begin{abstract}
Nowadays, the communication between brands and consumers is a complex process. The excessive amount of advertising creates higher selectivity and lower sensibility to persuasive messages that, in the past, have been effective. Then, monitoring and using the "word-ofmouth" (WOM), considered one of the most trustable media by consumers, became essential. The study about brands, WOM and their consequences to purchase decisions is not new to marketing literature; however, understanding how these constructs interact to each other at different levels of cognition has not been explored yet. Aiming to fulfill this gap, the present study was developed to investigate the effect of WOM valence and brand maturity level on purchase decisions taken at different levels of cognitive effort, assuming what is presented by dual-process cognitive theories. For this sake, an experiment was applied using a fullfactorial design, considering the manipulation of three treatments/ independent variables (WOM valence, brand maturity level and type of purchase decision) of two levels each (positive or negative, mature or new, urgent or planned, respectively) and the analysis of their effects on purchase intention (dependent variable). An online questionnaire was applied for data collection in eight different and independent groups of test $\left(2^{3}\right)$. For testing each one of the research hypotheses, general linear models were applied. Results showed that, in an urgent decision, when the level of cognitive effort is lower, the effect of WOM valence in purchase intention is stronger than the effect of brand maturity level. On the other hand, in a planned decision, when the level of cognitive effort is higher, the effect of brand maturity level is stronger than the effect of WOM valence. A new brand, which is beginning to build its equity, was more affected by WOM valence, thus, its purchase intention was more sensible in urgent decisions. For a mature brand, when exposed to positive WOM, there was no difference in its purchase intention comparing both types of decision. Although, when a mature brand was exposed to negative WOM, there was a higher sensibility and its purchase intention was more affected in an urgent decision. Finally, the interactive effect among the three treatments was significant, validating the existence of scenarios where the purchase intention of a new brand is parity to a mature brand. These findings may help on the development of marketing communication strategies, mainly to what refers to the usage and monitoring of "word-of-mouth" for stimulating the trial of a new brand or the protection of a mature brand.
\end{abstract}

Keywords: consumer behavior, brands, marketing. 


\section{SUMÁRIO}

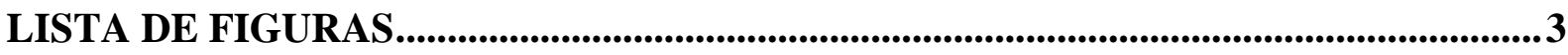

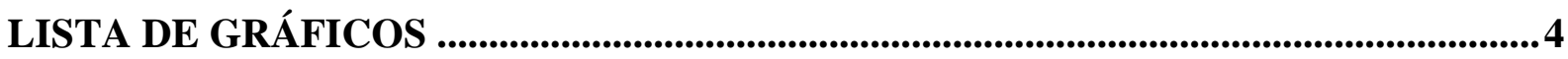

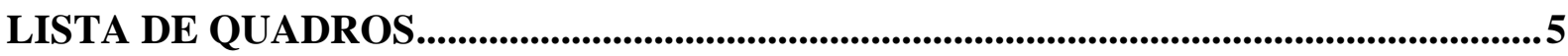

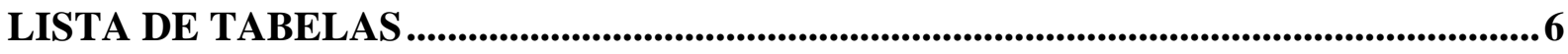

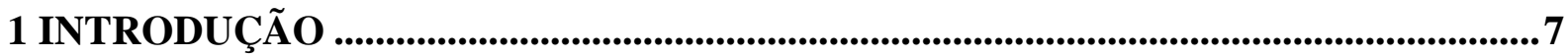

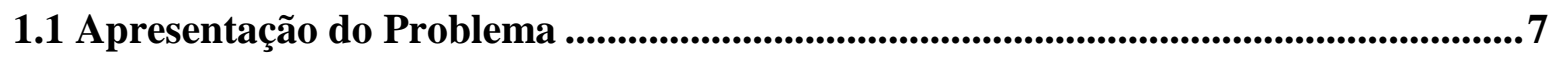

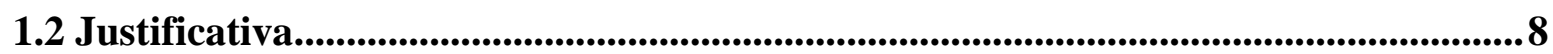

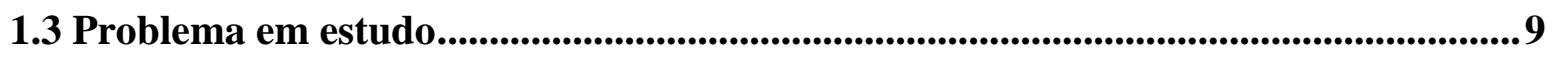

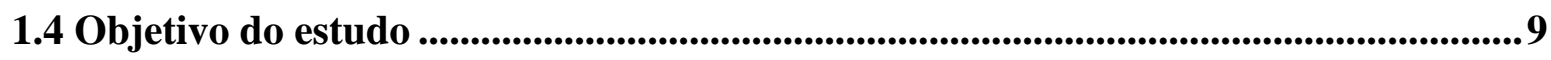

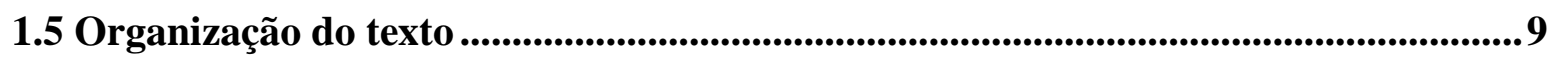

2 FUNDAMENTAÇÃO TEÓRICA .................................................................................11

$2.1 \mathrm{O}$ fenômeno do "boca a boca" ....................................................................................11

2.1.1 A relação entre marcas e a geração de "boca a boca" ............................................. 13

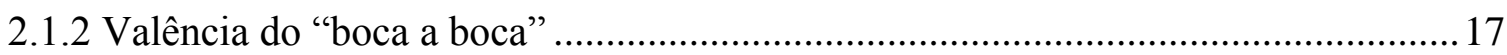

2.2 Maturidade de Marca.................................................................................................19

2.3 Processamento Cognitivo: Modelos de Duplo Processo (Dual-process models) ......22

2.3.1 Modelo de Probabilidade de Elaboração (ELM) .......................................................2 23

2.3.2 Modelo Heurístico-Sistemático (HSM) ................................................................. 24

2.3.3 Modelo de Kahneman: Sistema 1 e Sistema 2 .......................................................2. 25

2.4 Intenção de Compra .........................................................................................22

3 MODELO TEÓRICO PROPOSTO E HIPÓTESES DE PESQUISA ............................. 29

3.1 Apresentação do Modelo Teórico ...............................................................................29

3.2 Hipóteses de pesquisa propostas...........................................................................30

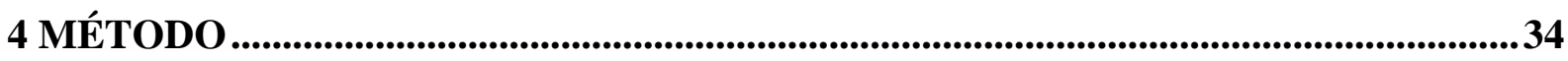

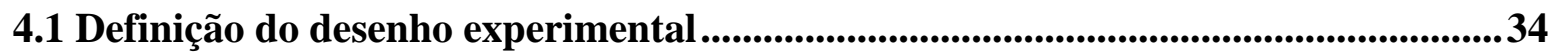

4.2 Instrumento de coleta de dados ............................................................................35

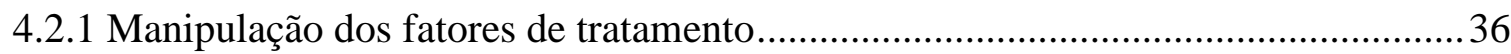

4.2.2 Definição de escala para mensuração de construto dependente ................................ 36

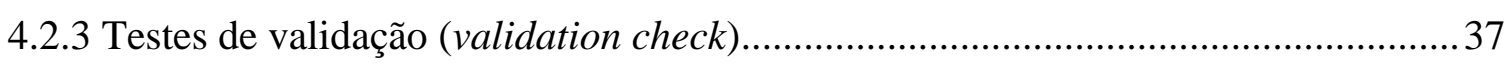

4.3 Abrangência e Método de coleta de dados............................................................337

4.4 Tipo, Tamanho e Perfil de Amostra ..............................................................................38 
5.1 Validação do construto latente de Intenção de Compra ...........................................42

5.2 Premissas para aplicação dos modelos lineares generalizados (ANOVAs) ..............44

5.3 ANOVA de dois fatores para validação de H1a .........................................................45

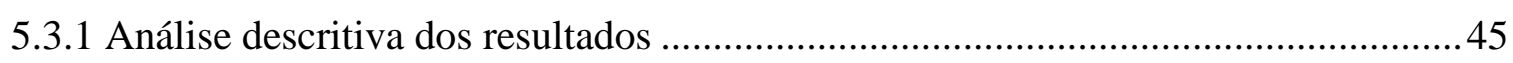

5.3.2 Teste de homogeneidade de variância entre os grupos de teste ...............................46

5.3.3 Avaliação do ajuste geral e efeito dos fatores no modelo ........................................46

5.4 ANOVA de dois fatores para validação de H1b................................................49

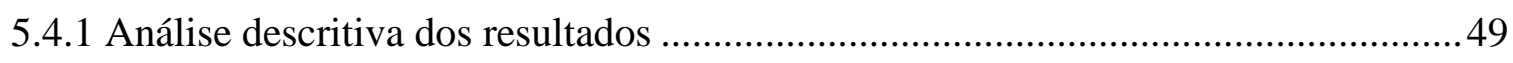

5.4.2 Teste de homogeneidade de variância entre os grupos de teste .............................. 49

5.4.3 Avaliação do ajuste geral e efeito dos fatores no modelo .......................................50

5.5 ANOVAs de um fator para validação de H2a e H2b..............................................52

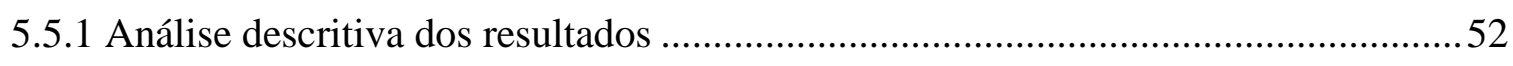

5.5.2 Teste de homogeneidade de variância entre os grupos de teste ................................52

5.5.3 Verificação da diferença de médias entre os grupos de teste ...................................53

5.6 ANOVAs de um fator para validação de H3a e H3b................................................54

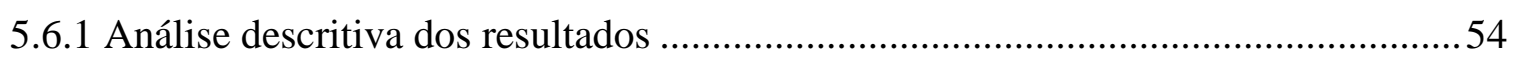

5.6.2 Teste de homogeneidade de variância entre os grupos de teste ................................55

5.6.3 Verificação da diferença de médias entre os grupos de teste ....................................55

5.7 ANOVA de três fatores para validação de H4 ................................................56

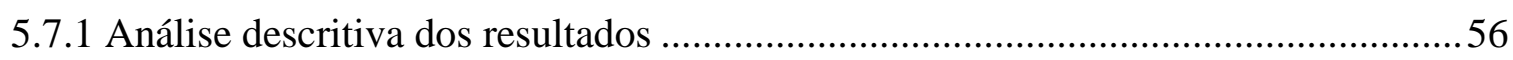

5.7.2 Teste de homogeneidade de variância entre os grupos de teste ...............................57

5.7.3 Avaliação do ajuste geral e efeito dos fatores no modelo .......................................58

5.8 Consolidação dos resultados para as hipóteses de pesquisa ...................................61

6 DISCUSSÃO DOS RESULTADOS E CONCLUSÕES....................................................62

7 LIMITAÇÕES DO ESTUDO E SUGESTÕES DE PESQUISAS FUTURAS................66

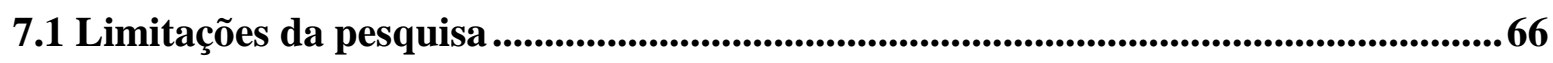

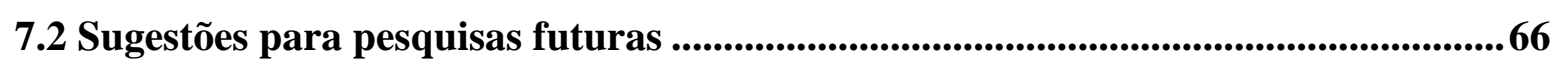

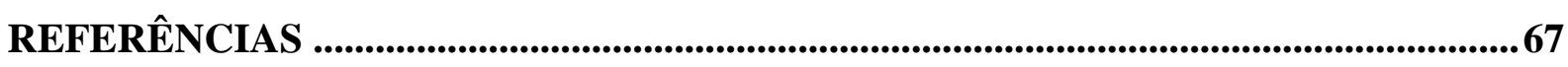

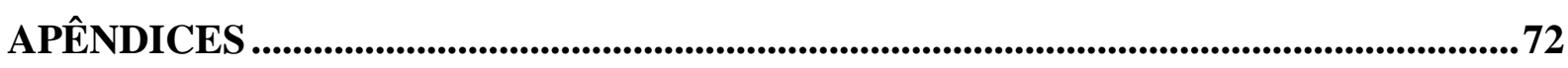

Apêndice A - Questionário aplicado na pesquisa de campo.........................................72

Apêndice B - Estímulos que compuseram as estórias apresentadas nas celas de teste 75 


\section{LISTA DE FIGURAS}

Figura 1 - Modelo de associação entre fatores de geração de "boca a boca" com características de marca proposto por Lovett, Peres e Shachar (2013) .......................................... 16

Figura 2 - Modelo de valor de marca baseado no cliente (CBBE) de Keller (1993) ...............20

Figura 3 - Sistemas 1 e 2 de processamento cognitivo de Kahneman .....................................25

Figura 4 - Representação gráfica das componentes do modelo teórico proposto ....................229

Figura 5 - Fluxo de aplicação e Módulos do questionário de pesquisa ....................................35 


\section{LISTA DE GRÁFICOS}

Gráfico 1 - Representação gráfica do efeito de interação entre fatores para decisão urgente .. 48 Gráfico 2 - Representação gráfica do efeito de interação entre fatores para decisão planejada 51

Gráfico 3 - Médias de intenção de compra para cada uma das celas de teste 59 


\section{LISTA DE QUADROS}

Quadro 1 - Relação de Motivações, Fatores de Geração de Boca a boca e Características de

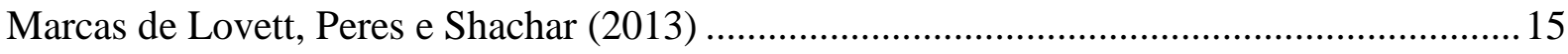

Quadro 2 - Relacionamento entre objetivos e hipóteses de pesquisa ........................................33

Quadro 3 - Fatores aplicados no experimento fatorial desenvolvido ...................................... 34

Quadro 4 - Estrutura das celas independentes de teste em função de cada fator ..................... 35

Quadro 5 - Atributos que compõem o construto dependente de Intenção de Compra..............37

Quadro 6 - Matriz de Amarração - Objetivos, hipóteses, variáveis de pesquisa e métodos de

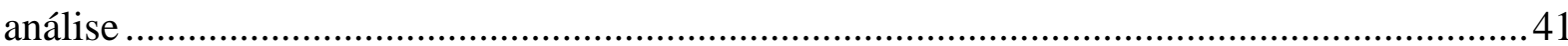

Quadro 7 - Resultado consolidado dos testes de hipóteses efetuados ...................................61 


\section{LISTA DE TABELAS}

Tabela 1 - Caracterização do Perfil da Amostra 39

Tabela 2 - Resultados da Análise Fatorial Exploratória pelo método de componentes principais 43

Tabela 3 - Estatísticas descritivas para ANOVA de 2 fatores em decisão urgente. 46

Tabela 4 - Teste univariado de Levene para ANOVA de 2 fatores em decisão urgente. 46

Tabela 5 - Resultados de análise de variância de dois fatores para decisão urgente. 47

Tabela 6 - Estatísticas descritivas para ANOVA de 2 fatores em decisão planejada. 49

Tabela 7 - Teste univariado de Levene para ANOVA de 2 fatores em decisão planejada .......50

Tabela 8 - Resultados de análise de variância de dois fatores para decisão planejada.............50

Tabela 9 - Estatísticas descritivas para as ANOVAs de 1 fator para marca nova ....................52

Tabela 10 - Teste univariado de Levene para as ANOVAs de 1 fator para marca nova..........53

Tabela 11 - Resultados de ANOVAs de um fator para marca nova .......................................53

Tabela 12 - Estatísticas descritivas para as ANOVAs de 1 fator para marca madura...............55

Tabela 13 - Teste univariado de Levene para as ANOVAs de 1 fator para marca madura ......55

Tabela 14 - Resultados de ANOVAs de um fator para marca madura......................................55

Tabela 15 - Estatísticas descritivas para ANOVA de três fatores ............................................57

Tabela 16 - Teste univariado de Levene para ANOVA de três fatores .....................................57

Tabela 17 - Resultados de análise de variância de três fatores................................................58

Tabela 18 - Estrutura das celas independentes de teste em função de cada fator.....................60

Tabela 19 - Comparação entre médias das celas de teste e níveis de significância do teste de Scheffé 


\section{INTRODUÇÃO}

\subsection{Apresentação do Problema}

Já não é novidade que, nos dias atuais, consumidores estão expostos a múltiplos tipos de meios de comunicação e são constantemente "bombardeados" por mensagens sobre produtos e marcas. Tal facilidade, rapidez e intensidade de acesso a informações impacta, diretamente, a forma como indivíduos se comportam em relação às suas decisões de consumo, tornando-os mais seletivos e menos sensíveis ao que produtos e marcas prometem (KELLER; MACHADO, 2007).

Dessa maneira, entender como criar atenção, gerar interesse e levar consumidores à ação de compra são etapas de um processo ainda mais complexo para empresas e profissionais de marketing. Por essa razão, identificar e saber como gerenciar meios de comunicação que possuem maior impacto em decisões de consumo é algo fundamental.

Um dos mais eficazes meios de comunicação que, muitas vezes, é deixado de lado pelas empresas, é o próprio consumidor. A força e o poder de influência que as opiniões de consumidores possuem em atitudes e comportamentos de outros indivíduos são de extrema relevância. Segundo o estudo geral sobre "Confiança Global em Publicidade e Mensagens de Marca”, realizado há dois anos pela Nielsen (2013), a recomendação de amigos e conhecidos é a forma mais confiável de comunicação e, também, aquela que mais motiva a ação de compra (84\%), superando os tradicionais comerciais em televisão (68\%) e anúncios em jornais e revistas (65\%). No Brasil, este número é ainda mais significativo: $93 \%$ dos indivíduos apontam que a recomendação de conhecidos é a forma de comunicação mais confiável (NIELSEN, 2013).

Tal processo de comunicação informal, confiável e econômico entre consumidores a respeito de suas opiniões sobre produtos e serviços, capaz de moldar atitudes de consumo, é popularmente conhecido como "boca a boca" (BROWN; REINGEN, 1987). Tradicionalmente associado a interações pessoais e presenciais entre indivíduos, o alcance do "boca a boca" expandiu-se significativamente com o advento da Internet e a explosão das mídias digitais, possibilitando que um único comentário positivo ou negativo sobre produtos e marcas tenha impacto em centenas ou milhares de consumidores (GUPTA; HARRIS, 2010).

Na literatura de marketing, o "boca a boca" é abordado há algum tempo, desde os clássicos trabalhos de Ditcher (1966) e Arndt (1967) até a recente publicação de Lovett, Peres 
e Shachar (2013). Entre os principais assuntos estudados até então, dois serão de grande importância para esta dissertação: a valência (ou direção) da recomendação (SAMSON, 2006; EAST; HAMMOND; WRIGHT, 2007) e a relação de "boca a boca" com tipos distintos de marcas, mais especificamente com aquelas em diferentes estágios de maturidade (SUNDARAM; WEBSTER, 1999).

Tais temas, de fato, não são novos. Por isso, o diferencial deste trabalho está em como ambos se relacionam com um terceiro elemento, ainda pouco aprofundado, mas de extrema relevância e significância prática: a relação entre o "boca a boca" e o nível de esforço cognitivo envolvido em decisões de compra.

Ao assumirmos a linha teórica proposta pelos modelos de duplo processo, consideramos que a mente humana é capaz de realizar dois caminhos para processar estímulos cognitivos: um mais rápido e automático baseado em heurísticas mentais, e outro mais lento e planejado, baseado na razão e maior elaboração (KAHNEMAN, 2003; GAWRONSKI; CREIGTHTON, 2013). Assim, na medida em que decisões de compra resultam de um processo cognitivo, é precipitado pensar que o nível de esforço dispendido por consumidores para o processamento de estímulos é exatamente o mesmo em toda e qualquer decisão que precisem tomar, independentemente da situação de compra a qual estão expostos.

Tendo em consideração que tanto a valência da recomendação quanto o estágio de maturidade de uma marca podem ser entendidos como mecanismos para a redução de dissonância cognitiva (ENGEL; KEGERREIS; BLACKWELL, 1969; KELLER, 2007), o propósito desta dissertação é investigar o impacto que ambos apresentam em dois tipos específicos de situações de decisão: uma urgente e rápida, que exige menor cognição, e outra mais planejada e lenta, que implica maior esforço cognitivo.

\subsection{Justificativa}

As justificativas para a realização deste trabalho podem ser resumidas em:

1) A proposta inovadora de investigação ao trabalhar, conjuntamente, com três fatores que, até então, foram abordados de forma independente em estudos sobre o processo de decisão de compra: valência da recomendação, estágio de maturidade de marcas e situações de decisão que implicam diferentes níveis de cognição. 
2) A significância prática dos resultados deste trabalho para gestores de marketing, principalmente no que se refere ao efeito combinado que marca e "boca a boca" podem trazer à decisão de compra em situações de maior e menor esforço cognitivo.

3) A insuficiência de discussões e publicações disponíveis que abordem a influência que o boca a boca pode causar em situações de decisão distintas, principalmente entre a publicação acadêmica nacional.

4) Também, por ser um dos primeiros estudos sobre o tema, estabelecer-se como fonte de consulta para outros pesquisadores de marketing focados no entendimento do fenômeno de interesse.

\subsection{Problema em estudo}

A partir da discussão apresentada sobre o problema e as justificativas desta dissertação, definiu-se o problema em estudo, expresso a seguir: Qual é o papel que a valência da recomendação e o estágio de maturidade de marcas apresentam em decisões de compra que exigem diferentes níveis de esforço cognitivo?

\subsection{Objetivo do estudo}

O objetivo principal desta dissertação é, portanto, investigar o papel que a valência da recomendação e o estágio de maturidade de marcas apresentam em decisões de compra que exigem diferentes níveis de esforço cognitivo.

A partir do objetivo principal, delineiam-se dois objetivos específicos:

- Investigar se a valência da recomendação e o estágio de maturidade de marca influenciam a intenção de compra e, em caso positivo, como essa relação varia entre os dois tipos de situações de decisão.

- Investigar se o efeito interativo entre valência da recomendação, estágio de maturidade de marca e/ou tipo de situação de decisão influencia a intenção de compra.

\subsection{Organização do texto}

A fim de atingir os objetivos propostos, esta dissertação foi organizada em sete capítulos. 
O primeiro faz a apresentação do tema e da justificativa do estudo, além dos objetivos principal e secundários.

O capítulo 2 apresenta toda a fundamentação teórica, englobando o detalhamento do conceito de "boca a boca" e valência da recomendação, a explicação sobre marcas e seus diferentes estágios de maturidade, um levantamento sobre alguns dos principais modelos de duplo processo cognitivo e, por fim, a definição do conceito de intenção de compra.

A partir da discussão e análise da bibliografia, o capítulo 3 traz o modelo teórico proposto e as respectivas hipóteses de pesquisa, associando-as a cada um dos objetivos de pesquisa delineados.

O capítulo 4 descreve o método a ser desenvolvido para validação do modelo teórico, sendo abordados o método de coleta de dados, a definição de tipo e tamanho de amostra, a explicação sobre o desenho do estudo e o instrumento de coleta de elementos, o detalhamento das escalas planejadas para mensuração dos construtos em teste e, por fim, a descrição do plano de análise. Este capítulo finaliza-se com a sugestão de matriz de amarração.

Por fim, os capítulos 5 e 6 trazem a discussão dos resultados encontrados e as conclusões em relação às hipóteses de pesquisa propostas, enquanto, no capítulo 7, são apresentadas as limitações do trabalho e as sugestões para estudos futuros. 


\section{FUNDAMENTAÇÃO TEÓRICA}

De acordo com a estrutura apresentada anteriormente para esta dissertação, o presente capítulo busca abordar tópicos e conceitos considerados relevantes para o tema central em discussão.

Sendo assim, a fundamentação teórica inicia-se com a introdução ao fenômeno do "boca a boca", definindo-o e apresentando o conceito de valência da recomendação. Na sequência, exploram-se outros dois fatores que serão tomados como variáveis independentes no modelo teórico para o qual se busca a validação: nível de maturidade de marca e tipos de situações de decisão. Por fim, apresenta-se um breve resumo sobre intenção de compra e sua associação com o fenômeno do boca a boca.

\subsection{O fenômeno do "boca a boca"}

Cada vez mais, gestores de marketing estão conscientes de que a comunicação de suas marcas é constantemente interrompida pela natural troca de informações entre consumidores, fenômeno tradicionalmente conhecido como "boca a boca" e definido por Ditcher (1966), Arndt (1967) e Brown e Reingen (1987) como um processo de comunicação informal, portanto, confiável e econômico, a respeito de avaliações que pessoas fazem sobre produtos e serviços, o qual é capaz de moldar atitudes de consumo.

Os primeiros registros de estudos sobre este fenômeno em marketing são da década de 40 e 50 do século passado, quando Katz e Lazarsfield indicaram que o efeito do "boca a boca" em comunicação é, no mínimo, duas vezes maior do que o efeito de ações massivas (KATZ, 1957). Alguns anos depois, Engel, Kegerreis e Blackwell (1969) apresentam relação de situações associadas a esta espécie de propaganda:

- Alto envolvimento de indivíduos com um tipo de produto ou atividade e consequente satisfação ao falar sobre isto com outras pessoas.

- Alto grau de conhecimento e especialização sobre produtos ou serviços e uso do "boca a boca" para valorização do ego do interlocutor.

- Interesse genuíno pelo bem-estar dos outros, utilizando-o como meio para evitar que comprem o que lhes é desnecessário e desperdicem tempo e dinheiro.

- Redução da dissonância cognitiva, ou seja, redução da incerteza associada a decisões de compra. O "falar" dá aos indivíduos uma oportunidade de gerar mais argumentos 
que sustentem sua compra e, em certos casos, angarie apoio de outros para validar sua decisão.

Em linha com a última situação apresentada por Engel, Kegerreis e Blackwell (1969), Anderson (1998), Mourali, Laroche e Frank (2005) e Keller (2007) afirmam que o "boca a boca" tem papel fundamental no processo de decisão de compra, atuando, essencialmente, como uma fonte de informações qualificada no momento pré-consumo. Lim e Chung (2011), ao analisarem a congruência de diferentes mídias com a comunicação de diversificados tipos de atributos de marca, também concluem que, no geral, esta modalidade tem impacto em atributos de procura, os quais consumidores conseguem racionalizar antes da decisão de compra e servem para qualificar as opções disponíveis.

A exceção ocorre para símbolos novos, com os quais consumidores estão pouco familiarizados. Para estes, o "boca a boca" funciona como um "certificado" de qualidade, substituindo outros signos já consolidados para marcas maduras (ex: nome da marca, seu logotipo). Com isso, impacta a percepção de atributos de crença, mais elaborados e associados à credibilidade.

Embora pareça claro que o "boca a boca" causa impacto no processo decisório de consumo, entender como mensurar este fenômeno ainda é um desafio para a maioria dos estudiosos de marketing. Brown et al. (2005) fazem interessante reflexão sobre o tema. Para os autores, há duas medidas possíveis para tal ato: a da atitude ou intenção, quando a ação de recomendar ainda não ocorreu, mas há a predisposição em fazê-la; e a do comportamento, quando, de fato, a ação de recomendar já ocorreu. Avaliando-se estudos acadêmicos sobre o tema, a medida comportamental do "boca a boca", por ser de natureza mais complexa, é menos utilizada do que a medida de intenção. Já Yang et al. (2012) consideram que a efetividade do "boca a boca" está no entendimento de dois processos: sua geração e seu consumo. Em outras palavras, defendem que entender como a recomendação se cria e é disseminada, assim como o impacto deste mecanismo em decisões de compra, é essencial.

No decorrer do estudo da geração dessa espécie de marketing, um dos processos evidenciados por Yang et al. (2012), já fora abordado em muitos outros estudos recentes. Embora este não seja o foco desta dissertação, é válido que se apresente um breve descritivo sobre o que já se analisou nesta perspectiva.

Considerando-se os fatores antecedentes ao "boca a boca", Matos e Rossi (2008) apontam que satisfação, confiança, comprometimento, lealdade, qualidade e valor percebido são os principais, tendo, todos estes, relação direta e positiva com a propensão em 
recomendar. Já quanto a fatores que mediam o fenômeno, perfil do interlocutor, tipo de produto, equity de marca e valência da recomendação (positiva ou negativa), estes já foram abordados em muitos estudos (BROWN et al., 2005; MATOS; ROSSI, 2008; MARTIN; LUEG, 2013; LOVETT; PERES; SHACHAR, 2013). Por fim, em relação às consequências do "boca a boca", a intenção de compra é um fator consequente clássico, porém, a criação de atitudes favoráveis/ desfavoráveis às marcas, credibilidade e, em instâncias específicas, impacto em lucratividade são outros possíveis resultados já estudados previamente (KELLER, 2007; EAST; HAMMOND; LOMAX, 2008).

\subsubsection{A relação entre marcas e a geração de "boca a boca"}

Lovett, Peres e Shachar (2013) desenvolveram um robusto estudo para entender como características de marcas estão relacionadas com a geração de "boca a boca", estendendo as descobertas feitas por Ditcher (1966) e Lim e Chung (2011). Como ponto de partida, os autores baseiam-se na teoria de que este tipo de propaganda é resultado de três fatores: funcional, social e emocional. $\mathrm{O}$ fator funcional está relacionado à necessidade de obtermos informações e à tendência de cedermos informações a outros; o fator social diz respeito ao desejo de socialização; e o fator emocional refere-se diretamente à expressão de emoções. Assim, afirmam que cada um destes está associado, de forma direta, a diferentes motivações que afetam o modo como os consumidores tomam suas decisões e, por sua vez, implicam um conjunto de características de marca que, de diferentes maneiras, estimulam a geração de "boca a boca".

Algo interessante é que esses três fatores de produção, de algum modo, foram citados por outros autores em estudos prévios ao de Lovett, Peres e Shachar (2013). Alguns aspectos do fator funcional foram mencionados por Rosen (2002 apud LOVETT; PERES; SHACHAR, 2013) ao considerar que os indivíduos se engajam em "boca a boca" para obter informações que necessitam para sobreviver, para interpretar o ambiente onde vivem e para se beneficiarem economicamente. Dois aspectos do fator social são discutidos por Grewal, Cline e Davies (2003): a criação de impressões positivas e status social por meio do "boca a boca". O fator emocional é mencionado na literatura na medida em que se sugere que esta forma de propaganda é motivada pela surpresa e prazer (GREWAL; CLINE; DAVIES, 2003) e pela paixão e afeto de consumidores por marcas (HILL; PROVOST; VOLINSKY, 2006; KELLER, 2007; FULLERTON, 2011). 
Avançando com seu modelo, após extensa revisão de literatura, Lovett, Peres e Shachar (2013) levantam oito motivações que derivam destes três fatores e estão associadas a características específicas que uma marca deve possuir para que haja engajamento em "boca a boca". O Quadro 1, a seguir, as resume individualmente, especificando os fatores aos quais estão associadas e as características de marca que implicam. Além disso, traz um compilado de estudos que também tratam sobre o tema e são prévios ao trabalho de Lovett, Peres e Shachar (2013): 
Quadro 1 - Relação de Motivações, Fatores de Geração de Boca a boca e Características de Marcas de Lovett, Peres e Shachar (2013)

\begin{tabular}{|c|c|c|c|c|}
\hline Motivações & \begin{tabular}{|l|} 
Fatores \\
\end{tabular} & Definiçãa & Características de Marca & Abordagens anteriores \\
\hline $\begin{array}{l}\text { Busca por informações } \\
\text { (Demand Information) }\end{array}$ & FUNCIONAL & $\begin{array}{l}\text { Associado à racionalização da tomada de decisão. Tipos de marcas mais } \\
\text { latentes: (i) marcas pioneiras/ novas; (ii) marcas muito inovadoras, cujo } \\
\text { entendimento é complexo para aqueles que não especialistas. }\end{array}$ & $\begin{array}{l}\text { Idade (estágio do ciclo de } \\
\text { vida) } \\
\text { Complexidade }\end{array}$ & $\begin{array}{l}\text { Easingwood, Mahajan e } \\
\text { Muller (1983) } \\
\text { Godes e Mayzlin (2004) } \\
\text { Anand e Shachar (2011) } \\
\end{array}$ \\
\hline $\begin{array}{l}\text { Fornecimento de } \\
\text { informações } \\
\text { (Supply Information) }\end{array}$ & FUNCIONAL & $\begin{array}{l}\text { Associada à necessidade de ajudar outros indivíduos por meio do } \\
\text { compartilhamento de dicas, comentários e sugestões. Para isso, marcas } \\
\text { devem ser familiares e conhecidas por quem as consome. }\end{array}$ & $\begin{array}{l}\text { Conhecimento/ } \\
\text { Familiaridade }\end{array}$ & $\begin{array}{l}\text { Sundaram, Mitra e Webster } \\
(1998) \\
\text { Sundaram e Webster (1999) }\end{array}$ \\
\hline $\begin{array}{l}\text { Exclusividade } \\
\text { (Uniqueness) }\end{array}$ & SOCIAL & $\begin{array}{l}\text { Associada ao desejo de "ser único" em comparação à maioria dos } \\
\text { indivíduos. Tende a estar relacionada a marcas inovadoras e exclusivas. }\end{array}$ & Diferenciação & Berger e Heath (2007) \\
\hline $\begin{array}{l}\text { Autovalorização } \\
\text { (Self Enhancement) }\end{array}$ & SOCIAL & $\begin{array}{l}\text { Associada à necessidade que indivíduos possuem em reforçar sua } \\
\text { expertise e posicionamento superior aos outros com quem se relacionam. } \\
\text { Quanto maior é a percepção de qualidade pelas marcas que se consome, } \\
\text { maior é a probabilidade que esta motivação impacte em "boca a boca". }\end{array}$ & Qualidade & $\begin{array}{l}\text { Sundaram, Mitra e Webster } \\
(1998)\end{array}$ \\
\hline $\begin{array}{l}\text { Desejo de conversar } \\
\text { (Desire to converse) }\end{array}$ & SOCIAL & $\begin{array}{l}\text { Relacionada ao básico desejo que indivíduos possuem de conversar e } \\
\text { interagir socialmente. Portanto, marcas que estejam sempre disponíveis e } \\
\text { presentes (top of mind) estão mais associadas a esta motivação. }\end{array}$ & Visibilidade/ Presença & Berger e Schwatz (2011) \\
\hline $\begin{array}{l}\text { Expressão de emoções } \\
\text { (Expressing emotions) }\end{array}$ & EMOCIONAL & $\begin{array}{l}\text { Consumir ou pensar sobre marcas pode produzir emoções positivas que } \\
\text { indivíduos tenham interesse em compartilhar com outros. Quanto maior } \\
\text { for o nível de entusiasmo e satisfação que uma marca conseguir gerar, } \\
\text { mais intensa será esta motivação. }\end{array}$ & $\begin{array}{l}\text { Entusiasmo } \\
\text { Satisfação }\end{array}$ & $\begin{array}{l}\text { Westbrook e Oliver (1991) } \\
\text { Peters e Kashima (2007) } \\
\text { Berger (2011) }\end{array}$ \\
\hline $\begin{array}{l}\text { Envolvimento } \\
\text { (Product Involvement) }\end{array}$ & $\begin{array}{l}\text { FUNCIONAL } \\
\text { EMOCIONAL }\end{array}$ & $\begin{array}{l}\text { Diferentes níveis de envolvimento implicam a intensidade de busca por } \\
\text { informações, assim como a criação de emoções favoráveis entre } \\
\text { consumidores e marcas. }\end{array}$ & Envolvimento & $\begin{array}{l}\text { Ditcher (1966) } \\
\text { Sundaram, Mitra e Webster } \\
(1998)\end{array}$ \\
\hline $\begin{array}{l}\text { Redução de Riscos } \\
\text { (Risk Reduction) }\end{array}$ & $\begin{array}{l}\text { FUNCIONAL } \\
\text { EMOCIONAL }\end{array}$ & $\begin{array}{l}\text { Consumidores tendem a minimizar riscos. Quanto maior o risco } \\
\text { envolvido, maior é a necessidade de acúmulo de informações (racional). } \\
\text { Ainda, risco percebido implica emoções pré-compra (ex: ansiedade). }\end{array}$ & Risco percebido & $\begin{array}{l}\text { Sundaram, Mitra e Webster } \\
(1998)\end{array}$ \\
\hline
\end{tabular}

Fonte: Elaborado pelo autor a partir de Lovett, Peres e Shachar (2013). 
A Figura 1 ilustra o modelo teórico proposto por Lovett, Peres e Shachar (2013), incluindo os três fatores fundamentais para geração de "boca a boca", assim como as motivações e características de marca que estão a estes associadas.

Figura 1 - Modelo de associação entre fatores de geração de "boca a boca" com características de marca proposto por Lovett, Peres e Shachar (2013)

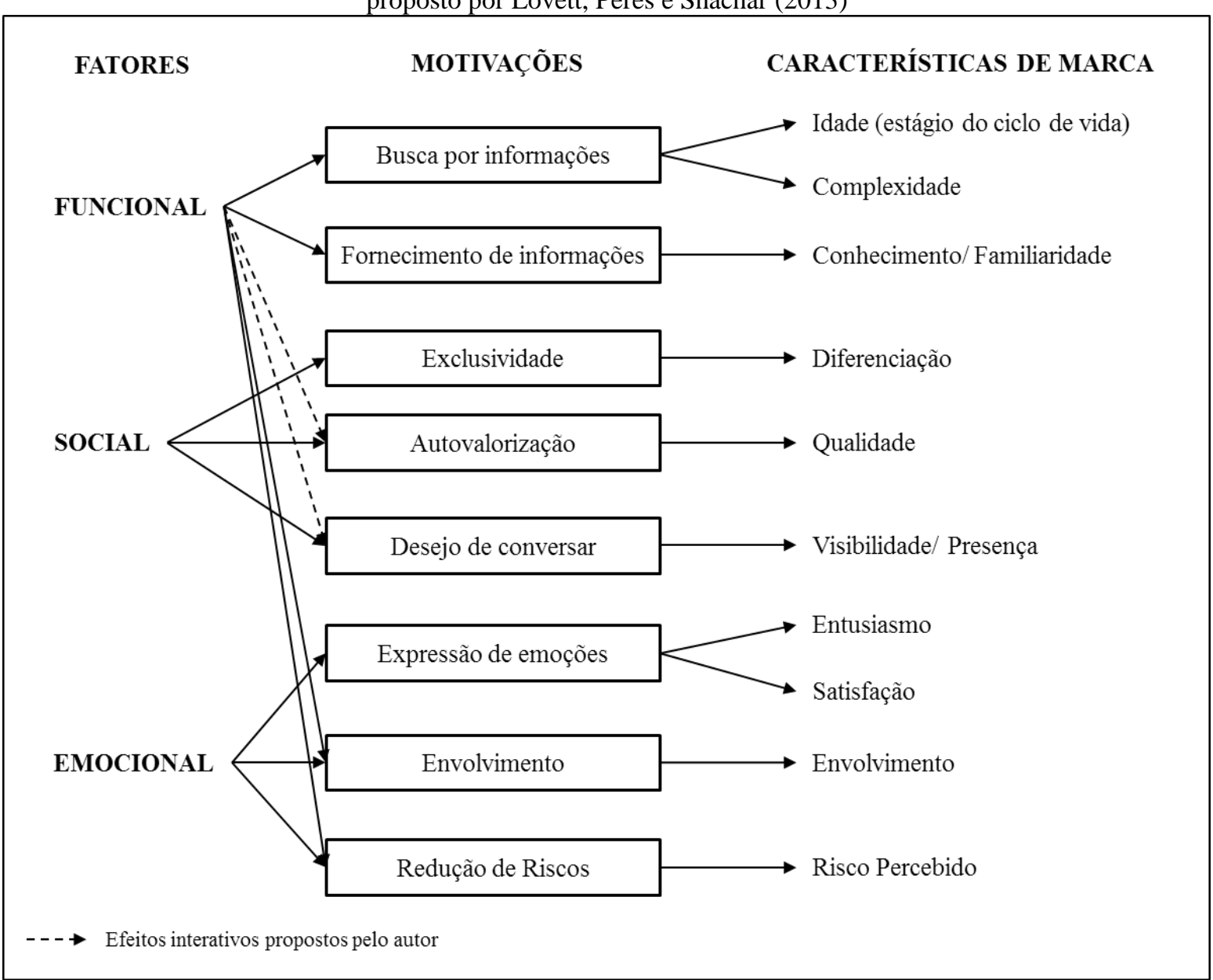

Fonte: Adaptado pelo autor a partir de Lovett, Peres e Shachar (2013).

Cabe aqui um adendo ao modelo proposto por Lovett, Peres e Shachar (2013). Principalmente em interações pessoais, a efetividade funcional da recomendação tende a ocorrer em momentos de socialização. A busca e o fornecimento de informações, por exemplo, são motivações diretamente associadas à necessidade e desejo de conversar. Portanto, é possível que se espere que também haja um efeito interativo entre os fatores funcionais e sociais. 


\subsubsection{Valência do "boca a boca"}

Ao se engajarem em ações de "boca a boca", consumidores podem falar bem ou mal das marcas com as quais tiveram alguma experiência, ou seja, sua recomendação pode assumir essência positiva ou negativa e, consequentemente, ajudar a construir ou arruinar marcas.

Harrison-Walker (2001) aborda tal tema a partir do entendimento de que a comunicação "boca a boca" é composta por duas dimensões. A primeira delas refere-se à ação de recomendar (activity), associada à frequência, número de pessoas impactadas e volume de informação comunicado pelo emissor da recomendação. Já a segunda refere-se à direção da recomendação (praise), associada à essência positiva ou negativa da mensagem que é emitida.

East, Hammond e Wright (2007), ao realizarem quinze estudos com usuários de marcas maduras de quinze diferentes categorias de produto, chegaram a conclusões relevantes sobre frequência e incidência da valência do "boca a boca". Os principais resultados estão apresentados abaixo:

- Independentemente da categoria de produto em estudo, pessoas tendem a recomendar marcas positivamente com mais frequência do que negativamente. Ou seja, a recomendação positiva é comportamento mais comum do que a negativa, sendo a razão média desta relação 3:1 (a cada três recomendações positivas, tem-se uma negativa).

- Categorias de produto com níveis mais elevados de "boca a boca" negativo tendem também a apresentar elevados níveis de recomendações positivas. Isso porque indivíduos que falam mal, também falam bem de marcas, o que aponta para o efeito de variáveis de perfil na propensão em produzir a propaganda de forma oral.

- Para todas as categorias estudadas, consumidores, em sua maioria, produzem "boca a boca" positivo para suas marcas principais, ou seja, aquelas que utilizam com mais frequência. Assim, é possível que se crie uma relação direta entre participação de mercado e a propensão em se recomendar marcas positivamente.

Samson (2006) complementa os resultados encontrados por East, Hammond e Wright (2007) ao afirmar que, apesar de menos frequente, recomendações negativas possuem maior impacto em julgamentos de consumidores, como intenção de compra e lealdade a marcas, do que recomendações positivas. Mittal, Ross e Baldasare (1998) já haviam sinalizado para a relação assimétrica entre informações positivas e negativas sobre a performance de produtos, apontando para o maior efeito que informações negativas trazem à satisfação e probabilidade 
de recompra.

Há algumas possíveis explicações para este maior poder persuasivo que recomendações negativas sobre produtos e serviços apresentam em atitudes e comportamentos de consumo. Mittal, Ross e Baldasare (1998) utilizam o conceito de aversão a perdas, implícito à teoria da perspectiva ${ }^{1}$ de Kahneman e Tversky (1979), para explicar essa relação. De acordo com os autores, a tendência de consumidores por minimizar perdas e a de maximizar ganhos faz com que uma avaliação negativa da performance de um produto ou serviço tenha um efeito maior sobre atitudes e comportamentos de consumo referentes a uma avaliação positiva.

Samson (2006) e East, Hammond e Wright (2007) baseiam suas explicações na teoria da desconfirmação ${ }^{2}$ de expectativas, desenvolvida por Oliver (1980). Assumindo-se que a recomendação de um produto e serviço é resultado da comparação entre sua performance e as expectativas estabelecidas antes de seu consumo, tem-se que uma avaliação negativa ocorre em apenas um dos três possíveis cenários, quando a performance é inferior às expectativas, enquanto que uma avaliação positiva pode existir desde que haja o cumprimento das expectativas criadas. Por isso, a frequência de recomendações negativas é menor e, normalmente, mais diagnóstica (portanto, mais útil) do que uma recomendação positiva. Ao serem menos frequentes e mais ricas em detalhes, informações negativas sobre produtos e serviços são mais surpreendentes e capturam mais facilmente a atenção de quem as recebe, tendo maior poder de mudança em julgamentos de consumo.

A proposta central desta dissertação é detalhar ainda mais o impacto que a valência de uma recomendação possui em situações de decisão que exigem maior ou menor grau de cognição, além de avaliar como tais relações variam em função do grau de maturidade de uma marca.

\footnotetext{
${ }^{1}$ A teoria da perspectiva (do inglês, prospect theory) foi apresentada por Kahneman e Tverky em clássico artigo na revista Econometrica, no ano de 1979, e traz uma nova abordagem para o entendimento da tomada de decisão em situações que envolvam risco ao afirmar que o resultado deriva da comparação entre o potencial de ganhos e perdas que se tem com cada decisão, ao invés da avaliação direta do resultado final do processo.

${ }^{2}$ A teoria da desconfirmação das expectativas (do inglês, expectation disconfirmation theory) foi desenvolvida por Richard L. Oliver (1980) com o intuito de explicar satisfação em função da comparação entre performance de produtos/ serviço $(\mathrm{P})$ e expectativas $(\mathrm{E})$ criadas em momento pré-consumo. Três são os possíveis resultados desta comparação: (1) performance é superior às expectativas ( $\mathrm{P}>\mathrm{E})$; (2) performance é igual às expectativas $(\mathrm{P}=\mathrm{E})$; (3) performance é inferior às expectativas $(\mathrm{P}<\mathrm{E})$. A insatisfação ocorre apenas no terceiro resultado.
} 


\subsection{Maturidade de Marca}

Já não é de hoje que indivíduos e empresas se deparam com mais e mais possibilidades de escolha por produtos e serviços para satisfazerem suas necessidades. Com isso, o processo de tomada de decisão torna-se moroso e mais difícil, aumentando a probabilidade de que se haja dissonância cognitiva no pós-compra (KELLER; MACHADO, 2007). É exatamente sob essa ótica que o papel qualificador das marcas se torna fundamental. Por meio de suas associações, uma marca é capaz de simplificar a decisão, reduzir riscos e incertezas, além de funcionar como mecanismo definidor de expectativas (KELLER, 1993).

Segundo a definição da American Marketing Association (AMA, 2014), “[...] marca é um nome, termo, símbolo, desenho ou uma combinação desses elementos que deve identificar bens ou serviços de um fornecedor ou grupo de fornecedores e diferenciá-los da concorrência". Portanto, resgatando-se a definição de Kotler e Levy (1969), pode-se considerar que uma marca é um produto, porém, um produto com elementos qualificadores, funcionais ou emocionais, que o diferenciam de demais produtos criados para satisfazer a mesma necessidade.

Tais elementos qualificadores que caracterizam uma marca são aqueles que definirão seu valor (equity) para o consumidor. Entre os diferentes modelos existentes na literatura com o intuito de explicar este conceito, será adotado por esta dissertação o apresentado por Keller (1993).

Para este autor, o entendimento do que faz e como se cria uma marca forte deriva do consumidor, uma vez que produtos e serviços são desenvolvidos em prol da satisfação de suas necessidades e desejos, alicerce fundamental para a prática do marketing. Assim, desenvolvese modelo de valor de marca baseado no cliente (CBBE - customer-based brand equity), o qual possui duas dimensões fundamentais apresentadas a seguir e pela Figura 2:

1) Lembrança de marca: consiste no potencial de lembrança espontânea, associada à capacidade dos consumidores de extrair a marca da memória quando lhes é estimulada a categoria de produto ou serviço de interesse, e reconhecimento da marca (ou lembrança estimulada), relacionado à capacidade dos consumidores de confirmar exposição prévia à marca quando esta lhes é apresentada.

2) Imagem de marca: é constituída por associações criadas ao nome do produto por meio de programas de marketing. Tais associações podem estar ligadas a atributos funcionais ou emocionais, sendo que quanto mais fortes, positivas/ favoráveis e exclusivas forem melhor será a imagem da marca. 
Figura 2 - Modelo de valor de marca baseado no cliente (CBBE) de Keller (1993)

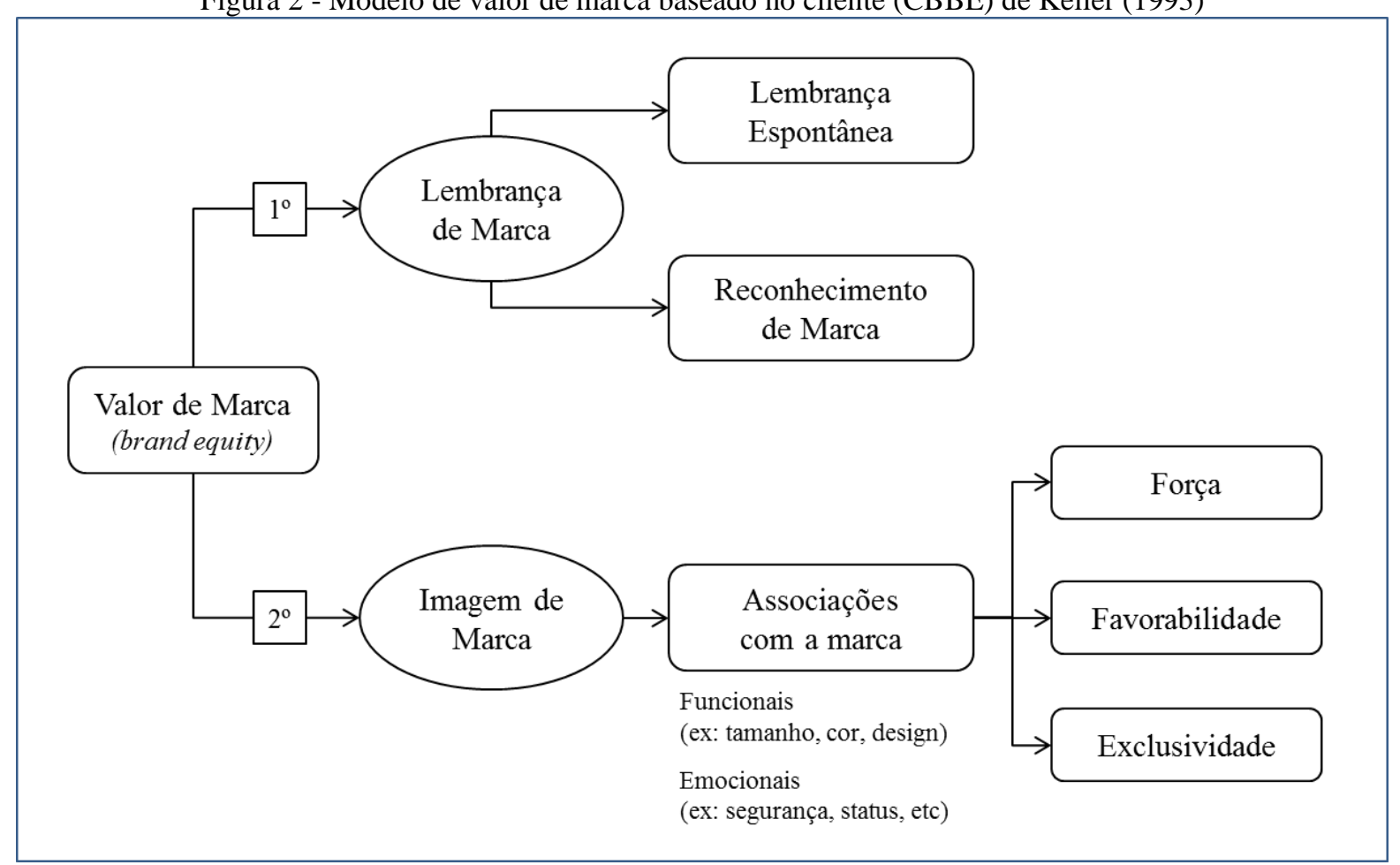

Fonte: Adaptado pelo autor a partir de Keller (1993)

Algo implícito ao modelo de Keller (1993) é que o estabelecimento de forte lembrança de marca é pré-requisito para que se desenvolvam associações e crie-se imagem do símbolo. Assim, a primeira etapa para todo e qualquer processo de criação de valor de marca é torná-la conhecida por seus consumidores, sejam eles indivíduos ou empresas.

A partir desta noção evolutiva apresentada pelo modelo CBBE, é possível assumir que marcas, assim como produtos, obedeçam a um ciclo de vida. Aplicando-se esta lógica ao modelo de ciclo de vida de produto, primeiramente apresentado por Smallwood (1973), podese criar o seguinte racional:

- A criação de lembrança espontânea e reconhecimento de marca ocorrem durante o estágio de sua introdução. Aqui, consumidores estabelecem o contato inicial, por isso, dificilmente são capazes de criar associações e constituir sua imagem.

- Durante o estágio de desenvolvimento, há a consolidação da lembrança e início da criação de associações do símbolo, pois, provavelmente, a partir dos benefícios entendidos por meio da lembrança de marca, consumidores já tenham incorrido em experimentação e validado suas expectativas.

- À medida que expectativas são satisfeitas no estágio de desenvolvimento, é na maturidade que os signos assumem sua imagem e se apropriam de atributos. Esse é o estágio no qual marcas de sucesso permanecem por muito tempo, dado que são 
capazes de manter a força, favorabilidade e exclusividade de suas associações às necessidades e desejos de seus consumidores.

- Para marcas que atingem a maturidade, porém não conseguem manter sua imagem positiva, ou seja, suas associações perdem força, favorabilidade e exclusividade, a tendência é que entrem em declínio e sejam descontinuadas.

Tal racional é importante para os objetivos desta dissertação, já que, entre outros fatores, será estudada a relação que a maturidade de marca, determinada pelo estágio de seu ciclo de vida (marca nova vs. madura), associada à valência de "boca a boca", apresenta em intenção de compra.

Sobre a relação entre o estágio de desenvolvimento de marcas e o "boca a boca", pode-se citar o estudo de Lovett, Peres e Shachar (2013), já apresentado no início deste capítulo. Embora os autores não estudem as consequências do processo de recomendação, afirmam que o tipo desta está diretamente relacionado às associações que uma marca carrega. Portanto, há indícios de que marcas maduras, cuja imagem já está estabelecida, tendem a gerar mais "boca a boca" do que as mais novas, cuja imagem ainda está em processo de criação.

Sundaram e Webster (1999) desenvolveram um trabalho interessante ao analisarem o papel mediador que a familiaridade de marca, construto correlato ao estágio de desenvolvimento, possui em intenção de compra e em criação de atitudes favoráveis para situações de "boca a boca" positivo e negativo. Embora entendam que consumidores se engajem em ações desta natureza para qualquer tipo de marca, os autores encontram resultados importantes ao compararem as familiares com as menos familiares:

- Marcas com menor grau de familiaridade (ou menos conhecidas e maduras) têm tanto sua intenção de compra quanto as atitudes que consumidores desenvolvem em relação a elas mais impactadas pela valência da recomendação, sendo que um único comentário positivo ou negativo pode mudar significativamente o que consumidores pensam.

- Por outro lado, marcas de maior familiaridade (mais conhecidas e maduras) são menos vulneráveis a ações de "boca a boca". O impacto da recomendação em intenção de compra e criação de atitudes é dependente de sua recorrência, ou seja, só haverá mudança se um comentário positivo ou negativo sobre determinada marca for feito mais de uma vez em um curto espaço de tempo.

Sundaram e Webster (1999) avaliaram o efeito que a valência da recomendação apresenta sobre intenção de compra de marcas com as quais os consumidores são mais ou 
menos familiarizados. Essa dissertação tem como objetivo tornar mais completo e complexo o estudo de tais relações ao analisar o efeito combinado que maturidade de marca e valência de uma recomendação apresentam em situações de decisão que exigem diferentes níveis de cognição, algo ainda não explorado pela literatura atual sobre o tema.

\subsection{Processamento Cognitivo: Modelos de Duplo Processo (Dual-process models)}

Durante as últimas três décadas, muitos estudos em psicologia cognitiva foram desenvolvidos com o objetivo de se entender "modelos de duplo processo" (dual-process models). A função central de tais modelos está na classificação dos processamentos mentais que definem atitudes e comportamentos em dois grupos: aqueles que resultam de processos automáticos, mais inconscientes (implícitos) e, consequentemente, mais rápidos; e aqueles que emergem de processos controlados, mais conscientes (explícitos) e, consequentemente, mais elaborados (GAWRONSKI; CREIGTHTON, 2013).

De acordo com Posner e Snyder (1987), processos mentais automáticos ocorrem quando: (1) o impulso à ação é espontâneo; (2) há baixo esforço cognitivo; (3) a ação não é voluntária; e (4) os estímulos são inconscientes. Por outro lado, processamentos mentais controlados ocorrem quando: (1) o impulso à ação é intencional; (2) há elevado esforço cognitivo; (3) a ação é voluntária (ou seja, pode ser interrompida); e (4) os estímulos são conscientes.

Muito se discute quanto à rigidez da aplicação desta classificação, uma vez que não há processos mentais perfeitos que se encaixem exatamente nos quatro critérios que definem cada um dos tipos. No entanto, mesmo com diferentes terminologias, são estes os quatro critérios - intencionalidade, esforço cognitivo, voluntariedade e consciência - utilizados pelos principais estudiosos de modelos de duplo processo (MOORS; DE HOUWER, 2006).

Dentre os diversos modelos de duplo processo, há dois que podem ser considerados os mais clássicos: Modelo de Probabilidade de Elaboração (em inglês, Elaboration Likelihood Model - ELM) de Petty e Cacciopo (1986) e o Modelo Heurístico-Sistemático (em inglês, Heuristic Sistematic Model - HSM) de Chaiken (1987). A questão central de ambos está associada ao entendimento do efeito da persuasão no processamento cognitivo. Embora tais modelos não sejam a referência teórica para o experimento desenvolvido nesta dissertação, é válido que se inclua um breve descritivo sobre cada um deles. 


\subsubsection{Modelo de Probabilidade de Elaboração (ELM)}

O Modelo de Probabilidade de Elaboração (ELM) sugere que a efetividade da persuasão está diretamente associada à probabilidade de sua elaboração em cada situação. Tal probabilidade varia em um contínuo, podendo ser alta ou baixa, e depende, essencialmente, de duas características principais do público que busca atingir com a mensagem persuasiva: sua motivação/ envolvimento e sua capacidade/ habilidade de engajamento em processamentos cognitivos (PETTY; CACCIOPO, 1986; GAWRONSKI; CREIGTHTON, 2013). Com isso, dependendo da probabilidade de elaboração cognitiva, a mensagem deve ser desenvolvida em função de duas possíveis "rotas" de comunicação:

1) Rota central, a ser utilizada quando indivíduos estão motivados e têm habilidade para se engajar no processo comunicativo, caracterizando situações de alta probabilidade de elaboração cognitiva. Desse modo, as mudanças de atitude via rota central tendem a ser mais fortes e duradouras.

2) Rota periférica, a ser utilizada em situações opostas à rota central, ou seja, em situações de baixa probabilidade de elaboração cognitiva, nas quais indivíduos são capazes de processar a mensagem sem que se engajem em raciocínios elaborados. Nestas, as mudanças de atitude via rotas periféricas tendem a ser mais fracas e efêmeras.

Andrade et al. (2011) aplicam o modelo ELM em estudo longitudinal para avaliação da evolução de anúncios impressos em revistas e afirmam que esta é uma das abordagens teóricas mais utilizadas para explicar alternativas estratégicas de abordagem e impacto ao comportamento de consumidores. Ainda, em relação às duas rotas de persuasão, os autores defendem que na dinâmica competitiva atual, na qual produtos e serviços são cada vez mais homogêneos, argumentos mais fortes e objetivos sobre uma oferta possuem menos impacto persuasivo do que no passado e dão espaço a maior subjetividade na decisão. Com isso, tornase necessário que rotas periféricas sejam acionadas por elementos secundários associados à oferta, como o uso de cores, sons e o endosso por celebridades.

Por fim, um último comentário válido sobre o modelo ELM é que, mesmo com sua ampla aplicação em estudos de comunicação persuasiva, a teoria não está isenta de críticas. A principal delas está associada à dificuldade de diferenciação entre o uso das rotas na prática. Autores defendem que aquilo que é central para uma pessoa pode ser considerado periférico para outra (TANG, 2009 apud ANDRADE et al., 2011). 


\subsubsection{Modelo Heurístico-Sistemático (HSM)}

Um segundo modelo de duplo processo bastante clássico é o Modelo HeurísticoSistemático (HSM). De forma similar ao modelo ELM de Petty e Cacciopo (1986), tal linha teórica descreve dois tipos de processamentos persuasivos que podem moldar atitudes e comportamentos (CHAIKEN, 1987):

1) Processamentos Sistemáticos, mais analíticos, detalhados e elaborados. Ocorrem quando há elevado nível de atenção por quem recebe e processa a mensagem persuasiva. Portanto, o esforço para cognição é alto e há foco no conteúdo principal do processo comunicativo.

2) Processamentos Heurísticos, mais automáticos, rápidos e espontâneos. Ocorrem quando algo que já foi aprendido (heurística) é utilizado como uma solução simples e rápida para o processamento da mensagem persuasiva. Portanto, o esforço para cognição é reduzido e há foco em atributos secundários do processo comunicativo (ex: credibilidade da fonte emissora).

Outra premissa central do modelo HSM está na possibilidade de coexistência entre processamentos sistemáticos e heurísticos, ou seja, eles podem ocorrer simultaneamente e produzir efeitos independentes e interdependentes no julgamento da mensagem persuasiva (GAWRONSKI; CREIGTHTON, 2013). Tal simultaneidade entre os dois tipos de processos estabelece três possíveis hipóteses para o modelo, assim descritas por Chaiken e Maheswaran (1994):

1) Hipótese da Atenuação: o processamento sistemático pode sobrepor os efeitos do processamento heurístico uma vez que a informação produzida sistematicamente seja contrária à validade persuasiva de uma simples heurística;

2) Hipótese de Adição: as informações produzidas por processamentos sistemáticos e heurísticos podem afetar as características do resultado de forma aditiva. Isso ocorre quando os dois processos não produzem reações contraditórias, ou seja, quando há sinergia entre a heurística e a produção sistemática.

3) Hipótese da Ambiguidade ou Viés: ocorre quando há ambiguidade na mensagem persuasiva e a heurística pode influenciar os efeitos do processamento sistemático.

Ao se entender a principal premissa do modelo HSM, nota-se que há muitas semelhanças com o padrão ELM. Ambos defendem a ideia de que mudanças de atitudes podem ocorrer tanto de forma sistemática/ central, exigindo maior nível de motivação e cognição, quanto de forma heurística/ periférica, requisitando menor nível de motivação e 
cognição. No entanto, diferem quanto à forma que tais mecanismos podem ocorrer. Para o modelo ELM, a rota central e a periférica são caminhos opostos e nunca acontecem simultaneamente; já para o HSM, o processamento sistemático pode coexistir com o processamento heurístico, gerando resultados cognitivos independentes e interdependentes (GAWRONSKI; CREIGTHTON, 2013).

\subsubsection{Modelo de Kahneman: Sistema 1 e Sistema 2}

Um terceiro e atual modelo de duplo processo é o elaborado por Kahneman (2003). De acordo com o autor, a cognição humana pode ser resumida a dois sistemas de processamento, assim definidos:

1) Sistema 1, baseado na intuição, é rápido, emocional, associativo, urgente e de esforço cognitivo mínimo. O comportamento resultante é algo imediato e bastante afetado por estímulos secundários à mensagem principal.

2) Sistema 2, baseado na razão, é lento, controlado, processual, pouco emocional e de esforço cognitivo elevado. O comportamento resultante é algo elaborado e longo, sendo pouco afetado por estímulos secundários à mensagem principal.

Figura 3 - Sistemas 1 e 2 de processamento cognitivo de Kahneman

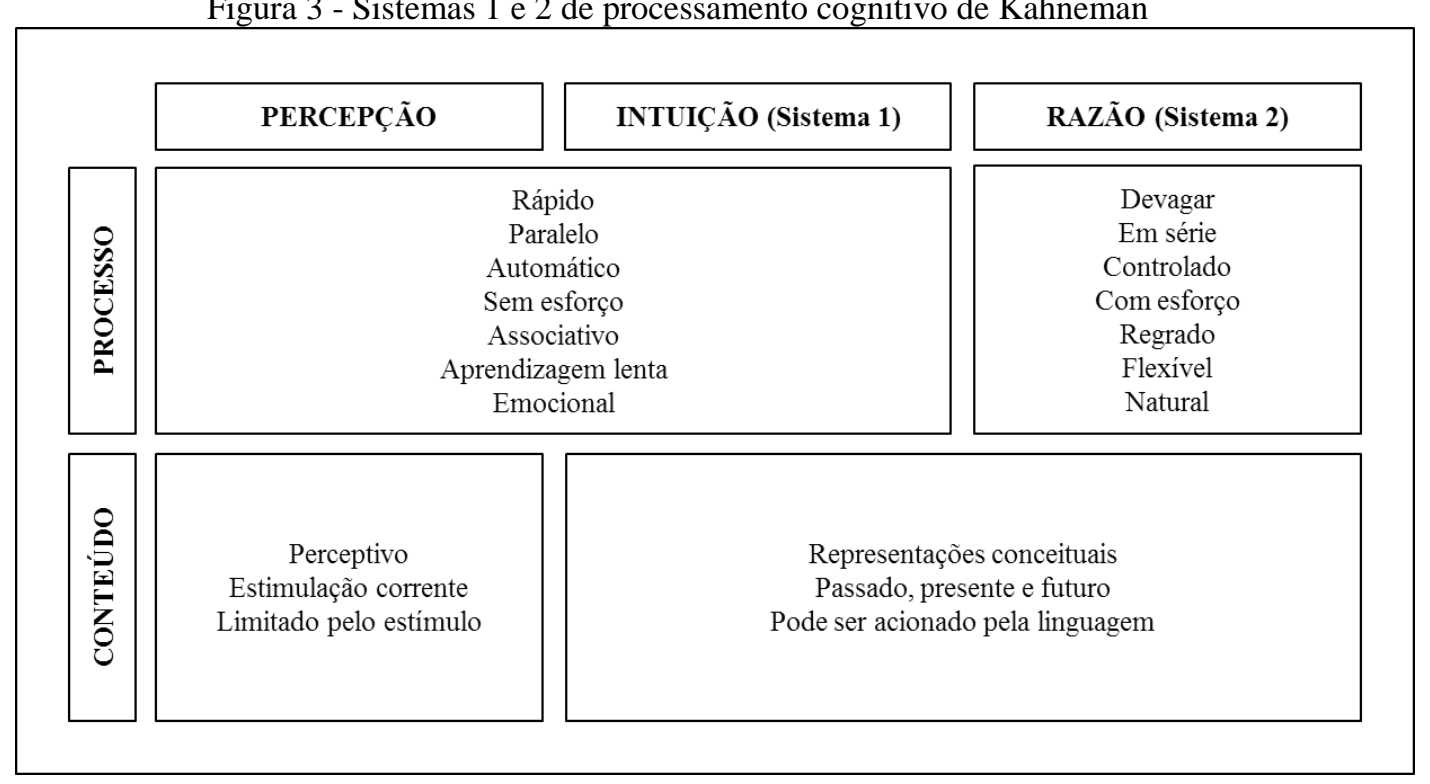

Fonte: Kahneman (2003, p. 698).

Ainda, Kahneman (2013) afirma que o Sistema 2 é o que consegue seguir "regras", comparar objetos em relação a diferentes atributos e fazer escolhas deliberadas entre as opções disponíveis. Por outro lado, o Sistema 1 não possui tais características. Sua função 
central está associada à detecção de simples e diretas associações ("essas opções são parecidas", "aquele indivíduo é mais alto do que eu", por exemplo), sendo incapaz de lidar com o processamento de mais de um estímulo mental por vez.

Assim como no modelo HSM de Chaiken (1987), há associação entre as funções desempenhadas entre ambos os sistemas. Gawronski e Creigthton (2013) descrevem que tal relação baseia-se, essencialmente, no monitoramento e controle que o Sistema 2 exerce sobre os pensamentos e ações sugeridos pelo Sistema 1, permitindo que alguns sejam expressos em comportamentos diretos, enquanto que outros sejam suprimidos ou adequados a regras racionais.

Kahneman (2013) sugere um bom exemplo para exemplificar essa relação entre os dois sistemas, representado pelo seguinte exercício ${ }^{3}$ :

$$
\begin{aligned}
& \text { Responda rapidamente: } \\
& \text { Uma bola e uma mola custam juntas R } \$ 1,10 \text {. } \\
& \text { A bola custa um real a mais do que a mola. } \\
& \text { Quanto custa a mola? }
\end{aligned}
$$

A resposta que vem à mente da maioria das pessoas é $\mathrm{R} \$ 0,10$ (dez centavos). Porém, se fizermos a matemática, caso a mola custasse $R \$ 0,10$, o custo total seria $R \$ 1,20(R \$ 0,10$ para a mola e $\mathrm{R} \$ 1,10$ para a bola), e não $\mathrm{R} \$ 1,10$. A resposta correta é $\mathrm{R} \$ 0,05$ (cinco centavos). Portanto, em certas situações, à medida que somos levados pela intuição (Sistema 1), sem o controle da razão (Sistema 2), podemos exercer comportamentos precipitados e incorretos.

A proposta inovadora desta dissertação está no estudo de como dois estímulos cognitivos, maturidade da marca e valência da recomendação, impactam a intenção de compra em situações de alta e baixa cognição. O modelo teórico proposto e as hipóteses de pesquisa levantadas serão apresentados no próximo capítulo.

\footnotetext{
${ }^{3}$ Traduzido do exercício original, em inglês, "bat-and-ball puzzle” de Kahneman (2013).
} 


\subsection{Intenção de Compra}

Uma das consequências esperadas da aplicação eficaz de um plano de marketing é a criação de consumidores predispostos a comprar aquilo que se está ofertando. Em outras palavras, é gerar impulso e fluidez à demanda. Portanto, em estudos de marketing, a consideração da intenção de compra em modelos teóricos que buscam a projeção de comportamento do consumidor é algo comum (KALWANI; SILK, 1982).

Segundo Porter (1974), essa predisposição a comprar resulta da capacidade dos consumidores adquirem informações e compararem atributos de produtos disponíveis para a satisfação de uma mesma necessidade. Após esta comparação, haverá maior predisposição à compra daquele produto que for percebido como mais diferenciado, ou seja, cujos atributos forem exclusivos e de difícil cópia, o que fará com que, em tese, haja maior inelasticidade (menor sensibilidade a variações de preço), redução de risco percebido, entre outros fatores.

Esse racional de Porter associa-se ao modelo de cinco estágios proposto por Kotler e Keller (2012) para mapeamento do processo de decisão do consumidor. Em especial, a intenção de compra pode ser considerada o primeiro resultado esperado pelo quarto estágio deste processo, quando o consumidor, a partir da coleta e comparação de informações disponíveis sobre as opções que possui para compra, decide se vale ou não a pena adquirir o produto em questão.

Entretanto, embora a intenção de compra seja uma métrica amplamente utilizada por acadêmicos, há algo que deve ser considerado em relação à sua capacidade preditiva do real comportamento de consumo. Morrison (1979) e, posteriormente, Kalwani e Silk (1982) estudam exatamente esta problemática, desenvolvendo e aprofundando um modelo matemático capaz de projetar a probabilidade real de compra a partir de medidas declaradas de intenção de aquisição. Fressart e Markowitz (2009) defendem que apenas a intenção não é suficiente para projetar o comportamento real de compra. Isso ocorre principalmente para produtos inovadores que, na maioria das vezes, possuem atributos para os quais a capacidade de cognição dos consumidores é reduzida, impactando em maior ou menor predisposição à compra. Para os autores, medidas como relevância, diferenciação e percepção de valor são construtos preditores que, associados à intenção de compra, podem melhorar a projeção de comportamentos.

Medidas de intenção de compra, portanto, são adequadas somente para capturar atitudes em relação à determinada decisão, não servindo como métrica confiável para projeção de comportamento de consumo, tampouco para qualquer estimação de volume e 
sucesso de vendas. É exatamente sob esta ótica que esse construto será considerado nesta dissertação.

Tendo-se esse ponto claro, na medida em que o acesso a informações sobre produtos é vital para a geração de intenção de compra, é possível que se estabeleça uma relação direta entre este construto e o "boca a boca", algo já comprovado por estudos passados e discutido em seções anteriores (SUNDARAM; WEBSTER, 1999). O objetivo desta dissertação é aprofundar tal investigação ao adicionar o nível de maturidade de uma marca e diferentes situações de decisão no impacto que recomendações positivas e negativas apresentam em intenção de compra. 


\section{MODELO TEÓRICO PROPOSTO E HIPÓTESES DE PESQUISA}

Conforme citado por Hernandez (2003), um modelo teórico é uma representação simplificada de um fenômeno real. Portanto, não corresponde à realidade, mas, sim, a uma tentativa de explicá-la e descrevê-la da melhor maneira possível por meio do estabelecimento de relações entre uma série de variáveis. Assim, sempre se baseará em alguns pressupostos e estará sujeito a limitações.

Partindo-se desta definição, esta dissertação propõe o modelo teórico descrito a seguir e desenvolvido com o intuito de satisfazer os objetivos específicos apresentados previamente.

\subsection{Apresentação do Modelo Teórico}

O modelo teórico proposto nesta dissertação busca estudar, essencialmente, processos de decisão de compra. Para tanto, considera avaliar qual é o impacto que o grau de maturidade de uma marca (nova ou madura) e a valência do "boca a boca" (positiva ou negativa) apresenta em intenção de compra em dois tipos diferentes de situações de decisão: (1) situação urgente, que exige rápida tomada de decisão e, consequentemente, envolve menor processamento cognitivo; (2) situação planejada, a qual possibilita maior tempo de raciocínio e elaboração antes da tomada de decisão e, consequentemente, permite maior processamento cognitivo (Figura 4).

Figura 4 - Representação gráfica das componentes do modelo teórico proposto

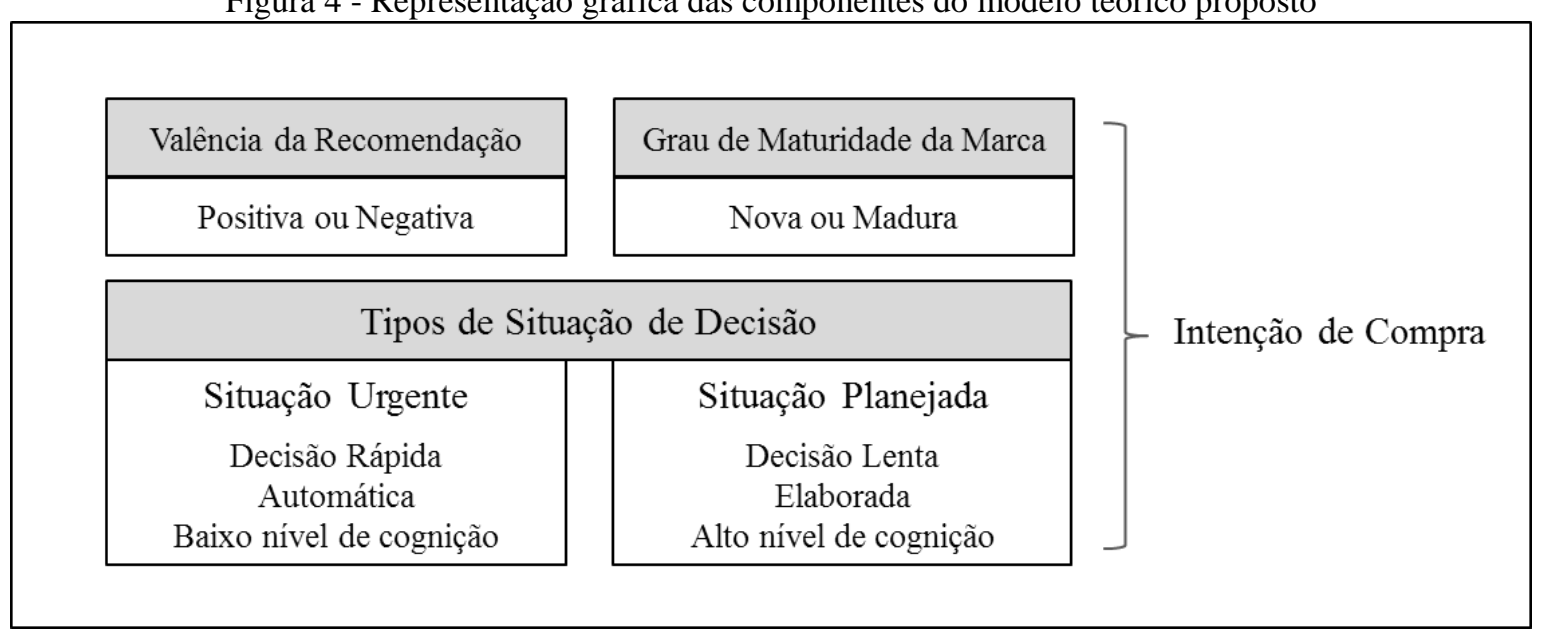

Fonte: Elaborado pelo autor.

Nos próximos parágrafos serão apresentadas as hipóteses de pesquisa associadas a este modelo teórico e que buscam responder os objetivos propostos por este trabalho. 


\subsection{Hipóteses de pesquisa propostas}

Ao retomarmos o que foi discutido, é possível que se criem associações interessantes entre as teorias de duplo processo cognitivo e os dois tipos de situação de decisão em avaliação pelo modelo teórico. Decisões urgentes, por definição, exigem rapidez, maior espontaneidade e menor esforço cognitivo. Por outro lado, as que são planejadas, por definição, exigem um plano, ou seja, são racionais, de alta elaboração mental e maior esforço cognitivo. Portanto, tais tipos de decisão enquadram-se, respectivamente, nos Sistema 1 e 2 de Kahneman (2013) ou na heurística e elaboração de Chaiken (1987).

Uma das consequências da classificação dos tipos de decisão em função de seu grau de cognição é a forma como os estímulos persuasivos são absorvidos em cada situação (POSNER; SNYDER, 1987). Tanto Petty e Cacciopo (1986) quanto Chaiken (1987) afirmam que a intensidade do foco no estímulo persuasivo principal é inversamente proporcional à intensidade do esforço cognitivo, ou seja, quanto menos elaborada for a cognição, menor será a atenção dada ao estímulo central que se busca transmitir e estímulos secundários tornam-se mais relevantes para a definição.

Tanto a maturidade de uma marca quanto a valência de uma recomendação podem ser consideradas estímulos cognitivos a serem processados nas situações de resolução do modelo teórico proposto. No entanto, seu conteúdo persuasivo difere em relevância. De acordo com Keller (1993), uma marca é um mecanismo histórico e recorrente, que consolida significados, e funciona como um qualificador de produtos, diferentemente de uma recomendação que, dependendo de sua recorrência e intensidade, pode ter efeitos limitados à tomada de decisão. Assim, pode-se considerar que a maturidade de uma marca é o estímulo central a ser processado, enquanto que a valência da recomendação é um estímulo secundário a este processo decisivo. Partindo-se desta suposição, formulam-se as primeiras hipóteses de pesquisa:

H1a: Em decisões urgentes, o impacto da valência da recomendação (estímulo secundário) em intenção de compra é maior do que o grau de maturidade da marca (estímulo primário).

H1b: Em decisões planejadas, o impacto da maturidade da marca (estímulo primário) em intenção de compra é maior do que o grau de valência da recomendação (estímulo secundário). 
Sundaram e Webster (1999) concluem que o efeito do "boca a boca" em intenção de compra por marcas menos conhecidas (ou novas), as quais estão em processo de formação de sua imagem, é mais intenso do que para as maduras. Embora tais autores cheguem a esta conclusão, não avaliam qual é a diferença deste efeito em função do nível de processamento cognitivo envolvido na decisão de compra de uma marca nova.

Assim, ao assumirmos que as duas situações de decisão propostas pelo modelo teórico implicam níveis de cognição diferentes (CHAIKEN, 1987; KAHNEMAN, 2013), afetando a forma como a valência da recomendação (considerada um estímulo cognitivo secundário) é processada, torna-se possível o estabelecimento de duas novas hipóteses:

H2a: Ao receber "boca a boca" positivo, a intenção de compra por marcas novas é maior em situações de decisão urgente do que em situações de decisão planejada.

H2b: Ao receber "boca a boca" negativo, a intenção de compra por marcas novas é menor em situações de decisão planejada do que em situações de decisão urgente.

Marcas maduras, já conhecidas e, portanto, com imagem mais sólida, são mais resistentes ao impacto do "boca a boca" em sua intenção de compra (SUNDARAM; WEBSTER, 1999). Mesmo assim, sabe-se que, independentemente do grau de maturidade de uma marca, o acesso a informações negativas sobre seu desempenho pode mudar significativamente o julgamento de consumidores, inclusive suas intenções de compra, algo que não ocorre na mesma proporção caso se "ouça falar bem" sobre sua performance (MITTAL; ROSS; BALDASARE, 1998; SAMSON, 2006; EAST; HAMMOND; WRIGHT, 2007). Associando este fato ao racional de que há diferentes níveis de atenção ao estímulo cognitivo secundário (valência da recomendação) em cada tipo de decisão, têm-se mais duas hipóteses de pesquisa:

H3a: Ao receber "boca a boca" positivo, a intenção de compra por marcas maduras não sofre diferença entre situações de decisão urgente e situações de decisão planejada.

H3b: Ao receber "boca a boca" negativo, a intenção de compra por marcas maduras é menor em situações de decisão urgente do que em situações de decisão planejada. 
Por fim, a última hipótese de pesquisa busca unir as conclusões de Sundaram e Webster (1999), os achados de Samson (2006) e East, Hammond e Wright (2007) e o que afirmam Petty e Cacciopo (1986), Chaiken (1987) e Kahneman (2013) sobre os diferentes tipos de processamento cognitivo. Para tanto, algumas premissas são consideradas: (1) marcas novas (menos conhecidas) são mais vulneráveis a ações de "boca a boca"; (2) recomendações negativas têm maior impacto em intenção de compra do que recomendações positivas. Tal fato é especialmente verdadeiro para marcas maduras (mais conhecidas), já que permitem a criação de expectativas a partir de sua imagem; (3) situações de alta cognição tendem a dar mais atenção ao estímulo central da mensagem persuasiva, enquanto que situações de baixa cognição tendem a direcionar mais cuidado aos estímulos secundários da mensagem.

Portanto, pensando nas duas situações de decisão propostas pelo modelo teórico, ao considerarmos que maturidade de marca e valência da recomendação são estímulos central e secundário, respectivamente, tem-se que a probabilidade de uma marca nova ter sua intenção de compra, no mínimo, igual à de uma marca madura é maximizada quando essa for impulsionada por "boca a boca" positivo em situações de decisão urgente e sofrer "boca a boca" negativo em situações de decisão planejada. Tal relação pode ser descrita pela seguinte hipótese:

H4: Ao receber "boca a boca" positivo em situações de decisão urgente, a intenção de compra por uma marca nova é, no mínimo, igual à intenção de compra de uma marca madura que recebeu "boca a boca" negativo em situações de decisão planejada.

O Quadro 2 relaciona as hipóteses descritas aos objetivos de pesquisa propostos por esta dissertação. 
Quadro 2 - Relacionamento entre objetivos e hipóteses de pesquisa

\begin{tabular}{|c|c|c|}
\hline Objetivo Geral & Objetivos Específicos & Hipóteses de Pesquisa \\
\hline \multirow{7}{*}{$\begin{array}{l}\text { Investigar o papel que } \\
\text { valência da recomendação e } \\
\text { o estágio de maturidade de } \\
\text { marcas apresentam em } \\
\text { decisões de compra que } \\
\text { exigem diferentes níveis de } \\
\text { esforço cognitivo }\end{array}$} & \multirow{2}{*}{$\begin{array}{l}\text { Investigar se a valência de } \\
\text { recomendação e o estágio de } \\
\text { maturidade de marca influenciam } \\
\text { a intenção de compra e, em caso } \\
\text { positivo, como esta relação varia } \\
\text { entre os dois tipos de situações } \\
\text { de decisão. }\end{array}$} & $\begin{array}{l}\text { H1a: Em decisões urgentes, o impacto da } \\
\text { valência da recomendação (estímulo } \\
\text { secundário) em intenção de compra é maior } \\
\text { do que o grau de maturidade da marca } \\
\text { (estímulo primário). }\end{array}$ \\
\hline & & $\begin{array}{l}\text { H1b: Em decisões planejadas, o impacto da } \\
\text { maturidade da marca (estímulo primário) } \\
\text { em intenção de compra é maior do que o } \\
\text { grau de valência da recomendação } \\
\text { (estímulo secundário). }\end{array}$ \\
\hline & \multirow{5}{*}{$\begin{array}{l}\text { Investigar se o efeito interativo } \\
\text { entre valência de recomendação, } \\
\text { estágio de maturidade de marca } \\
\text { e/ ou tipo de situação de decisão } \\
\text { influencia a intenção de compra. }\end{array}$} & $\begin{array}{l}\text { H2a: Ao receber "boca a boca" positivo, a } \\
\text { intenção de compra por marcas novas é } \\
\text { maior em situações de decisão urgente do } \\
\text { que em situações de decisão planejada. }\end{array}$ \\
\hline & & $\begin{array}{l}\text { H2b: Ao receber "boca a boca" negativo, a } \\
\text { intenção de compra por marcas novas é } \\
\text { menor em situações de decisão planejada do } \\
\text { que em situações de decisão urgente. }\end{array}$ \\
\hline & & $\begin{array}{l}\text { H3a: Ao receber "boca a boca" positivo, a } \\
\text { intenção de compra por marcas maduras } \\
\text { não sofre diferença entre situações de } \\
\text { decisão urgente e situações de decisão } \\
\text { planejada. }\end{array}$ \\
\hline & & $\begin{array}{l}\text { H3b: Ao receber "boca a boca" negativo, a } \\
\text { intenção de compra por marcas maduras é } \\
\text { menor em situações de decisão urgente do } \\
\text { que em situações de decisão planejada. }\end{array}$ \\
\hline & & $\begin{array}{l}\text { H4: Ao receber "boca a boca" positivo em } \\
\text { situações de decisão urgente, a intenção de } \\
\text { compra por uma marca nova é, no mínimo, } \\
\text { igual à de uma marca madura que recebeu } \\
\text { "boca a boca" negativo em situações de } \\
\text { decisão planejada. }\end{array}$ \\
\hline
\end{tabular}

Fonte: Elaborado pelo autor. 


\section{MÉTODO}

As hipóteses apresentadas no capítulo anterior foram testadas por meio de um planejamento experimental. Malhotra (2012) afirma que tal método é um conjunto de processos que especifica: (1) as unidades de teste e como estas devem ser divididas em subamostras homogêneas, (2) as variáveis independentes, denominadas tratamentos ou fatores, que devem ser manipuladas, (3) as variáveis dependentes que devem ser medidas e (4) como variáveis externas ao experimento devem ser controladas.

Nas próximas seções, o experimento desenvolvido nesta dissertação será descrito em função de cada um desses aspectos.

\subsection{Definição do desenho experimental}

Para responder aos objetivos de pesquisa propostos, desenvolveu-se um experimento de desenho fatorial com a manipulação de três fatores de dois níveis (tipo de decisão, maturidade de marca e valência de "boca a boca") para avaliação de efeito em uma única variável dependente (intenção de compra), criando-se oito celas ou subamostras independentes de teste $\left(2^{3}=2 \times 2 \times 2\right)$. A decisão por tal desenho experimental se deu por seu caráter inovador entre os estudos sobre o tema que, em sua maioria, trabalham, no máximo, com a combinação de dois fatores de tratamento.

Cada um dos tratamentos, seus respectivos níveis e a estrutura de cada cela de teste são apresentados pelos Quadros 3 e 4.

Quadro 3 - Fatores aplicados no experimento fatorial desenvolvido
\begin{tabular}{|ll|}
\hline Tratamento & Nível \\
\hline Tipo de Decisão (TIPO_PROCESS) & Urgente (1) \\
& Planejado (2) \\
Maturidade de Marca (TIPO_MARCA) & Madura (1) \\
& Nova (2) \\
Valência de Boca a Boca (WOM) & Positivo (1) \\
& Negativo (2) \\
\hline
\end{tabular}

Fonte: Elaborado pelo autor. 
Quadro 4 - Estrutura das celas independentes de teste em função de cada fator

\begin{tabular}{|c|c|c|c|}
\hline CELA & TIPO_PROCESS & TIPO_MARCA & WOM \\
\hline $\mathbf{1}$ & 1 & 1 & 1 \\
\hline $\mathbf{2}$ & 1 & 1 & 2 \\
\hline $\mathbf{3}$ & 1 & 2 & 1 \\
\hline $\mathbf{4}$ & 1 & 2 & 2 \\
\hline $\mathbf{5}$ & 2 & 1 & 1 \\
\hline $\mathbf{6}$ & 2 & 1 & 2 \\
\hline $\mathbf{7}$ & 2 & 2 & 1 \\
\hline $\mathbf{8}$ & 2 & 2 & 2 \\
\hline
\end{tabular}

Fonte: Elaborado pelo autor.

O efeito de variáveis externas ao experimento foi minimizado pelo instrumento (questionário) e método de coleta de dados utilizados, uma vez que implicaram em aleatorização e emparelhamento dos indivíduos que participaram do estudo. Tais detalhes serão melhor explicados adiante neste capítulo.

\subsection{Instrumento de coleta de dados}

Foi elaborado um questionário estruturado com duração média de 10 minutos, composto apenas por perguntas fechadas e que, antes de ser aplicado, foi ajustado por meio de pré-teste para validação de tempo de entrevista e escala para mensuração do construto dependente (intenção de compra).

Uma cópia do questionário está disponível no Apêndice A desta dissertação e os módulos que o compõem são detalhados na Figura 5.

Figura 5 - Fluxo de aplicação e Módulos do questionário de pesquisa

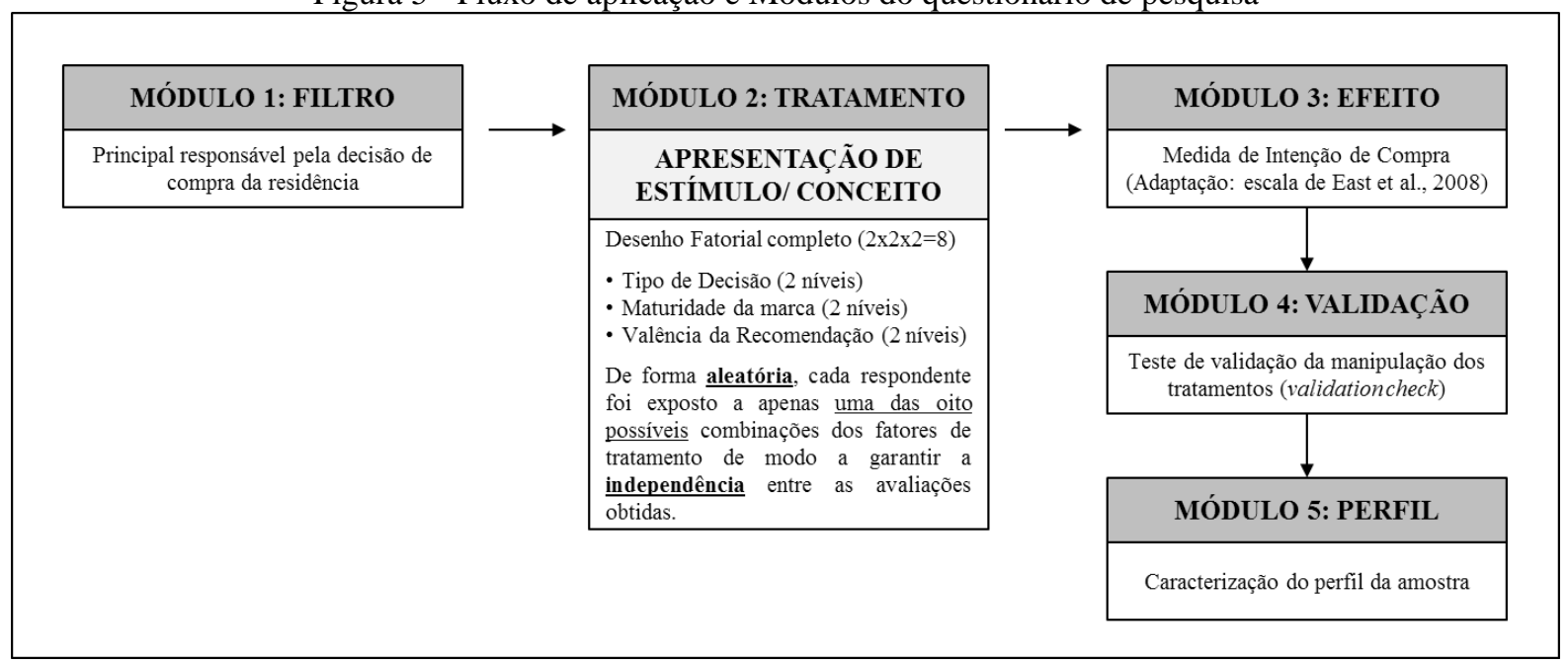

Fonte: Elaborado pelo autor. 
4.2.1 Manipulação dos fatores de tratamento

Pelo desenho experimental aplicado buscou-se garantir a independência entre as observações na medida em que cada respondente foi exposto a apenas uma das opções de combinações de níveis dos fatores de tratamento (celas de teste), fato que é de extrema importância para a significância estatística das técnicas de análise aplicadas (HAIR JR. et al., 2009; TABACHNICK; FIDELL, 2007; MALHOTRA, 2012).

Em cada uma das celas de teste, foram criados estímulos para a montagem de uma "estória" na qual os fatores de tratamento eram manipulados na seguinte ordem: tipo de decisão (urgente ou planejada), tipo de marca (madura ou nova) e valência de "boca a boca" (positivo ou negativo).

$\mathrm{Na}$ tentativa de se obter maior neutralidade nas respostas (MALHOTRA, 2012), optou-se pelo uso de técnica projetiva e as "estórias" foram apresentadas em terceira pessoa. Todos os estímulos utilizados para a manipulação dos fatores estão disponíveis no Apêndice B.

Entre os estímulos elaborados para a representação dos tratamentos, é necessário um comentário quanto à categoria de produto selecionada para a manipulação do fator "maturidade de marca". A escolha pela categoria de geladeiras se deu pelo fato desta ser considerada, pela maioria das pessoas, um bem de compra comparada e, portanto, capaz de gerar maior dissonância cognitiva no momento de sua escolha (COPELAND, 1923), o que é positivo para os objetivos deste estudo. Ainda, para garantir que os respondentes considerassem que geladeiras são bens de compra comparada, já que tal classificação pode sofrer variações de indivíduo para indivíduo (HOLTON, 1948), após a manipulação do tratamento, foi incluído um teste de validação (validation check).

\subsubsection{Definição de escala para mensuração do construto dependente}

A mensuração da variável dependente, intenção de compra, foi feita a partir da adaptação da escala utilizada por East, Hammond e Lomax (2008) em seu estudo sobre o impacto da valência de recomendação em probabilidade de compra, conforme Quadro 5. 
Quadro 5 - Atributos que compõem o construto dependente de Intenção de Compra

\begin{tabular}{|l|l|}
\hline \multicolumn{1}{|c|}{ VARIÁVEL } & \multicolumn{1}{c|}{ ATRIBUTOS* } \\
\hline \multirow{2}{*}{$\begin{array}{l}\text { Intenção de Compra } \\
\text { (EAST; HAMMOND; LOMAX, 2008) } \\
\text { Nome: INT_COMPRA }\end{array}$} & $\begin{array}{l}\text { (INT_1) A geladeira que João pretende comprar é uma boa opção } \\
\text { para ele. }\end{array}$ \\
\cline { 2 - 2 } & $\begin{array}{l}\text { (INT_2) João definitivamente deve comprar a geladeira sobre a qual } \\
\text { ouviu falar. }\end{array}$ \\
\hline
\end{tabular}

* Escritos conforme estudo, ou seja, em terceira pessoa (João) e para a categoria de interesse (geladeiras) Fonte: Elaborado pelo autor.

Ambos os atributos foram avaliados com base em uma escala Likert de sete pontos (1 = Discordo Totalmente e 7 = Concordo Totalmente), a qual, sob o ponto de vista puramente estatístico, deve ser classificada como ordinal e aplicável apenas para indicar a posição relativa na comparação de objetos, mas não a magnitude da diferença entre eles (MORETTIN; BUSSAB, 2010; MALHOTRA, 2012).

No entanto, verifica-se já há algum tempo que, entre os acadêmicos de marketing, escalas ordinais são assumidas intervalares para que técnicas estatísticas multivariadas baseadas em cálculos de escores médios sejam viáveis de aplicação (MAZZON, 1981). Este pressuposto também é adotado por esta dissertação.

\subsubsection{Teste de validação (validation check)}

Com o intuito de garantir que a manipulação dos fatores de tratamento foi percebida pelos respondentes, é necessário que se incluam perguntas para validar as premissas assumidas pelo pesquisador no momento em que planejou o experimento (TABACHNICK; FIDELL, 2007). Tais perguntas são chamadas de teste de validação (validation check).

Foram quatro as premissas assumidas pela manipulação dos tratamentos pelo desenho experimental aplicado nesta dissertação: (1) entrevistados percebem a diferença entre situação de compra urgente e planejada, (2) geladeiras são consideradas bens de compra comparada, (3) BRASTEMP é uma marca de geladeira conhecida e (4) BRASTEMP é marca líder entre as geladeiras. Um teste de validação para cada uma das premissas foi incluído no questionário e seus resultados serão mencionados ainda neste capítulo.

\subsection{Abrangência e Método de coleta de dados}

A coleta de dados limitou-se à cidade de São Paulo e foi realizada pela Internet. A escolha do meio online se deu por três motivos principais (GONÇALVES, 2008): 
- Possibilidade de aleatorização no envio de convites de participação, o que é positivo para controle na tendenciosidade de seleção (variável estranha) associada a métodos de coleta presenciais;

- Maior interatividade, flexibilidade e adaptabilidade do questionário aos módulos de pesquisa propostos, fato que favoreceu a adequação dos estímulos utilizados no experimento;

- Rapidez na coleta, tratamento e limpeza de dados se comparado a métodos presenciais tradicionais, o que trouxe ganhos em tempo para a execução do estudo.

A aplicação dos questionários foi feita por meio de painel online de respondentes gentilmente cedido pela empresa eCGlobal Solutions, composto de mais de 400.000 domicílios registrados como aptos a participar de pesquisas no Brasil, condição que garantiu a aleatoriedade na seleção dos indivíduos que compuseram a amostra deste estudo.

\subsection{Tipo, Tamanho e Perfil de Amostra}

A coleta de dados foi realizada por meio de envio de convites aleatórios aos panelistas da eCGlobal. Reposições automáticas e aleatórias foram feitas à medida que respondentes não se qualificaram no teste de validação da manipulação dos tratamentos, condição essa relevante para aplicação do questionário. Considerando que a recusa ao convite para participar da pesquisa foi nula e baixa a reposição decorrente do teste de validação da manipulação dos tratamentos, pode-se considerar que o processo de amostragem seguiu critérios probabilísticos de seleção dos domicílios dos respondentes (MALHOTRA, 2012).

Para estimular a participação, é comum que empresas que gerenciam painéis online associem prêmios e brindes por pesquisa completa. Portanto, para que tal prática não crie consequências negativas à qualidade das respostas (ex: “respondentes profissionais"), há processos qualificadores rigorosos, como a própria aleatoriedade na seleção, a definição de um número máximo de participações mensais por respondente, a constante atualização cadastral da base de panelistas, entre outros mecanismos.

A amostra final foi composta por 240 casos válidos, distribuída igualmente entre as oito celas de teste (30 casos válidos). O tamanho da amostra por cela foi definido de modo a minimizar os possíveis problemas que se poderia detectar com erros do tipo I e tipo II, afetando, consequentemente, o efeito dos tratamentos e o poder dos testes estatísticos que foram aplicados durante a análise dos dados (HAIR JR. et al., 2009; TABACHNICK; FIDELL, 2007). 
Para se chegar aos casos totais, foram necessárias 329 entrevistas, já que 89 respondentes foram anulados por não se qualificarem nos testes de validação, principalmente, por não classificarem corretamente o tipo de decisão a ser tomada (55\%) ou por considerarem que geladeiras são bens de especialidade (39\%).

A amostra final e válida foi composta por maioria de mulheres $(62 \%$, principal decisora de compras para o lar), entre 31 e 40 anos (38\%), que atualmente não estão trabalhando (55\%) e que se classificam em estratos sociais A e B (82\%), segundo o critério desenvolvido por Mazzon e Kamakura (2013). Ainda, todos os respondentes qualificados declararam serem os principais responsáveis pelas decisões de compra de suas residências. As informações gerais quanto ao perfil da amostra estão consolidadas na Tabela 1 .

Tabela 1 - Caracterização do Perfil da Amostra

\begin{tabular}{|c|c|c|c|}
\hline Variável & Nível & $\mathbf{n}$ & $\%$ \\
\hline \multirow{2}{*}{ SEXO } & Homem & 91 & $38 \%$ \\
\hline & Mulher & 149 & $62 \%$ \\
\hline \multirow{4}{*}{$\begin{array}{c}\text { IDADE } \\
\text { Média: } 35 \text { anos }\end{array}$} & 20 a 24 anos & 20 & $8 \%$ \\
\hline & 25 a 30 anos & 56 & $23 \%$ \\
\hline & 31 a 40 anos & 92 & $38 \%$ \\
\hline & Acima de 40 anos & 72 & $30 \%$ \\
\hline \multirow{3}{*}{ ESTADO CIVIL } & Solteiro (a) & 86 & $36 \%$ \\
\hline & Casado ou União Estável & 137 & $57 \%$ \\
\hline & Divorciado/ Separado (a) & 17 & $7 \%$ \\
\hline \multirow{5}{*}{$\begin{array}{l}\text { PESSOAS NA } \\
\text { RESIDENCIA }\end{array}$} & Apenas uma - Eu moro sozinho (a) & 12 & $5 \%$ \\
\hline & Duas pessoas & 46 & $19 \%$ \\
\hline & Três pessoas & 71 & $30 \%$ \\
\hline & Quatro pessoas & 78 & $33 \%$ \\
\hline & Cinco ou mais pessoas & 33 & $14 \%$ \\
\hline \multirow{3}{*}{ OCUPAÇÃO } & Não estou trabalhando & 131 & $55 \%$ \\
\hline & Trabalho meio período (até 20 horas semanais) & 20 & $8 \%$ \\
\hline & Trabalho em tempo integral (40 horas semanais ou mais) & 89 & $37 \%$ \\
\hline \multirow{5}{*}{ CLASSE SOCIAL } & $\mathrm{A}$ & 58 & $24 \%$ \\
\hline & $\mathrm{B} 1$ & 56 & $23 \%$ \\
\hline & B2 & 81 & $34 \%$ \\
\hline & $\mathrm{C} 1$ & 36 & $15 \%$ \\
\hline & $\mathrm{C} 2$ & 8 & $3 \%$ \\
\hline
\end{tabular}

Fonte: Elaborado pelo autor. 


\subsection{Plano de análise}

A análise dos dados e a validação das hipóteses de pesquisa baseou-se em duas técnicas estatísticas multivariadas: Análise Fatorial e Análise de Variância (ANOVA). Com o intuito de facilitar o entendimento do que se abordará no próximo capítulo, faz-se uma breve introdução aos conceitos básicos de cada uma das técnicas:

- Análise Fatorial: técnica de interdependência entre variáveis métricas (intervalares ou de razão), cujo principal objetivo é, a partir da estrutura de correlações, reduzir variáveis observadas em construtos latentes, conhecidos como fatores. Cada fator gerado é responsável pela explicação de uma parcela da variância original dos dados, está mais associado a um conjunto restrito de variáveis observadas (por meio das cargas fatoriais) e pode ser representado por uma medida composta, resultante da combinação linear das variáveis observadas, denominada escore fatorial. A análise fatorial pode ser exploratória (AFE), quando não há evidências anteriores sobre a forma como as variáveis observadas se correlacionam e agrupam-se em fatores latentes, ou confirmatória (AFC), aplicada a situações nas quais o pesquisador conhece a priori a forma como variáveis observadas estão correlacionadas e estruturam fatores latentes (HAIR JR et al, 2009). Em especial, nesta dissertação, este método de análise terá como objetivo o teste de unidimensionalidade do construto dependente de intenção de compra, já que o uso da técnica fatorial para a validação de uma escala composta por apenas dois itens não é algo usual (MALHOTRA, 2012).

- Análise Univariada de Variância (ANOVA): é um dos tipos de modelos lineares generalizados, aplicado para se identificar a diferença entre médias de uma variável dependente métrica entre dois ou mais grupos formados por variáveis independentes não-métricas (fatores). A hipótese nula em análise de variância univariada é de que a média da variável dependente entre os grupos é igual (HAIR JR. et al., 2009; MALHOTRA, 2012).

Unindo os métodos de análise utilizados na avaliação das hipóteses propostas pelo modelo teórico com os objetivos de pesquisa, este capítulo se encerra com a apresentação da matriz de amarração desta dissertação (Quadro 6). 
Quadro 6 - Matriz de Amarração - Objetivos, hipóteses, variáveis de pesquisa e métodos de análise

\begin{tabular}{|c|c|c|c|c|}
\hline Objetivo Geral & Objetivos Específicos & Hipóteses de Pesquisa & Variáveis de Pesquisa & Métodos de Análise \\
\hline \multirow{6}{*}{$\begin{array}{l}\text { Investigar o papel de fatores } \\
\text { antecedentes à geração de } \\
\text { intenção de boca a boca e a } \\
\text { influência que fatores } \\
\text { qualificadores deste } \\
\text { processo apresentam em } \\
\text { suas consequências para } \\
\text { consumidores de diferentes } \\
\text { tipos de bens de consumo }\end{array}$} & $\begin{array}{l}\text { Investigar se a valência de } \\
\text { recomendação e estágio de } \\
\text { maturidade de marca } \\
\text { influenciam intenção de } \\
\text { compra e, em caso positivo, } \\
\text { como esta relação varia entre } \\
\text { os dois tipos de situações de } \\
\text { decisão }\end{array}$ & $\begin{array}{l}\text { H1a: Em decisões urgentes, o impacto da valência da } \\
\text { recomendação (estímulo secundário) em intenção de compra é } \\
\text { maior do que o grau de maturidade da marca (estímulo primário). }\end{array}$ & $\begin{array}{l}\text { TIPO_MARCA, WOM, } \\
\text { INT_COMPRA }\end{array}$ & $\begin{array}{c}\text { AFE } \\
\text { ANOVA de } 2 \text { fatores }\end{array}$ \\
\hline & \multirow{5}{*}{$\begin{array}{l}\text { Investigar se o efeito } \\
\text { interativo entre valência de } \\
\text { recomendação, estágio de } \\
\text { maturidade de marca e/ ou } \\
\text { tipo de situação de decisão } \\
\text { influencia intenção de } \\
\text { compra }\end{array}$} & $\begin{array}{l}\text { H2a: Ao receber boca a boca positivo, a intenção de compra por } \\
\text { marcas novas é maior em situações de decisão urgente do que em } \\
\text { situações de decisão planejada. }\end{array}$ & \multirow{4}{*}{$\begin{array}{l}\text { TIPO_PROCESS, } \\
\text { INT_COMPRA }\end{array}$} & \multirow{4}{*}{$\begin{array}{c}\text { AFE } \\
\text { ANOVA de } 1 \text { fator }\end{array}$} \\
\hline & & $\begin{array}{l}\text { H2b: Ao receber boca a boca negativo, a intenção de compra por } \\
\text { marcas novas é menor em situações de decisão planejada do que } \\
\text { em situações de decisão urgente. }\end{array}$ & & \\
\hline & & $\begin{array}{l}\text { H3a: Ao receber boca a boca positivo, a intenção de compra por } \\
\text { marcas maduras não sofre diferença entre situações de decisão } \\
\text { urgente e situações de decisão planejada. }\end{array}$ & & \\
\hline & & $\begin{array}{l}\text { H3b: Ao receber boca a boca negativo, a intenção de compra por } \\
\text { marcas maduras é menor em situações de decisão urgente do que } \\
\text { em situações de decisão planejada. }\end{array}$ & & \\
\hline & & $\begin{array}{l}\text { H4: Ao receber boca a boca positivo em situações de decisão } \\
\text { urgente, a intenção de compra por uma marca nova é, no mínimo, } \\
\text { igual à intenção de compra de uma marca madura que recebeu } \\
\text { boca a boca negativo em situações de decisão planejada. }\end{array}$ & $\begin{array}{l}\text { TIPO_PROCESS, } \\
\text { TIPO_MARCA, WOM, } \\
\text { INT_COMPRA }\end{array}$ & $\begin{array}{l}\text { AFE } \\
\text { ANOVA de } 3 \text { fatores } \\
\text { Teste } \text { post hoc de } \\
\text { Scheffé }\end{array}$ \\
\hline
\end{tabular}

Fonte: Elaborado pelo autor. 


\section{ANÁLISE DOS DADOS}

Este capítulo fará o detalhamento da análise dos dados. Inicia-se com a explicação da técnica fatorial aplicada para validação do construto latente de intenção de compra e finalizase com a apresentação de cada um dos modelos lineares generalizados (ANOVAs) desenvolvidos para testes individuais das hipóteses de pesquisa.

\subsection{Validação do construto latente de Intenção de Compra}

Embora a escala utilizada para medir o construto de intenção de compra já tenha sido validada por East, Hammond e Lomax (2008) e contenha apenas dois atributos, decidiu-se pela aplicação de uma análise fatorial exploratória (AFE). O uso desta técnica, como já destacado, não é usual para uma escala que contenha apenas dois itens (MALHOTRA, 2012). Entretanto, escolheu-se por sua aplicação, em primeiro lugar, para validar a hipótese de unidimensionalidade dos dois atributos, garantindo que não mensurem fatores diferentes, e, em segundo lugar, para a obtenção de escores fatoriais que, por serem medidas padronizadas, atendem aos pressupostos de normalidade requeridos por modelos lineares generalizados (HAIR JR et al., 2009).

Como o principal objetivo com a aplicação da técnica foi maximizar a variância explicada dos dados originais após a extração do fator latente, decidiu-se pela análise por componentes principais (MALHOTRA, 2012). Os resultados obtidos estão consolidados na Tabela 2. 
Tabela 2 - Resultados da Análise Fatorial Exploratória pelo método de componentes principais

\section{ESTATÍSTICAS DESCRITIVAS}

\section{Atributos}

A geladeira que João pretende comprar é uma boa opção para ele.

Média

DesvPad

$C V^{*}$

João definitivamente deve comprar a geladeira sobre a qual ouviu falar.

4,44

1,80

$40 \%$

Coeficiente de Correlação de Pearson

4,33

1,70

$39 \%$

$0,843(\mathrm{p}=0,000)$

\section{TESTES DE ADEQUAÇÃO DOS DADOS AO MODELO FATORIAL}

Teste de Esferecidade de Bartlett

Qui-quadrado aproximado $=295,099, \mathrm{gl}=1, \mathrm{p}=0,000$

Medida de adequação da amostra $\mathrm{KMO}=0,500$

\section{COMUNALIDADES}

\section{Atributos}

A geladeira que João pretende comprar é uma boa opção para ele.

João definitivamente deve comprar a geladeira sobre a qual ouviu falar.

AUTOVALORES EXTRAÍDOS

Fator

1

2

\section{MATRIZ DE CARGAS FATORIAIS}

Atributos

A geladeira que João pretende comprar é uma boa opção para ele.

João definitivamente deve comprar a geladeira sobre a qual ouviu falar.

\section{COEFICIENTE ALFA DE CRONBACH = 0,914}

* Coeficiente de variação $=($ DesvPad $/$ Média $)$

Fonte: Elaborado pelo autor.

A análise descritiva dos dados originais mostrou padrões similares de comportamento das variáveis, já que tanto as médias quanto as medidas de variabilidade são similares. Ainda, pelo coeficiente de correlação de Pearson, notou-se que há forte associação positiva entre os dois atributos utilizados no modelo fatorial $(0,843, p=0,000)$, fato que atende à premissa de multicolinearidade entre as variáveis originais (HAIR JR. et al., 2009).

Pelo Teste de Esfericidade de Bartllet, que coloca à prova a hipótese nula $\left(\mathrm{H}_{0}\right)$ de que os dados não são correlacionados e seus índices de correlação seguem uma matriz identidade (MALHOTRA, 2012), verifica-se que a mesma foi rejeitada $\left.\chi_{\text {aproximado }}=295,099, \mathrm{gl}=1, \mathrm{p}=0,000\right) . \mathrm{O}$ valor da medida de adequação da amostra KMO foi de 0,500, algo já esperado por termos apenas dois atributos em análise, o que acarreta a igualdade entre as matrizes obtidas para correlações totais e parciais (HAIR JR. et al., 2009). Portanto, os dados são considerados adequados para a aplicação da técnica fatorial.

Como o objetivo foi a redução de apenas dois atributos a um fator latente, não se aplicou qualquer mecanismo de rotação de cargas fatoriais e assumiu-se a solução de autovalores iniciais como a final. Tal particularidade também faz com que a variância 
explicada pelo fator latente gerado seja igual à variância compartilhada pelos dois atributos, ou seja, sua comunalidade. Assim, após a extração do fator, conseguiu-se explicar, aproximadamente, $92 \%$ da variância dos dados originais, sendo, portanto, resultado satisfatório para os objetivos desta etapa de análise.

Após a extração do fator, calculou-se o coeficiente alfa de Cronbach, medida utilizada para avaliação de confiabilidade interna de escalas e construtos latentes. Hair Jr. et al. (2009) afirmam que seu valor deve ser superior a 0,70 para que o construto medido seja confiável. Como o valor de alfa obtido superou tal patamar $(\alpha=0,914)$, considerou-se satisfatória a escala utilizada para medir a intenção de compra.

Tendo-se a validação da escala utilizada e alta explicação da variância original dos dados, por serem medidas padronizadas e atenderem aos princípios de normalidade (HAIR JR. et al., 2009), definiu-se pela utilização dos escores fatoriais para a representação do construto "intenção de compra", variável dependente em todos os modelos lineares que serão apresentados na sequência deste capítulo.

\subsection{Premissas para aplicação dos modelos lineares generalizados (ANOVAs)}

Antes que se avance com o teste das hipóteses de pesquisa, é importante que se destaquem as premissas implícitas a todo e qualquer modelo linear generalizado. Tabachnick e Fidell (2007) apontam os seguintes pressupostos principais:

1) Independência entre os fatores de tratamento: simples, mas a mais séria premissa para aplicação dos modelos. Como o delineamento experimental deste estudo seguiu um desenho fatorial completo, ou seja, todos os níveis dos fatores de tratamento foram combinados e avaliados o mesmo número de vezes, garantiu-se ortogonalidade e, portanto, tal pressuposto foi satisfeito.

2) Normalidade da variável dependente métrica: a avaliação da normalidade univariada dos atributos que compõem a escala de "intenção de compra" leva à rejeição da hipótese nula $\left(\mathrm{H}_{0}\right)$ do teste de Kolmogorov-Smirnov, indicando que ambos não atendem aos princípios de normalidade. Entretanto, ao se considerarem os escores fatoriais para representação da variável dependente, tem-se que tal pressuposto é atendido, já que, por definição, tais medidas são padronizadas e, portanto, distribuemse normalmente com média igual a 0 e desvio-padrão igual a 1 (HAIR JR. et al., 2009). 
3) Homogeneidade de variância entre os grupos de tratamento: para que se avaliem os efeitos reais dos tratamentos aplicados nas unidades de prova, é necessário que se controle a variância dentro dos grupos de teste. Tal pressuposto será validado pelo teste de Levene, a ser aplicado em cada um dos modelos lineares desenvolvidos nesta dissertação e que testa a hipótese nula $\left(\mathrm{H}_{0}\right)$ de que a variância entre os grupos de tratamento é igual.

Tendo-se definidos os pressupostos, apresentam-se a seguir os resultados obtidos para cada um dos modelos lineares desenvolvidos.

\subsection{ANOVA de dois fatores para validação de H1a}

Para a validação de H1a, isolaram-se os grupos de teste expostos às situações de decisão urgente e aplicou-se uma ANOVA de dois fatores, sendo "maturidade de marca" (TIPO_MARCA) e "valência de 'boca a boca" (WOM) as variáveis independentes e “intenção de compra” (INT_COMPRA) a variável dependente do modelo. Os resultados obtidos serão descritos a seguir.

\subsubsection{Análise descritiva dos resultados}

Pela análise descritiva dos resultados obtidos neste primeiro modelo, há indícios de efeito da valência da recomendação em intenção de compra, já que, independentemente do tipo de marca, as médias dos grupos que foram expostos a situações de "boca a boca" positivo foram maiores. Da mesma forma, parece que o tipo de marca também apresentou efeito em intenção de compra, pois a média dos grupos expostos à marca madura demonstraram médias superiores aos demais.

Além disso, notou-se que a amplitude da diferença entre as médias dos grupos expostos a cada uma das situações de "boca a boca" para marca nova é maior do que a dos grupos expostos à marca madura, o que pode significar que haja algum efeito combinado entre os fatores de tratamento. 
Tabela 3 - Estatísticas descritivas para ANOVA de 2 fatores em decisão urgente

\begin{tabular}{llrrr}
\hline TIPO_MARCA & WOM & Média & DesvPad & N \\
MADURA & WOM POSITIVO &, 929 &, 489 & 30 \\
& WOM NEGATIVO &,- 498 &, 511 & 30 \\
& Total &, 216 &, 874 & 60 \\
\hline \multirow{2}{*}{ NOVA } & WOM POSITIVO &, 665 &, 376 & 30 \\
& WOM NEGATIVO & $-1,554$ &, 373 & 30 \\
& Total &,- 444 & 1,179 & 60 \\
\hline \multirow{2}{*}{ Total } & WOM POSITIVO &, 797 &, 452 & 60 \\
& WOM NEGATIVO & $-1,026$ &, 693 & 60 \\
\hline Fon & Total &,- 114 & 1,085 & 120 \\
\hline
\end{tabular}

Fonte: Elaborado pelo autor.

5.3.2 Teste de homogeneidade de variância entre os grupos de teste

O pressuposto de igualdade de variância foi avaliado pelo teste univariado de Levene sob a hipótese nula $\left(\mathrm{H}_{0}\right)$ de que a variância da variável dependente (intenção de compra) é igual entre os grupos de teste. De acordo com a Tabela 4, não se rejeita $\mathrm{H}_{0}$, já que o valor de $\mathrm{F}$ é pequeno e o nível de significância $(0,411)$ excede o nível de crítico assumido para erros do tipo I ( $\alpha=0,05$ ). Portanto, é possível assumir que a variância entre os grupos é igual.

Tabela 4 - Teste univariado de Levene para ANOVA de 2 fatores em decisão urgente

\begin{tabular}{lcccc}
\hline Situação de Decisão & F & df1 & df2 & Sig. \\
\hline URGENTE &, 967 & 3 & 116 &, 411 \\
\hline Ho $_{0}$ variância da variável dependente é igual entre os grupos de teste \\
a. Design: Intercepto + TIPO_MARCA + WOM + TIPO_MARCA * WOM \\
Fonte: Elaborado pelo autor.
\end{tabular}

\subsubsection{Avaliação do ajuste geral e efeito dos fatores no modelo}

A Tabela 5 apresenta os resultados da ANOVA 2 × 2 feita com auxílio do software SPSS. O primeiro passo foi avaliar a significância e a magnitude do efeito global do modelo, ou seja, a proporção da variabilidade geral que é explicada pela manipulação de todos os tratamentos. Nota-se que o efeito global do modelo é significativo, já que o poder do teste excede 0,80 e a hipótese nula de igualdade de médias gerais entre os grupos é rejeitada pelo teste $\mathrm{F}(200,705$, sig $=0,000)$, e sua magnitude é expressiva, pois explica mais de $80 \%$ da variabilidade da variável dependente $\left(\eta_{\text {múltiplo }}^{2}=117,488 / 140,123=0,829\right)$, minimizando o efeito da componente de erro nos resultados obtidos. 
Tabela 5 - Resultados de análise de variância de dois fatores para decisão urgente

\begin{tabular}{lrrrrrrr}
\hline \multicolumn{1}{c}{ Fontes de variação } & $\begin{array}{c}\text { Soma de } \\
\text { Quadrados }\end{array}$ & gl & \multicolumn{1}{c}{$\begin{array}{c}\text { Quadrado } \\
\text { Médio }\end{array}$} & \multicolumn{1}{c}{ F } & Sig. $^{\text {a }}$ & $\begin{array}{c}\text { Efeito } \\
\left.\text { (Eta }^{2}\right)\end{array}$ & Poder \\
\hline Intercepto & 1,570 & 1 & 1,570 & 8,045 & 0,005 & 0,011 & 0,803 \\
TIPO_MARCA * WOM & 4,713 & 1 & 4,713 & 24,153 & 0,000 & 0,033 & 0,998 \\
TIPO_MARCA & 13,075 & 1 & 13,075 & 67,007 & 0,000 & 0,092 & 1,000 \\
WOM & 99,701 & 1 & 99,701 & 510,956 & 0,000 & 0,704 & 1,000 \\
Modelo Geral & 117,488 & 3 & 39,163 & 200,705 & 0,000 & 0,829 & 1,000 \\
Erro & 22,635 & 116 & 0,195 & & & 0,160 & \\
Total & 140,123 & 120 & & & & & \\
\hline
\end{tabular}

a. nível de significância considerado $(0,05)$.

Fonte: Elaborado pelo autor.

Uma vez que o efeito global do modelo se apresentou significativo, iniciou-se a análise dos efeitos de tratamento pela interação entre eles (HAIR JR. et al., 2009; MALHOTRA, 2012). Para o efeito da interação entre "maturidade de marca e valência da recomendação", a soma de quadrados é $S Q_{\text {TIPO_MARCA*WOM }}=4,713$, com $(2-1)$ x $(2-1)=1$ graus de liberdade, o que resulta em $Q M_{T I P O}{ }_{\text {_MARCA*WOM }}=4,713$. Avaliando-se o poder do teste $(0,998)$ e o resultado do teste F para igualdade de médias entre os grupos $(24,153$, sig = 0,000), pode-se dizer que, em situação de decisão urgente, o efeito de interação entre maturidade de marca e valência de "boca a boca" em intenção de compra é significativo, ou seja, o efeito da maturidade de marca (TIPO_MARCA) em intenção de compra (INT_COMPRA) depende da valência da recomendação (WOM), algo que já havia sido notado pela breve análise de estatísticas descritivas.

A interpretação da interação entre os fatores de tratamento demonstra-se melhor graficamente. O eixo vertical do Gráfico 1 representa as avaliações médias da variável dependente do modelo (INT_COMPRA) para cada um dos quatro grupos de teste; o eixo horizontal representa as duas categorias do fator "maturidade de marca" (TIPO_MARCA) e as retas conectam as médias dos grupos de teste em função do nível da "valência da recomendação" (WOM). Pelo comportamento das retas, notou-se que o efeito de interação entre os tratamentos é ordinal, ou seja, embora os efeitos de tratamento não sejam constantes entre os níveis, a sua ordem de classificação atribuível a um fator não se modifica ao longo dos níveis do segundo fator (MALHOTRA, 2012). Ou seja, a diferença entre médias aumenta ao passarmos de marca madura para marca nova, mas a ordem relativa entre os níveis de valência de recomendação é a mesma, com as maiores médias associadas a situações de "boca a boca" positivo.

Como a interação significativa é ordinal e seu efeito sobre a variável dependente é pequeno $\left(\eta^{2}=4,713 / 140,123=0,033\right)$, permite-se que o efeito principal de cada variável 
independente seja interpretado. Caso estes princípios não fossem satisfeitos, a interpretação dos efeitos principais seria inviável (TABACHNICK; FIDELL, 2007).

Gráfico 1 - Representação gráfica do efeito de interação entre fatores para decisão urgente

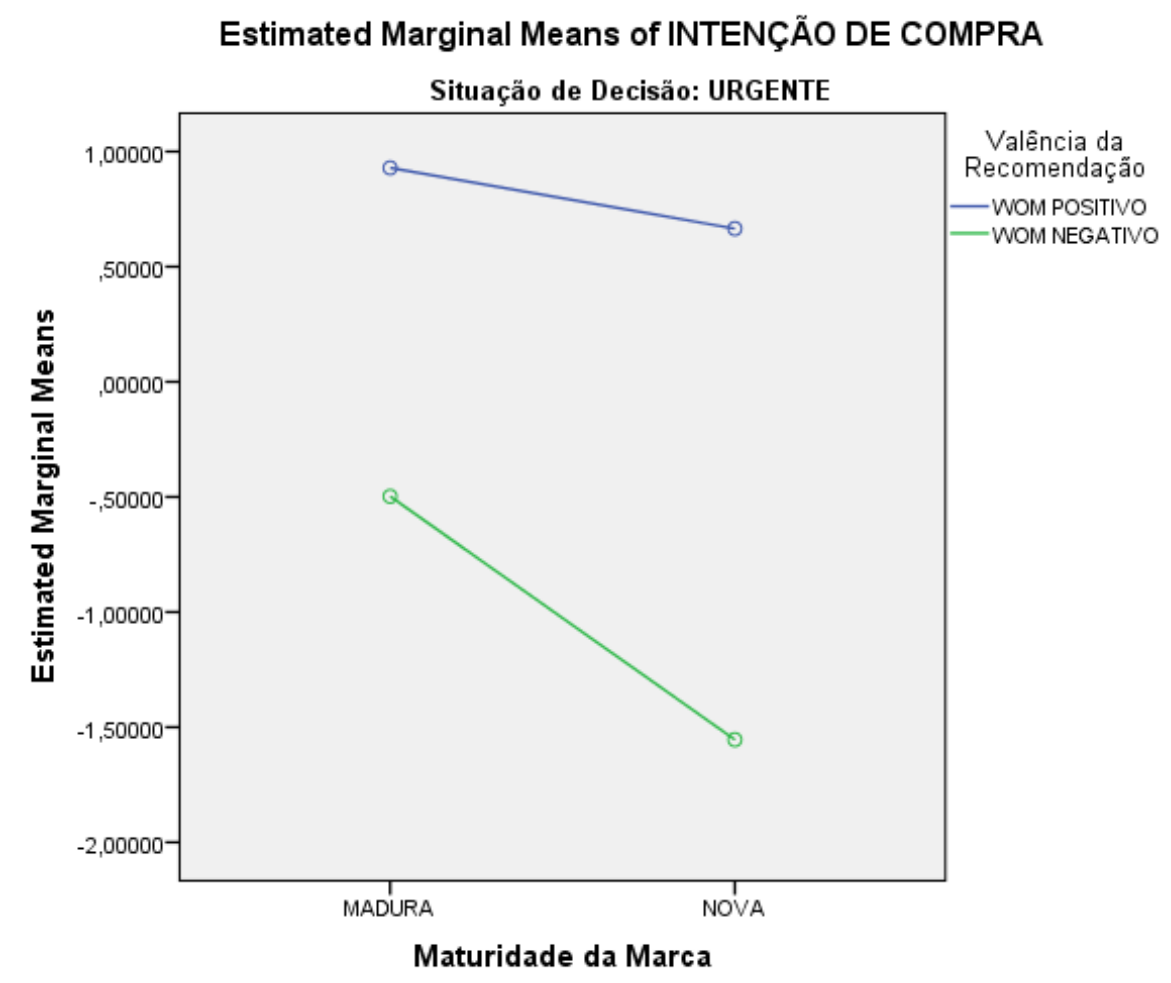

Fonte: Extraído do software SPSS.

Ao se analisarem o poder e o resultado do teste $\mathrm{F}$ para os efeitos principais de "maturidade de marca" (TIPO_MARCA) e "valência da recomendação" (WOM), observa-se que os mesmos são considerados significativos, uma vez que os valores de poder excederam 0,80 e as hipóteses nulas de igualdade de médias entre os grupos de teste foram rejeitadas $($ sig. $<0,05)$.

A partir da validação da significância dos efeitos principais, a relação proposta por H1a pode ser testada. Os valores de $\operatorname{eta}^{2}\left(\eta^{2}\right)$ apontaram a importância de cada fator de tratamento na explicação da variância total do modelo e funcionaram particularmente bem para experimentos com desenhos fatoriais completos nos quais a amostra é igual entre todos os grupos de teste (TABACHNICK; FIDELL, 2007). Pelos valores de eta² obtidos, obteve-se que a variável mais importante no modelo gerado para situação de decisão urgente é a "valência de 'boca a boca"” (WOM), responsável por pouco mais de 70\% da variância total, valor bastante superior à importância associada ao segundo tratamento, "maturidade de marca" $\left(\eta^{2}=0,092\right)$. Portanto, a H1a não pode ser rejeitada. 


\subsection{ANOVA de dois fatores para validação de H1b}

Para a validação de $\mathrm{H} 1 \mathrm{~b}$, isolaram-se os grupos de teste expostos às situações de decisão planejada e aplicou-se uma ANOVA de dois fatores, sendo "maturidade de marca" (TIPO_MARCA) e "valência de boca a boca" (WOM) as variáveis independentes e "intenção de compra" (INT_COMPRA) a variável dependente do modelo. Os resultados obtidos serão descritos a seguir.

\subsubsection{Análise descritiva dos resultados}

Assim como apontado pelo primeiro modelo, a análise descritiva indica indícios de que há efeito da valência da recomendação e de maturidade de marca em intenção de compra, já que as médias dos grupos independentes são diferentes para cada um dos níveis de cada fator.

Por outro lado, parece que o efeito combinado entre os dois fatores foi menor neste segundo modelo, pois as amplitudes de variação das médias entre os grupos de teste intercalados são similares.

\begin{tabular}{llrrr}
\multicolumn{5}{c}{ Tabela 6 - Estatísticas descritivas para ANOVA de 2 fatores em decisão planejada } \\
\hline TIPO_MARCA & WOM & Média & DesvPad & N \\
& WOM POSITIVO & 1,174 &, 478 & 30 \\
MADURA & WOM NEGATIVO &, 187 &, 522 & 30 \\
& Total &, 680 &, 703 & 60 \\
\hline \multirow{2}{*}{ NOVA } & WOM POSITIVO &,- 009 &, 434 & 30 \\
& WOM NEGATIVO &,- 895 &, 614 & 30 \\
& Total &,- 452 &, 691 & 60 \\
\hline \multirow{2}{*}{ Total } & WOM POSITIVO &, 582 &, 749 & 60 \\
& WOM NEGATIVO &,- 354 &, 785 & 60 \\
& Total &, 114 &, 897 & 120 \\
\hline
\end{tabular}

Fonte: Elaborado pelo autor.

5.4.2 Teste de homogeneidade de variância entre os grupos de teste

O pressuposto de igualdade de variância foi novamente avaliado pelo teste univariado de Levene sob a hipótese nula $\left(\mathrm{H}_{0}\right)$ de que a variância da variável dependente (intenção de compra) é igual entre os grupos de teste. De acordo com a Tabela 7 , não se pode rejeitar $\mathrm{H}_{0}$, já que o valor de $\mathrm{F}$ é pequeno e o nível de significância $(0,558)$ excede o nível de crítico 
assumido para erros do tipo I ( $\alpha=0,05$ ). Portanto, é possível assumir que a variância entre os grupos é igual.

Tabela 7 - Teste univariado de Levene para ANOVA de 2 fatores em decisão planejada

\begin{tabular}{lrrrr}
\hline Situação de Decisão & F & df1 & df2 & Sig. \\
\hline PLANEJADA &, 694 & 3 & 116 &, 558 \\
\hline
\end{tabular}

$\mathrm{H}_{0}$ : variância da variável dependente é igual entre os grupos de teste

a. Design: Intercepto + TIPO_MARCA + WOM + TIPO_MARCA * WOM

Fonte: Elaborado pelo autor.

5.4.3 Avaliação do ajuste geral e efeito dos fatores no modelo

A Tabela 8 apresenta os resultados da segunda ANOVA $2 \times 2$ feita com auxílio do software SPSS. Nota-se que o efeito global do modelo é significativo, já que o poder do teste excedeu 0,80 e a hipótese nula de igualdade de médias gerais entre os grupos foi rejeitada pelo teste $\mathrm{F}(81,007$, sig $=0,000)$, e sua magnitude, embora inferior ao primeiro modelo, foi expressiva, pois explica mais de $65 \%$ da variabilidade da variável dependente ( $\left.\eta_{\text {múltiplo }}^{2}=64,805 / 97,308=0,666\right)$.

Tabela 8 - Resultados de análise de variância de dois fatores para decisão planejada

\begin{tabular}{lrrrrrrr}
\hline \multicolumn{1}{c}{ Fontes de variação } & $\begin{array}{c}\text { Soma de } \\
\text { Quadrados }\end{array}$ & gl & $\begin{array}{c}\text { Quadrado } \\
\text { Médio }\end{array}$ & F & Sig. $^{\text {a }}$ & $\begin{array}{c}\text { Efeito } \\
\left.\text { (Eta }^{2}\right)\end{array}$ & Poder \\
\hline Intercepto & 1,570 & 1 & 1,570 & 5,886 & 0,017 & 0,016 & 0,672 \\
TIPO_MARCA * WOM & 0,076 & 1 & 0,076 & 0,285 & 0,595 & 0,001 & 0,083 \\
TIPO_MARCA & 38,432 & 1 & 38,432 & 144,121 & 0,000 & 0,395 & 1,000 \\
WOM & 26,297 & 1 & 26,297 & 98,614 & 0,000 & 0,270 & 1,000 \\
Modelo Geral & 64,805 & 3 & 21,602 & 81,007 & 0,000 & 0,666 & 1,000 \\
Erro & 30,933 & 116 & 0,267 & & & 0,318 & \\
Total & 97,308 & 120 & & & & & \\
\hline
\end{tabular}

a. nível de significância considerado $(0,05)$

Fonte: Elaborado pelo autor.

Para o efeito da interação entre "maturidade de marca e valência da recomendação", a soma de quadrados é $S Q_{T I P O}$ MARCA*WOM $=0,076$, com $(2-1)$ x $(2-1)=1$ graus de liberdade, o que resulta em $Q M_{T I P O \_}{ }_{\text {MARCA }}{ }_{\text {WOM }}=0,076$. Avaliando-se o poder do teste $(0,083)$ e o resultado do teste $\mathrm{F}$ para igualdade de médias entre os grupos $(0,285$, sig $=0,595)$, pode-se dizer que, em situação de decisão planejada, o efeito de interação entre maturidade de marca e valência de "boca a boca" em intenção de compra não é significativo. Tal relação representou-se pelo comportamento paralelo das retas no Gráfico 2. Caso o efeito interativo fosse significativo, 
haveria alguma distinção no padrão das médias entre os níveis, como encontrado pela primeira ANOVA de dois fatores.

Gráfico 2 - Representação gráfica do efeito de interação entre fatores para decisão planejada

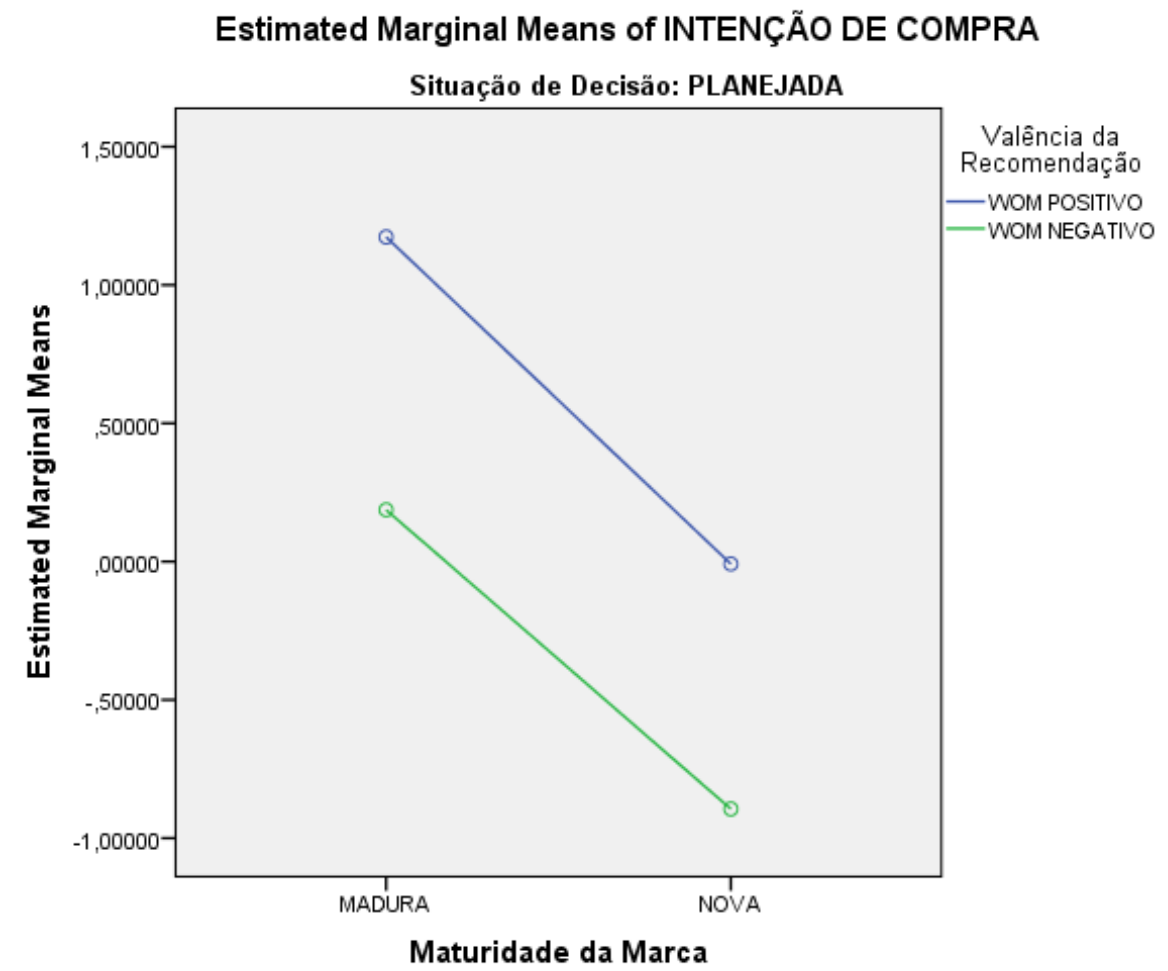

Fonte: Extraído do software SPSS.

Como o efeito da interação não foi significativo partiu-se direto para a interpretação dos efeitos principais de cada um dos tratamentos. De maneira análoga aos resultados obtidos pelo primeiro modelo, ao se analisarem o poder e o resultado do teste $\mathrm{F}$ para os efeitos principais de "maturidade de marca" (TIPO_MARCA) e "valência da recomendação" (WOM), é possível que ambos sejam considerados significativos, uma vez que os valores de poder excederam 0,80 e as hipóteses nulas de igualdade de médias entre os grupos de teste foram rejeitadas $($ sig. $<0,05)$.

A partir da validação da significância dos efeitos principais, a relação proposta por H1b pode ser testada. Pelos valores de eta ${ }^{2}$ obtidos, tem-se que a variável mais importante no modelo gerado para situação de decisão planejada é a "maturidade de marca" (TIPO_MARCA), responsável por 40\% da variância total $\left(\eta^{2}=0,395\right)$. Embora tal resultado nos leve a não rejeitar o que propõe H1b, é importante ressaltar que o impacto de "valência de recomendação" não foi tão pequeno como o encontrado para "maturidade de marca" em situação de decisão urgente, já que seu valor eta² é de 0,270 . 


\subsection{ANOVAs de um fator para validação de H2a e H2b}

Para a validação de $\mathrm{H} 2 \mathrm{a}$ e $\mathrm{H} 2 \mathrm{~b}$, isolaram-se os grupos de testes expostos à marca nova e duas ANOVAs de um fator foram aplicadas. Para a primeira delas (ANOVA 1), elaborada para teste de H2a, separaram-se os dois grupos de teste expostos às situações de "boca a boca" positivo, enquanto que, para a segunda delas (ANOVA 2), elaborada para teste de $\mathrm{H} 2 \mathrm{~b}$, apartaram-se os dois grupos de teste expostos às situações de "boca a boca" negativo. Em ambas, o efeito da variável independente "situação de decisão" (TIPO_PROCESS) sobre a variável dependente "intenção de compra” (INT_COMPRA) foi avaliado. Os resultados obtidos serão descritos a seguir.

\subsubsection{Análise descritiva dos resultados}

Pela análise descritiva, como esperado, notou-se que, independentemente da situação de decisão, as médias para intenção de compra por marca nova são maiores em situações de "boca a boca" positivo em relação ao negativo. Entretanto, há indícios de maior sensibilidade a situações de decisão urgente, pois parece que as maiores e as menores médias ocorrem para este tipo de situação na presença de "boca a boca" positivo e negativo, respectivamente.

Tabela 9 - Estatísticas descritivas para as ANOVAs de 1 fator para marca nova

\begin{tabular}{|c|c|c|c|c|c|c|c|c|c|}
\hline \multirow{2}{*}{ Grupos de teste } & & \multirow{2}{*}{$\mathbf{n}$} & \multirow{2}{*}{ Média } & \multirow{2}{*}{$\begin{array}{l}\text { Desvio } \\
\text { Padrão }\end{array}$} & \multirow{2}{*}{$\begin{array}{c}\text { Erro } \\
\text { Padrão }\end{array}$} & \multicolumn{2}{|c|}{ Intervalo de Confiança } & \multirow{2}{*}{ Min } & \multirow{2}{*}{ Máx } \\
\hline & & & & & & Inferior & Superior & & \\
\hline ANOVA 1 & URGENTE & 30 & 665 & ,376 & ,069 &, 525 & ,806 &,- 229 & 1,272 \\
\hline \multirow{2}{*}{$\begin{array}{l}\text { WOM } \\
\text { POSITIVO }\end{array}$} & PLANEJADA & 30 &,- 009 & ,434 & 079 &,- 171 &, 154 &,- 826 & ,965 \\
\hline & Total & 60 & ,328 &, 527 &, 068 &, 192 & ,464 &,- 826 & 1,272 \\
\hline \multirow{3}{*}{$\begin{array}{l}\text { ANOVA } 2 \\
\text { WOM } \\
\text { NEGATIVO }\end{array}$} & URGENTE & 30 & $-1,554$ & ,373 & ,068 & $-1,693$ & $-1,415$ & $-2,020$ &,- 826 \\
\hline & PLANEJADA & 30 &,- 895 & ,614 &, 112 & $-1,124$ &,- 665 & $-2,020$ & ,368 \\
\hline & Total & 60 & $-1,224$ & ,603 & 078 & $-1,380$ & $-1,068$ & $-2,020$ &, 368 \\
\hline
\end{tabular}

Fonte: Elaborado pelo autor.

5.5.2 Teste de homogeneidade de variância entre os grupos de teste

Para as duas ANOVAs, o pressuposto de igualdade de variância foi avaliado pelo teste univariado de Levene. De acordo com a Tabela 10, não se deve rejeitar H0 em ambos os modelos, já que os níveis de significância $(0,128$ e 0,068, respectivamente) excedem o nível 
de crítico assumido para erros do tipo I $(\alpha=0,05)$. Portanto, é possível assumir que a variância entre os grupos é igual para a ANOVA 1 e 2.

Tabela 10 - Teste univariado de Levene para as ANOVAs de 1 fator para marca nova

\begin{tabular}{lcccc}
\hline Situação de Decisão & Estatística de Levene & df1 & df2 & Sig. \\
\hline ANOVA 1 & 2,380 & 1 & 58 &, 128 \\
\hline ANOVA 2 & 3,450 & 1 & 58 &, 068 \\
\hline
\end{tabular}

$\mathrm{H}_{0}$ : variância da variável dependente é igual entre os grupos de teste Fonte: Elaborado pelo autor.

5.5.3 Verificação da diferença de médias entre os grupos de teste

A Tabela 11 apresenta os resultados de cada ANOVA de um fator feitos com o auxílio do software SPSS.

\begin{tabular}{|c|c|c|c|c|c|c|}
\hline & Fontes de variação & $\begin{array}{c}\text { Soma de } \\
\text { Quadrados }\end{array}$ & gl & $\begin{array}{l}\text { Quadrado } \\
\text { Médio }\end{array}$ & $\mathbf{F}$ & Sig. ${ }^{a}$ \\
\hline \multirow{3}{*}{$\begin{array}{l}\text { ANOVA } 1 \\
\text { WOM } \\
\text { POSITIVO }\end{array}$} & Entre os grupos & 6,810 & 1 & 6,810 & 41,261 &, 000 \\
\hline & Dentro dos grupos & 9,573 & 58 & 0,165 & & \\
\hline & Total & 16,383 & 59 & & & \\
\hline \multirow{3}{*}{$\begin{array}{l}\text { ANOVA } 2 \\
\text { WOM } \\
\text { NEGATIVO }\end{array}$} & Entre os grupos & 6,527 & 1 & 6,527 & 25,326 &, 000 \\
\hline & Dentro dos grupos & 14,947 & 58 & 0,258 & & \\
\hline & Total & 21,473 & 59 & & & \\
\hline
\end{tabular}

a. nível de significância considerado $(0,05)$

Fonte: Elaborado pelo autor.

Para a ANOVA 1, a situação de decisão foi responsável pela explicação de $42 \%$ da variação de intenção de compra $\left(\eta^{2}=6,810 / 16,383=0,416\right)$, o que pode ser considerado um efeito moderado. Como o valor calculado de F para 1 e 58 graus de liberdade $(41,261)$ excede o valor crítico $(4,00$, com $\alpha=0,05)$, rejeitou-se a hipótese nula $\left(\mathrm{H}_{0}\right)$ de igualdade de médias entre os dois grupos de teste e concluiu-se que a média de intenção de compra para marca nova em situações de "boca a boca" positivo é maior em situação de decisão urgente do que na planejada. Portanto, não se pode rejeitar H2a.

Para a ANOVA 2, a situação de decisão foi responsável pela explicação de $30 \%$ da variação de intenção de compra $\left(\eta^{2}=6,527 / 21,473=0,304\right)$, inferior ao efeito encontrado pela ANOVA 1. Isso pode ser explicado pelo aumento do valor da componente de erro $\left(S Q_{\text {dentro }}\right)$, algo que também afetou a sensibilidade do teste univariado de Levene, mas que não 
invalidou os resultados obtidos pela técnica, uma vez que o valor calculado de $\mathrm{F}(25,326)$ também excedeu o valor crítico $(4,00$, com $\alpha=0,05)$. Portanto, a hipótese nula $\left(\mathrm{H}_{0}\right)$ de igualdade de médias entre os dois grupos de teste foi rejeitada e averiguou-se que a média de intenção de compra para marca nova em situações de "boca a boca" negativo é menor em situação de decisão urgente do que nas situações planejadas. Dessa forma, deve-se rejeitar $\mathrm{H} 2 \mathrm{~b}$.

\subsection{ANOVAs de um fator para validação de H3a e H3b}

Para a validação de $\mathrm{H} 3 \mathrm{a}$ e $\mathrm{H} 3 \mathrm{~b}$, isolaram-se os grupos de testes expostos à marca madura e duas ANOVAs de um fator foram aplicadas. Para a primeira delas (ANOVA 3), elaborada para teste de $\mathrm{H} 3 \mathrm{a}$, isolaram-se os dois grupos de teste expostos às situações de "boca a boca" positivo enquanto que, para a segunda delas (ANOVA 4), desenvolvida para teste de H3b, isolaram-se os dois grupos de teste expostos às situações de "boca a boca" negativo. Em ambas, o efeito da variável independente "situação de decisão" (TIPO_PROCESS) sobre a variável dependente "intenção de compra" (INT_COMPRA) foi avaliado. Os resultados obtidos serão descritos a seguir.

\subsubsection{Análise descritiva dos resultados}

Pela análise descritiva, assim como obtida para os grupos expostos à marca nova, notou-se que, independentemente da situação de decisão, as médias para intenção de compra são maiores em situações de "boca a boca" positivo do que no negativo.

Diferentemente do que foi observado para as ANOVAs anteriores, parece não haver diferenças entre as médias para intenção de compra para marca madura entre situação urgente e planejada quando há a exposição ao "boca a boca" positivo. A mesma relação parece não ocorrer para os grupos expostos ao "boca a boca" negativo, já que a média para a situação de decisão urgente aparenta ser menor do que em situação planejada. 
Tabela 12 - Estatísticas descritivas para as ANOVAs de 1 fator para marca madura

\begin{tabular}{|c|c|c|c|c|c|c|c|c|c|}
\hline \multirow{2}{*}{\multicolumn{2}{|c|}{ Grupos de teste }} & \multirow{2}{*}{ n } & \multirow{2}{*}{ Média } & \multirow{2}{*}{$\begin{array}{l}\text { Desvio } \\
\text { Padrão }\end{array}$} & \multirow{2}{*}{$\begin{array}{c}\text { Erro } \\
\text { Padrão }\end{array}$} & \multicolumn{2}{|c|}{ Intervalo de Confiança } & \multirow{2}{*}{ Min } & \multirow{2}{*}{ Máx } \\
\hline & & & & & & Inferior & Superior & & \\
\hline \multirow{3}{*}{$\begin{array}{l}\text { ANOVA 3 } \\
\text { WOM } \\
\text { POSITIVO }\end{array}$} & URGENTE & 30 & ,929 & 489 & 089 & ,747 & 1,112 &,- 229 & 1,562 \\
\hline & PLANEJADA & 30 & 1,174 &, 478 & ,087 & ,995 & 1,352 &, 078 & 1,562 \\
\hline & Total & 60 & 1,051 & ,495 & 064 & ,923 & 1,179 &,- 229 & 1,562 \\
\hline \multirow{3}{*}{$\begin{array}{l}\text { ANOVA 4 } \\
\text { WOM } \\
\text { NEGATIVO }\end{array}$} & URGE & 30 &,- 498 &, 511 & ,093 &,- 689 &,- 307 & $-1,730$ & ,368 \\
\hline & PLANEJADA & 30 & , 187 &, 522 & ,095 &,- 008 & ,382 &,- 826 & 1,562 \\
\hline & Total & 60 &,- 155 & 618 & ,080 &,- 315 & 004 & $-1,730$ & 1,562 \\
\hline
\end{tabular}

Fonte: Elaborado pelo autor.

5.6.2 Teste de homogeneidade de variância entre os grupos de teste

Novamente, a igualdade de variância foi avaliada pelo teste univariado de Levene. De acordo com a Tabela 13, não se deve rejeitar H0 em ambos os modelos, já que os níveis de significância (0,128 e 0,068, respectivamente) excedem o grau de crítico assumido para erros do tipo I ( $\alpha=0,05$ ). Portanto, foi possível admitir que a variância entre os grupos fosse igual para a ANOVA 3 e 4.

Tabela 13 - Teste univariado de Levene para as ANOVAs de 1 fator para marca madura

\begin{tabular}{lcccc}
\hline Situação de Decisão & Estatística de Levene & df1 & df2 & Sig. \\
\hline ANOVA 3 &, 352 & 1 & 58 &, 555 \\
\hline ANOVA 4 &, 312 & 1 & 58 &, 578 \\
\hline
\end{tabular}

$\mathrm{H}_{0}$ : variância da variável dependente é igual entre os grupos de teste Fonte: Elaborado pelo autor.

5.6.3 Verificação da diferença de médias entre os grupos de teste

A Tabela 14 apresenta os resultados de cada ANOVA de um fator feitas com o auxílio do software SPSS.

\begin{tabular}{|c|c|c|c|c|c|c|}
\hline & Fontes de variação & $\begin{array}{c}\text { Soma de } \\
\text { Quadrados }\end{array}$ & gl & $\begin{array}{c}\text { Quadrado } \\
\text { Médio }\end{array}$ & $\mathbf{F}$ & Sig. \\
\hline \multirow{3}{*}{$\begin{array}{l}\text { ANOVA } 3 \\
\text { WOM } \\
\text { POSITIVO }\end{array}$} & Entre os grupos & 0,897 & 1 & 0,897 & 3,838 & 055 \\
\hline & Dentro dos grupos & 13,556 & 58 & 0,234 & & \\
\hline & Total & 14,453 & 59 & & & \\
\hline \multirow{3}{*}{$\begin{array}{l}\text { ANOVA } 4 \\
\text { WOM } \\
\text { NEGATIVO }\end{array}$} & Entre os grupos & 7,031 & 1 & 7,031 & 26,321 & ,000 \\
\hline & Dentro dos grupos & 15,492 & 58 & 0,267 & & \\
\hline & Total & 22,523 & 59 & & & \\
\hline
\end{tabular}

a. nível de significância considerado $(0,05)$

Fonte: Elaborado pelo autor. 
Para a ANOVA 3, a situação de decisão foi responsável pela explicação de menos de $10 \%$ da variação de intenção de compra $\left(\eta^{2}=0,897 / 14,453=0,062\right)$. O baixo efeito do tratamento foi justificado pelo fato de o valor calculado de F para 1 e 58 graus de liberdade $(3,838)$ não exceder o valor crítico $(4,00, \operatorname{com} \alpha=0,05)$. Com isso, a hipótese nula $\left(\mathrm{H}_{0}\right)$ de igualdade de médias entre os dois grupos de teste deve ser aceita e, portanto, para os grupos expostos à marca madura, a média de intenção de compra para situação de decisão urgente deve ser considerada igual à média de intenção de compra para situação de decisão planejada. Portanto, não se pode rejeitar H3a.

Para a ANOVA 4, a situação de decisão foi responsável pela explicação de $31 \%$ da variação de intenção de compra $\left(\eta^{2}=7,031 / 22,523=0,312\right)$, o que pode ser considerado um efeito moderado. Como o valor calculado de F para 1 e 58 graus de liberdade $(36,321)$ excede o valor crítico $(4,00$, com $\alpha=0,05)$, rejeitou-se a hipótese nula $\left(\mathrm{H}_{0}\right)$ de igualdade de médias entre os dois grupos de teste e inferiu-se que a média de intenção de compra para marca madura em situações de "boca a boca" negativo é menor em situação de decisão urgente do que em situações decisivas planejadas. Portanto, também não se pode rejeitar H3b.

\subsection{ANOVA de três fatores para validação de H4}

Para a validação de H4, aplicou-se uma ANOVA de três fatores com o teste post hoc de Scheffé para a comparação das médias obtidas pelos oito grupos analisados. As variáveis "situação de decisão" (TIPO_PROCESS), "maturidade de marca" (TIPO_MARCA) e "valência de 'boca a boca"” (WOM) foram os três fatores de tratamento considerados para avaliação de efeito na variável dependente, “intenção de compra” (INT_COMPRA). Os resultados obtidos serão descritos a seguir.

\subsubsection{Análise descritiva dos resultados}

As análises das estatísticas descritivas indicaram que há diferenças entre as médias de intenção de compra na comparação dos oito grupos de teste, sendo que a maior delas associada a situações de decisão planejada por marca madura e a menor associada à situação de decisão urgente por marca nova. Ainda, observa-se que as amplitudes das diferenças de 
5.7.3 Avaliação do ajuste geral e efeito dos fatores no modelo

A Tabela 17 exibe os resultados da segunda ANOVA 2 × 2 × 2 feita com auxílio do software SPSS. Nota-se que o efeito global do modelo é significativo, já que o poder do teste excede 0,80 e a hipótese nula de igualdade de médias gerais entre os grupos é rejeitada pelo teste $\mathrm{F}(114,729$, sig $=0,000)$, e sua magnitude é expressiva, pois explica $78 \%$ da variabilidade da variável dependente $\left(\eta_{\text {múltiplo }}^{2}=185,432 / 239,000=0,776\right)$.

Tabela 17 - Resultados de análise de variância de três fatores

\begin{tabular}{lrrrrrrr}
\hline \multicolumn{1}{c}{ Fontes de variação } & $\begin{array}{r}\text { Soma de } \\
\text { Quadrados }\end{array}$ & gl & $\begin{array}{c}\text { Quadrado } \\
\text { Médio }\end{array}$ & \multicolumn{1}{c}{ F } & Sig. $^{\text {a }}$ & $\begin{array}{c}\text { Efeito } \\
\text { Eta }^{2}\end{array}$ & Poder \\
\hline Intercepto & 0,000 & 1 & 0,000 & 0,000 & 1,000 & 0,000 & 0,050 \\
TIPO_MARCA * WOM * & 2,993 & 1 & 2,993 & 12,962 & 0,000 & 0,013 & 0,948 \\
TIPO_PROCESS & 1,796 & 1 & 1,796 & 7,778 & 0,006 & 0,008 & 0,793 \\
TIPO_MARCA * WOM & 3,337 & 1 & 3,337 & 14,453 & 0,000 & 0,014 & 0,966 \\
TIPO_MARCA * TIPO_PROCESS & 11,795 & 1 & 11,795 & 51,084 & 0,000 & 0,049 & 1,000 \\
WOM * TIPO_PROCESS & 48,169 & 1 & 48,169 & 208,620 & 0,000 & 0,202 & 1,000 \\
TIPO_MARCA & 114,202 & 1 & 114,202 & 494,608 & 0,000 & 0,478 & 1,000 \\
WOM & 3,139 & 1 & 3,139 & 13,597 & 0,000 & 0,013 & 0,957 \\
TIPO_PROCESS & 185,432 & 7 & 26,490 & 114,729 & 0,000 & 0,776 & 1,000 \\
Modelo Geral & 53,568 & 232 & 0,231 & & & 0,224 & \\
Erro & 239,000 & 240 & & & & & \\
Total & & & & & & & \\
\hline
\end{tabular}

a. nível de significância considerado $(0,05)$

Fonte: Elaborado pelo autor.

Dado que o efeito global do modelo foi significativo, iniciou-se a análise dos efeitos de interação pela combinação entre os três tratamentos. Para o efeito da interação entre "situação de decisão, maturidade de marca e valência da recomendação", a soma de

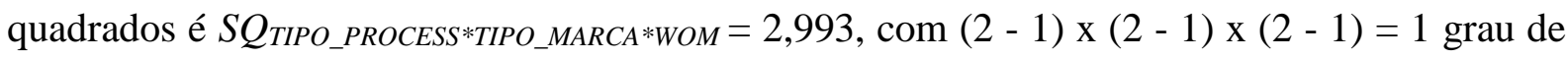

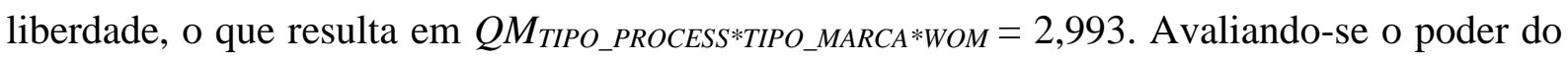
teste $(0,948)$ e o resultado do teste $\mathrm{F}$ para igualdade de médias entre os grupos $(12,962$, sig $=$ 0,000), foi possível afirmar que o efeito interativo entre os três tratamentos se apresentou significativo e sua magnitude, embora pequena, foi igual à do efeito principal da variável “situação de decisão" ( $\left.\eta^{2}=2,993 / 239,000=0,013\right)$.

A significância estatística do efeito interativo entre os três fatores de tratamento implica assumir que o efeito de situação de decisão em intenção de compra depende do grau de maturidade de marca, assim como da valência da recomendação. Tal achado é relevante para a relação que se busca validar por H4. Aliando esse motivo à dificuldade de se caracterizar o tipo de efeito interativo entre as três variáveis, diferentemente do que foi feito 
para $\mathrm{H} 1$, os demais efeitos de tratamento (interativos e principais) resultantes da ANOVA de três fatores não serão interpretados.

O próximo passo para validação de H4 foi a aplicação do teste post hoc de Scheffé para a comparação dois oito grupos de teste resultantes da combinação entre os fatores de tratamento. Como o efeito interativo entre eles é significante, esperou-se que pelo menos um dos grupos apresentasse média de intenção de compra significativamente distinta dos demais. A escolha do teste post hoc de Scheffé se deu por ser mais conservador em relação ao erro do Tipo I (HAIR et al., 2009). Os resultados das comparações de médias de intenção de compra entre os grupos estão representados pelo Gráfico 3 e Tabelas 18 e 19.

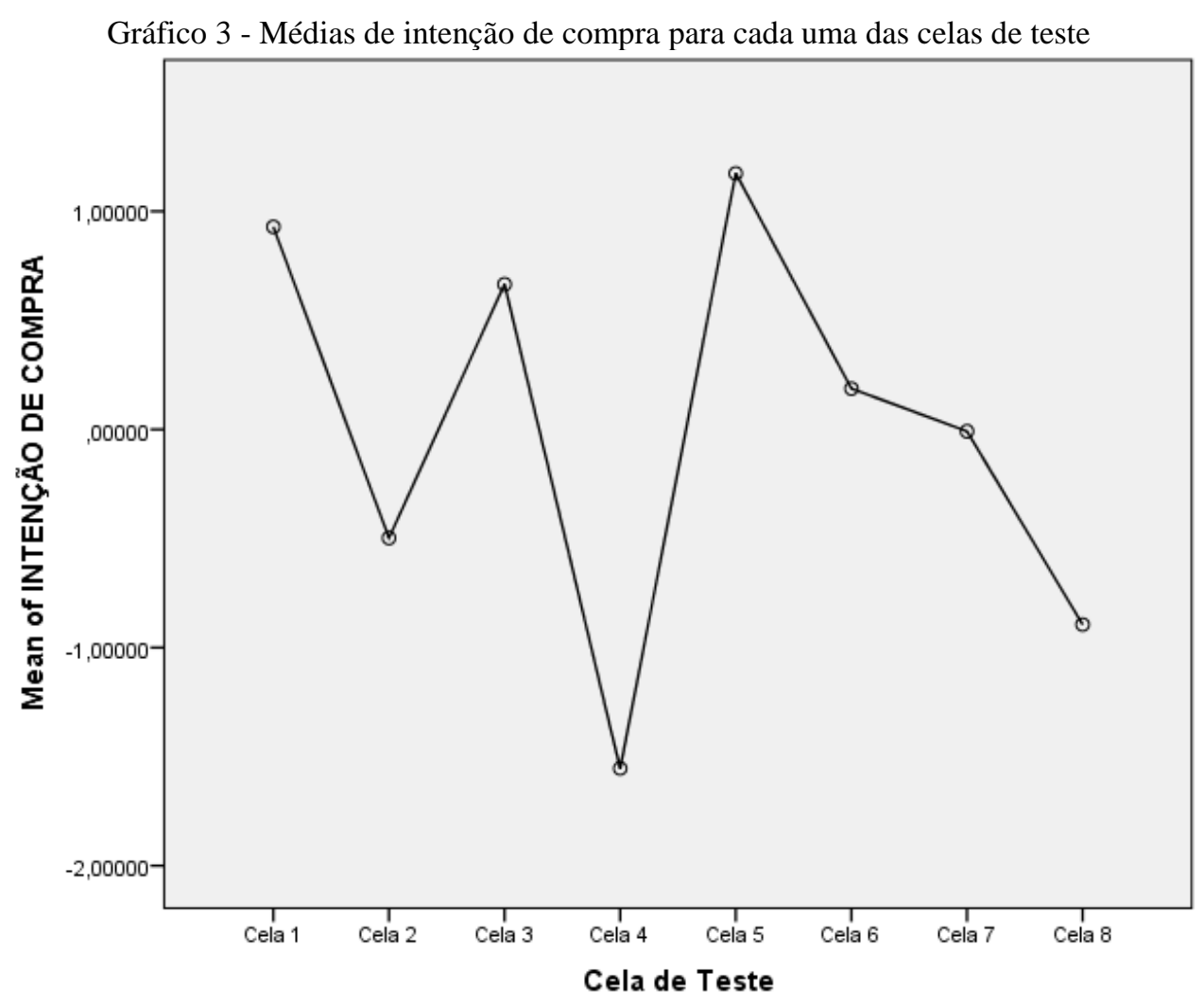

Fonte: Extraído do software SPSS. 


\begin{tabular}{cccc}
\multicolumn{4}{c}{ Tabela 18 - Estrutura das celas independentes de teste em função de cada fator } \\
CELA & TIPO_PROCESS & TIPO_MARCA & WOM \\
\hline $\mathbf{1}$ & URGENTE & MARCA MADURA & POSITIVO \\
$\mathbf{2}$ & URGENTE & MARCA MADURA & NEGATIVO \\
$\mathbf{3}$ & URGENTE & MARCA NOVA & POSITIVO \\
$\mathbf{4}$ & URGENTE & MARCA NOVA & NEGATIVO \\
$\mathbf{5}$ & PLANEJADO & MARCA MADURA & POSITIVO \\
$\mathbf{6}$ & PLANEJADO & MARCA MADURA & NEGATIVO \\
$\mathbf{7}$ & PLANEJADO & MARCA NOVA & POSITIVO \\
$\mathbf{8}$ & PLANEJADO & MARCA NOVA & NEGATIVO \\
\hline Fonte: Elaborado pelo autor & &
\end{tabular}

Tabela 19 - Comparação entre médias das celas de teste e níveis de significância do teste de Scheffé

\begin{tabular}{|c|c|c|c|c|c|c|c|c|c|c|}
\hline Celas & Médias & $\begin{array}{c}\text { Diferença positiva e } \\
\text { com sig }<0.05\end{array}$ & $\begin{array}{c}\text { Cela } 1 \\
\text { (A) }\end{array}$ & $\begin{array}{c}\text { Cela } 2 \\
\text { (B) }\end{array}$ & $\begin{array}{c}\text { Cela } 3 \\
\text { (C) }\end{array}$ & $\begin{array}{c}\text { Cela } 4 \\
\text { (D) }\end{array}$ & $\begin{array}{c}\text { Cela } 5 \\
(\mathbf{E})\end{array}$ & $\begin{array}{c}\text { Cela } 6 \\
(\mathrm{~F})\end{array}$ & $\begin{array}{c}\text { Cela } 7 \\
(\mathbf{G})\end{array}$ & $\begin{array}{c}\text { Cela } 8 \\
\text { (H) }\end{array}$ \\
\hline Cela 1 (A) & ,929 & (B) (D) (F) (G) (H) & &, $000 *$ &, 718 &, $000 *$ &, 792 &, $000 *$ &, $000 *$ &, $000 *$ \\
\hline Cela 2 (B) &,- 498 & (D) &, $000 *$ & &, $000 *$ &, $000 *$ &, $000 *$ &, $000 *$ &, $034 *$ & , 182 \\
\hline Cela 3 (C) & 665 & $(\mathrm{~B})(\mathrm{D})(\mathrm{F})(\mathrm{G})(\mathrm{H})$ & ,718 &, $000 *$ & &, $000 *$ &, $022 *$ &, $042 *$ &, $000 *$ &, $000 *$ \\
\hline Cela 4 (D) & $-1,554$ & &, $000^{*}$ &, $000 *$ &, $000 *$ & &, $000 *$ &, $000 *$ &, $000^{*}$ &, $000 *$ \\
\hline Cela 5 (E) & 1,174 & $(\mathrm{~B})(\mathrm{C})(\mathrm{D})(\mathrm{F})(\mathrm{G})(\mathrm{H})$ & ,792 &, $000 *$ &, $022 *$ &, $000 *$ & &, $000 *$ &, $000 *$ &, $000 *$ \\
\hline Cela 6 (F) &, 187 & (B) (D) $(\mathrm{H})$ &, $000 *$ &, $000 *$ &, $042 *$ &, $000 *$ &, $000 *$ & & ,927 &, $000 *$ \\
\hline Cela 7 (G) &,- 009 & (D) $(\mathrm{H})$ &, $000 *$ &, $034 *$ &, $000 *$ &, $000 *$ &, $000 *$ & ,927 & &, $000 *$ \\
\hline Cela $8 \quad(\mathrm{H})$ &,- 895 & (D) &, $000 *$ & , 182 &, $000 *$ &, $000 *$ &, $000 *$ &, $000 *$ &, $000 *$ & \\
\hline
\end{tabular}

*níveis de significância inferiores ao valor crítico $(0,05)$

Fonte: Elaborado pelo autor.

As combinações entre os níveis de fatores de tratamento que definem cada uma das oito celas de teste foram apresentadas no capítulo anterior, pelo Quadro 4. Antes que se analisem os resultados dos testes de Scheffé, a interpretação do Gráfico 3 traz indícios de que há diferenças significativas entre as médias de intenção de compra entre os grupos, sendo os grupos 5, 1 e 3 aqueles com os maiores valores.

A Tabela 19 consolidou os resultados obtidos pelo teste de Scheffé, apresentando as médias de intenção de compra por cela, os níveis de significância extraídos pela diferença de médias entre todos os pares de celas possíveis e um resumo das diferenças positivas e significativas obtidas por cada uma destas. Notou-se, portanto, que os indícios identificados pelo Gráfico 3 são reforçados pelos resultados dos testes de significância, já que os grupos 5 , 1 e 3, respectivamente, são aqueles que apresentam o maior número de diferenças positivas e significativas ao nível crítico de $5 \%$ em relação aos demais grupos.

A relação de interesse para validação de $\mathrm{H} 4$ foi a estabelecida entre a cela 3 e 6 . Descritivamente, percebeu-se que a média da cela 3 é ligeiramente superior à da cela $6(0,665$ e 0,187 , respectivamente). Pelo resultado do teste de Scheffé, tem-se que o nível de 
significância encontrado é inferior ao nível crítico de $5 \%(\operatorname{sig}=0,042)$. No entanto, mesmo sendo o teste de Scheffé o mais conservador em relação ao erro do tipo I, a conclusão quanto à maior média do grupo 3 deve ser feita com cautela, uma vez que o nível de significância é compartilhado entre as comparações e está bastante próximo à área crítica. Portanto, foi sensato considerar que a média do grupo 3 se apresentou, no mínimo, igual à média do grupo 6, o que possibilitou que H4 não fosse rejeitada.

\subsection{Consolidação dos resultados para as hipóteses de pesquisa}

Após a análise dos dados, o Quadro 7 consolida as hipóteses de pesquisa e respectivos resultados.

Quadro 7 - Resultado consolidado dos testes de hipóteses efetuados

\begin{tabular}{|c|c|}
\hline Hipóteses de Pesquisa & Resultado \\
\hline $\begin{array}{l}\text { H1a: Em decisões urgentes, o impacto da valência da recomendação (estímulo } \\
\text { secundário) em intenção de compra é maior do que o grau de maturidade da marca } \\
\text { (estímulo primário). }\end{array}$ & $\begin{array}{l}\text { Não pode ser } \\
\text { rejeitada }\end{array}$ \\
\hline $\begin{array}{l}\text { H1b: Em decisões planejadas, o impacto da maturidade da marca (estímulo } \\
\text { primário) em intenção de compra é maior do que o grau de valência da } \\
\text { recomendação (estímulo secundário). }\end{array}$ & $\begin{array}{l}\text { Não pode ser } \\
\text { rejeitada }\end{array}$ \\
\hline $\begin{array}{l}\text { H2a: Ao receber "boca a boca" positivo, a intenção de compra por marcas novas é } \\
\text { maior em situações de decisão urgente do que em situações de decisão planejada. }\end{array}$ & $\begin{array}{l}\text { Não pode ser } \\
\text { rejeitada }\end{array}$ \\
\hline $\begin{array}{l}\text { H2b: Ao receber "boca a boca negativo", a intenção de compra por marcas novas é } \\
\text { menor em situações de decisão planejada do que em situações de decisão urgente. }\end{array}$ & Rejeitada \\
\hline $\begin{array}{l}\text { H3a: Ao receber "boca a boca" positivo, a intenção de compra por marcas maduras } \\
\text { não sofre diferença entre situações de decisão urgente e situações de decisão } \\
\text { planejada. }\end{array}$ & $\begin{array}{l}\text { Não pode ser } \\
\text { rejeitada }\end{array}$ \\
\hline $\begin{array}{l}\text { H3b: Ao receber "boca a boca" negativo, a intenção de compra por marcas } \\
\text { maduras é menor em situações de decisão urgente do que em situações de decisão } \\
\text { planejada. }\end{array}$ & $\begin{array}{l}\text { Não pode ser } \\
\text { rejeitada }\end{array}$ \\
\hline $\begin{array}{l}\text { H4: Ao receber "boca a boca" positivo em situações de decisão urgente, a intenção } \\
\text { de compra por uma marca nova é, no mínimo, igual à intenção de compra de uma } \\
\text { marca madura que recebeu boca a boca negativo em situações de decisão } \\
\text { planejada. }\end{array}$ & $\begin{array}{l}\text { Não pode ser } \\
\text { rejeitada }\end{array}$ \\
\hline
\end{tabular}

Fonte: Elaborado pelo autor. 


\section{DISCUSSÃO DOS RESULTADOS E CONCLUSÕES}

A primeira hipótese de pesquisa buscou entender o efeito que ambos os estímulos estudados, valência da recomendação e maturidade de marca, apresentaram em intenção de compra para dois tipos de situações de decisão: a urgente e a planejada. As análises descritas no capítulo anterior apontam para resultados interessantes.

Em situação de decisão urgente, quando há menor nível de esforço e elaboração cognitiva, o efeito de valência da recomendação é muito superior ao efeito que o nível de maturidade de uma marca pode gerar em intenção de compra, o que valida o princípio de atenção seletiva e foco no estímulo principal proposto por Petty e Cacciopo (1986) e Chaiken (1987). Ou seja, presta-se mais atenção no estímulo considerado secundário e de menor complexidade, valência da recomendação, do que no estímulo considerado primário e de maior complexidade, a marca.

Outra possível conclusão que se pode chegar ao se estudar uma decisão urgente é sua relação com o modelo de Lovett, Peres e Shachar (2013) que associa o "boca a boca" a características de marcas, mais especificamente, à significância que a dimensão funcional/ racional da recomendação. Já que o foco principal do processamento cognitivo se volta para a valência da recomendação, tem-se que consumidores racionalizam sua decisão com base na direção desta informação e, dessa forma, esta assume tanto o papel de fonte de informações quanto de fator para a decisão.

Já em situação de decisão planejada, quando há maior esforço e elaboração cognitiva, os resultados encontrados são diferentes, porém mantém a congruência com a teoria de Petty e Cacciopo (1986) e Chaiken (1987). O efeito de maturidade de marca, estímulo primário, recebe mais atenção durante o processamento cognitivo e supera o efeito de valência da recomendação na geração de intenção de compra.

No entanto, embora inferior, se comparado ao efeito que a maturidade de marca apresenta em situação de decisão urgente, o efeito de valência da recomendação em situação planejada é significativo. Isso significa dizer que, mesmo que a maior capacidade de racionalização permita atenção ao estímulo mais complexo, a marca, o estímulo secundário, valência da recomendação, também impacta a tomada de decisão. Se analisado sob a ótica dos sistemas cognitivos de Kahneman (2003), pode ser que tal resultado indique o controle que a razão aplica sobre a intuição em situações de processamento cognitivo elaborado. Dessa forma, a marca processada pelo Sistema 2 foi capaz de corrigir os possíveis efeitos que o Sistema 1 poderia gerar ao processar o estímulo imediato do "boca a boca". 
Em termos práticos, a validação da primeira hipótese de pesquisa também traz contribuições práticas relevantes, principalmente no que se refere à gestão de uma marca. Ao retomarmos os conceitos de Keller (1993), nota-se, claramente, que a sensibilidade ao valor de uma marca varia em função do tipo de decisão de consumo, sendo que, quanto maior a cognição, maior é o impacto que as associações de uma marca podem gerar em intenção de compra. Portanto, quando há urgência na decisão e o "ouvir falar" (recomendação) torna-se mais importante do que o "significar" (maturidade da marca), a ameaça de um novo entrante pode ser algo crítico.

A segunda hipótese de pesquisa teve como objetivo aprofundar os achados de Sundaram e Webster (1999) ao incluir a avaliação do tipo de processamento cognitivo envolvido na tomada de decisão de compra por marcas novas. Pode-se dizer que o resultado foi parcialmente satisfatório.

De fato, quando exposta ao "boca a boca" positivo, uma marca nova gera intenção de compra superior em situações de decisão urgente do que em situações de decisão planejada, corroborando os princípios de atenção seletivos e foco de Petty e Cacciopo (1986) e Chaiken (1987), que também auxiliariam a explicação dos resultados obtidos pelo teste da primeira hipótese de pesquisa. Entretanto, quando há exposição ao "boca a boca" negativo, esperava-se que o resultado em intenção de compra para situações de decisão planejada fosse inferior a situações de decisão urgente, visto que se projetava um foco cognitivo maior no nível de maturidade da marca, o que não ocorreu.

A explicação para tal fato pode estar na possível dificuldade de diferenciação cognitiva entre os dois estímulos, valência da recomendação e uma marca nova, já que ambos são de fácil e rápido processamento. A marca nova (e hipotética) utilizada nas simulações de compra não possui imagem formada, portanto, não exige elaboração mental complexa, da mesma maneira que a recomendação é input rápido e direto para a tomada de decisão. Assim, como o efeito da valência da recomendação é mais significativo em situações de decisão urgente, como validado pela primeira hipótese de pesquisa, a intenção de compra fica mais sensível e acompanha a direção do "boca a boca" com mais intensidade do que em situações de decisão planejada.

Uma consequência prática associada à maior sensibilidade de uma marca nova à decisão urgente está no gerenciamento de seu "boca a boca". Em situações de recomendação positiva, quanto mais se facilitar a tomada de decisão, reduzindo o esforço cognitivo, melhor será o resultado para a marca nova. Por outro lado, em situações de "boca a boca" negativo, 
quanto mais se dificultar a tomada de decisão, aumentando o esforço cognitivo, melhor será o resultado para a marca nova.

Além de complementar os achados de Sundaram e Webster (1999), a terceira hipótese de pesquisa foi formulada com o intuito de adicionar complexidade ao que propuseram Mittal, Ross e Baldasare (1998), Samson (2006) e East, Hammond e Wright (2007) sobre o impacto do "boca a boca" negativo em marcas maduras. Os resultados encontrados foram congruentes com a hipótese em teste.

A exposição de uma marca madura ao "boca a boca" positivo é capaz de gerar a mesma intenção de compra, independentemente do tipo de processamento cognitivo envolvido na decisão. Tal conclusão complementa o que propõem Sundaram e Webster (1999) e East, Hammond e Wright (2007), pois, além de validar a maior resistência de marcas maduras a ações positivas de recomendações, uma vez que se confirma a expectativa criada para uma marca antecipadamente conhecida pelos consumidores, demonstra que esta relação independe do nível de cognição envolvido na tomada de decisão.

No entanto, quando marcas maduras são expostas ao "boca a boca" negativo, sua intenção de compra é menor em situações de decisão urgente do que em situações de decisão planejadas. À medida que marcas maduras sofrem recomendações negativas, cria-se um cenário de desconfirmação de expectativas (SAMSON, 2006; EAST; HAMMOND; WRIGHT, 2007). Como a atenção à valência da recomendação é maior em situações de decisão urgente, tem-se que o impacto de tal desconfirmação é mais agudo, o que afeta sua intenção de compra de forma mais significativa.

Portanto, em termos práticos, para a gestão de uma marca madura, mais importante do que promover "boca a boca" positivo é controlar e monitorar ações de "boca a boca" negativo, especialmente se estas ocorrerem em situações de compra nas quais os consumidores precisam decidir rapidamente, sem muito esforço.

Por fim, a última hipótese foi elaborada a partir das relações assumidas pelas hipóteses anteriores e, a priori, buscou avaliar a comparação entre dois cenários de decisão sob os quais a probabilidade de se maximizar a intenção de compra por uma marca nova, no mínimo, igualaria a intenção por outra madura. O resultado obtido foi satisfatório e, além disso, outros cenários se mostraram tão positivos quanto para a intenção de compra por marcas novas em comparação a marcas maduras.

Pode-se considerar que a intenção de compra por uma marca nova, quando exposta ao "boca a boca" positivo em situação de decisão urgente, é, no mínimo, párea à intenção de compra por uma madura quando esta é exposta ao "boca a boca" negativo em situação de 
decisão planejada. Isto é consequência do que já foi evidenciado por hipóteses anteriores, ou seja, maior impacto da valência de recomendação quando há menor esforço cognitivo, o que impulsiona a intenção de compra da marca nova, e a ação interativa entre o sistema 1 (intuição) e sistema 2 (razão) de Kahneman (2003) que levam à redução da intenção de compra da marca madura.

Ainda, aprendizados obtidos por meio das hipóteses anteriores auxiliam a explicação de outras situações de decisão nas quais a intenção de compra por uma marca nova iguala ou supera outra madura. Nota-se que, em situações de decisão urgente, quando uma marca nova é exposta ao "boca a boca" positivo, sua intenção de compra se iguala a mesma de uma marca madura que também recebeu recomendações positivas e, logicamente, supera a intenção de aquisição da considerada madura que recebeu recomendações negativas.

A explicação de tal resultado está, em primeiro lugar, na maior sensibilidade de marcas novas à valência da recomendação em decisão urgente, discutida pela segunda hipótese de pesquisa, e, em segundo lugar, pela confirmação e desconfirmação de expectativas associadas à valência da recomendação por marcas maduras em decisão urgente, discutidas pela terceira hipótese.

Há outras situações comparativas, nas quais a intenção de compra por uma marca nova iguala a de uma marca madura, que podem ser explicadas, novamente, pela desconfirmação de expectativas (MITTAL; ROSS; BALDASARE, 1998; EAST; HAMMOND; WRIGHT, 2007): quando uma marca nova recebe "boca a boca" positivo e uma marca madura obtém "boca a boca" negativo em decisão planejada e, ainda, quando uma marca madura recebe "boca a boca negativo" em decisão urgente e uma marca nova obtém "boca a boca" negativo em decisão planejada.

Consolidando os aprendizados com cada hipótese de pesquisa, tem-se que o diferencial competitivo que uma marca madura apresenta em relação a uma marca nova, seu valor (equity), perde relevância em dois cenários de decisão principais: (1) quando a marca nova recebe recomendação positiva e a decisão exige baixo esforço cognitivo; ou (2) quando a marca madura recebe recomendação negativa, independentemente do nível de esforço cognitivo envolvido na decisão. 


\section{LIMITAÇÕES DO ESTUDO E SUGESTÕES DE PESQUISAS FUTURAS}

\subsection{Limitações da pesquisa}

Os resultados apresentados por este trabalho possuem algumas limitações associadas às premissas metodológicas assumidas em seu desenvolvimento, podendo ser resumidas pelos seguintes tópicos:

- Embora selecionados de forma probabilística, a amostra do estudo foi composta por principais responsáveis pela compra e escolha de marcas em domicílios da cidade de São Paulo, limitando, portanto, a extrapolação das conclusões.

- A seleção de um bem de compra comparada (geladeiras) pode não refletir o mesmo efeito que a valência da recomendação, a maturidade de uma marca e o nível de esforço cognitivo em uma decisão de compra possui para bens de conveniência ou especialidade.

- A escala considerada para medir o construto de intenção de compra, por ser composta por apenas dois itens, pode não contemplar o alcance que se gostaria de medir por este fator.

- Embora se tenham seguido os princípios de aleatorização e emparelhamento, ao se escolher pelo método de coleta online, o controle de variáveis estranhas ao experimento foi menos rigoroso, possibilitando que parte da variabilidade dos resultados encontrados tenha sofrido impacto de fatores que não foram medidos diretamente.

\subsection{Sugestões para pesquisas futuras}

Há alguns possíveis caminhos para estudos futuros que poderiam ampliar os resultados encontrados por esta pesquisa:

1) Expandir a geografia de coleta para além da cidade de São Paulo.

2) Realizar experimento similar para bens que se enquadram em outra tipologia e exigem padrões de decisão diferentes (ex: bem de especialidade).

3) Estudar a relação entre valência da recomendação, maturidade de marca e tipos de decisão em ambiente de compra online.

4) Incluir outros possíveis tratamentos ao estudo da relação proposta, como, por exemplo, a variável preço. 


\section{REFERÊNCIAS}

AMERICAN MARKETING ASSOCIATION. Disponível em: <https://www.ama.org/ resources/Pages/Dictionary.aspx?dLetter=B>. Acesso em: 01 nov. 2014.

ANAND, B. N.; SHACHAR, R. Advertising, the matchmaker. RAND Journal of Economics, Santa Monica - CA, v. 42, n. 2, p. 205-245, May 2011.

ANDERSON, E. W. Customer Satisfaction and Word of Mouth. Journal of Service Research, [S.1], v. 1, n. 1, p. 5-17, 1998.

ANDRADE, J; HEMZO, M. A.; MAZZON, J. A. Quatro Décadas Persuadindo Leitores: Uma Aplicação do ELM no Estudo do Uso de Rotas Centrais e Periféricas em Anúncios Impressos de Veja.Comunic@acción: Revista de Investigación en Comunicación y Desarrollo, Peru, v. 2, n. 2, p. 16-26, 2011.

ARNDT, J. The role of product-related conversation in the diffusion of a new product. Journal of Marketing Research, Chicago, v. 4, n. 3, p. 291-95, Aug. 1967.

BERGER, J. Arousal Increases Social Transmission of Information. Psychological Science, Washington, v. 22, n. 7, p. 891-893, 2011.

BERGER, J.; HEATH, C. Where consumers diverge from others: identity signaling and product domains. Journal of Consumer Research, Chicago, v. 34, n. 2, p. 121-134, 2007.

BERGER, J.; SCHWARTZ, E. What drivers immediate and ongoing word of mouth. Journal of Marketing Research, Chicago, v. 48, p. 869-880, Oct. 2011.

BROWN, J. J.; REIGNEN, P. H. Social ties and word-of-mouth referral behavior. Journal of Consumer Research, Chicago, v. 14, n. 3, p. 350-62, 1987.

BROWN, T. J. et al. Spreading the Word: Investigating Antecedents of Consumers' Positive Word-of-Mouth Intentions and Behaviors in a Retailing Context. Journal of the Academy of Marketing Science, [S.1], v. 33, n. 2, p. 123-138, 2005.

CHAIKEN, S. The heuristic model of persuasion. In: ZANNA, M. P.; OLSON, J. M.; HERMAN, C. P. (Ed.). Social influence: The Ontario symposium. Hillsdale, NJ: Erlbaum, 1987. p. 3-39. v. 5.

CHAIKEN, S.; MAHESWARAN, D. Heuristic Processing Can Bias Systematic Processing: Effects of Source Credibility, Argument Ambiguity, and Task Importance on Attitude Judgment. Journal of Personality and Social Psychology, Washington, v. 66, n. 3, p. 460-473, 1994.

COPELAND, M. T. Relation of consumers' buying habits to marketing methods. Harvard Business Review, Watertown, v.1, p. 282-289, Apr. 1923.

DITCHER, E. How word-of-mouth advertising works. Harvard Business Review, Watertown, v. 44, n. 6, p. 147-66, 1966. 
EASINGWOOD, C. J.; MAHAJAN, V.; MULLER, E. A non-uniform influence innovation diffusion model of new product acceptance. Marketing Science, Cambridge, v. 2, n. 3, p. 273$295,1983$.

EAST, R.; HAMMOND, K.; WRIGHT, M. The relative incidence of positive and negative word of mouth: a multi category study. International Journal of Research in Marketing, [S.1], v. 24, n. 2, p. 175-184, 2007.

EAST, R.; HAMMOND, K; LOMAX, W. Measuring the impact of positive and negative word of mouth on brand purchase probability. International Journal of Research in Marketing, [S.1], v. 25, n. 3, p. 215-224, 2008.

ECGLOBAL PANELS STATS. Disponível em: <http://www.youblisher.com/p/612829Panel-Book-2013-eCGlobal-Solutions-PT/>. Acesso em: 3 nov. 2014.

ENGEL, J. F.; KEGERREIS, R. J.; BLACKWELL, R. D. Word-of-mouth communications by the innovator. Journal of Marketing, Chicago, v. 33, p. 15-19, July 1969.

FRESSART, B.; MARKOWITZ, L. Code RED: Relevance. Expensiveness. Differentiation. The Best Measures for Choosing High Potential Consumer Goods Concepts. Ipsos Marketing, Paris, p. 1-4, Mar. 2009.

FULLERTON, G. Creating advocates: The roles of satisfaction, trust and commitment. Journal of Retailing and Consumer Services, [S.1], v. 18, n. 1, p. 92-100, 2011.

GONÇALVES, D. Pesquisas de Marketing pela Internet: as percepções sob a ótica dos entrevistados. Revista de Administração Mackenzie, São Paulo, v. 9, n. 7, p. 70-88, 2008.

GAVRONSKI, B.; CREIGTHTON, L. A. Dual Process Theories. In: CARLSTON, D. E. (Ed.). The Oxford handbook of social cognition. New York, NY: Oxford University Press, 2013. p. 282-312.

GODES, D.; MAYZLIN, D. Using online conversations to study word of mouth communication. Marketing Science, Cambridge, v. 23, n. 4, p. 545-560, 2004.

GREWAL, R.; CLINE, T. W.; DAVIES, A. Early-entrant advantage, word-of-mouth communication, brand similarity, and the consumer decision-making process. Journal of Consumer Psychology, Chicago, v. 13, n. 3, p. 187-197, 2003.

HAIR JR., J. F. et al. Análise multivariada de dados. 6. ed. Porto Alegre: Bookman, 2009.

HARRISON-WALKER, J. The measurement of word-of-mouth communication and an investigation of service quality and consumer commitment potential antecedents. Journal of Service Research, [S.1], v. 4, n. 1, p. 60-75, 2001.

HERNANDEZ, J. M. C. Elaboração de um modelo de compra na internet: o papel da confiança do consumidor no varejista eletrônico em diferentes situações de risco percebido. 2003. 191 f. Tese (Doutorado em Administração) - Fundação Getúlio Vargas, Escola de Administração de Empresas de São Paulo, São Paulo, 2003. 
HILL, S.; PROVOST, F.; VOLINSKY, C. Network based marketing: identifying likely adopters via consumer networks. Statistical Sciences, [S.1], v. 21, n. 2, p. 256-276, 2006.

HOLTON, R. H. The Distinction between Convenience goods, Shopping Goods, and Specialty Goods. Journal of Marketing, Chicago, v. 13, p. 202-217, 1948.

KALWANI, M. U.; SILK, A. J. On the reliability and predictive validity of purchase intention measures. Marketing Science, Cambridge, v. 1, n. 3, p. 243-286, 1982.

KAHNEMAN, D. A Perspective on Judgment and Choice: Mapping Bounded Rationality. American Psychologist, Washington, v. 58, n. 9, p. 697-720, Sept. 2003.

Thinking, fast and slow. New York: Farrar, Straus and Giroux, 2013.

KAHNEMAN, D.; TVERSKY, A. An Analysis of Decision under Risk. Econometrica, v. 47, n. 2, p. 263-292, Mar. 1979.

KATZ, E. The two-step flow of communication: an up-to-date report on an hypothesis. The Public Opinion Quarterly, Oxford, v. 21, n. 1, p. 61-78, 1957.

KELLER, E. Unleashing the power of word of mouth: creating brand advocacy to driver growth. Journal of Advertising Research, Oxfordshire, v. 47, n. 4, p. 448-452, Dec. 2007.

KELLER, K. L. Conceptualizing, measuring and managing customer-based brand equity. Journal of Marketing, Chicago, v. 57, n. 1, p. 1-22, 1993.

KELlER, K. L.; MACHADO, M. Gestão Estratégica de Marcas. São Paulo: Pearson Prentice Hall, 2007.

KOTLER, P.; KELLER, K. L. Administração de Marketing. 14. ed. São Paulo: Pearson Prentice Hall, 2012.

KOTLER, P.; LEVY, S. J. Broadening the concept of marketing. Journal of Marketing, Chicago, v. 33, n. 1, p. 10-15, Jan. 1969.

LIM, B. C.; CHUNG, C. M. Y. The impact of word-of-mouth communication on attribute evaluation. Journal of Business Research, [S.1], v. 64, n. 1, p. 18-23, 2011.

LOVETT, M. J.; PERES, R.; SHACHAR, R. On brands and word of mouth. Journal of Marketing Research, Chicago, v. 50, n. 4, p. 427-444, 2013.

MALHOTRA, N. Pesquisa de marketing: uma orientação aplicada. 3. ed. Porto Alegre: Bookman, 2012.

MARTIN, W. C.; LUEG, J. E. Modeling word-of-mouth usage. Journal of Business Research, [S.1], v. 66, n. 7, p. 801-808, 2013.

MATOS, C. A.; ROSSI, C. A. V. Word-of-mouth communications in marketing: a metaanalytic review of antecedents and moderators. Journal of the Academy of Marketing Sciences, Greenvale, v. 36, n. 4, p. 578-596, Sept. 2008. 
MAZZON, J. A. Análise do programa de alimentação do trabalhador sob o conceito de marketing social. 1981. Tese (Doutorado em Administração) - Programa de Pós-graduação em Administração, Faculdade de Economia, Administração e Contabilidade da Universidade de São Paulo, São Paulo, 1981.

MAZZON, J. A.; KAMAKURA, W. A. Estratificação Socioeconômica e Consumo no Brasil. São Paulo: Blucher, 2013.

MITTAL, V.; ROSS, W. T.; BALDASARE, P. M. The Asymmetric Impact of Negative and Positive Attribute-Level Performance on Overall Satisfaction and Repurchase Intentions. Journal of Marketing, Chicago, v. 62, n. 1, p. 33-47, Jan. 1998.

MOORS, A.; DE HOUWER, J. Automaticity: A Theoretical and Conceptual Analysis. Psychological Bulletin, Ghent, v. 132, n. 2, p. 297-326, 2006.

MORETTIN, P. A.; BUSSAB, W. O. Estatística Básica. 6. ed. São Paulo: Saraiva, 2010.

MORRISON. D. G. Purchase intentions and purchase behavior. Journal of Marketing, Chicago, v. 43, p. 65-74, 1979.

MOURALI, M.; LAROCHE, M.; FRANK, P. Antecedents of consumer relative preference for interpersonal information sources in pre-purchase search. Journal of Consumer Behavior, [S.1], v. 4, n. 5, p. 307-18, 2005.

NIELSEN. Confiança Global em Publicidade e Mensagens de Marcas. 2013. Disponível em: <http://www.nielsen.com/content/dam/corporate/ Brasil/ reports/ 2013/ Confianc\%CC\%A7aConsumidor_Set13.pdf>. Acesso em: 09 nov. 2014.

OLIVER, R. L. A cognitive model of the antecedents and consequences of satisfaction decisions. Journal of Marketing Research, Chicago, v. 17, n. 4, p. 460-9, Nov. 1980.

PETERS, K.; KASHIMA, Y. From social talk to social action: Shaping the social triad with emotion sharing. Journal of Personality and Social Psychology, Washington, v. 93, n. 5, p. 780-797, 2007.

PETTY, R. E.; CACCIOPO, J. T. The Elaboration Likelihood Model of Persuasion. Advances in Experimental Social Psychology, New York, v. 19, p. 123-205, 1986.

PORTER, M. C. Consumer behavior, retailer power and market performance in consumer goods industries. The Review of Economics and Statistics, Cambridge, v. 56, n.4, p. 419-436, 1974.

POSNER, M. I.; SNYDER, D. E. Selective attention and cognitive control. Perspective, Amsterdan, v. 10, n. 1, p. 13-17, Jan. 1987.

SAMSOM, A. Understanding the buzz that matters: negative vs positive word of mouth. International Journal of Market Research, London, v. 48, n. 6, p. 647-657, 2006. 
SUNDARAM, D. S.; WEBSTER, C. The role of brand familiarity on the impact of word-ofmouth communication on brand evaluation. Advances in Consumer Research, [S.1], v. 26, p. 664-670, 1999.

SUNDARAM, D. S.; MITRA, K.; WEBSTER, C. Word-of-mouth communications: a motivational analysis. Advances in Consumer Research, [S.1], v. 25, p. 527-531, 1998.

SMALWOOD, J. E. The product life cycle: a key to strategic marketing planning. $M S U$ Business Topics, Michigan, v. 21, n. 1, p. 29-35, 1973.

TABACHNICK, B. G.; FIDELL, L. S. Experimental Design Using ANOVA. Belmont: Thomson Higher Education, 2007.

WESTBROOK, R. A.; OLIVER, R. L. The dimensionality of consumption emotion patterns and consumer satisfaction. Journal of Consumer Research, Chicago, v. 18, n. 1, p. 84-91, 1991.

YANG, S. et al. An empirical study of word-of-mouth generation and consumption. Marketing Science, Cambridge, v. 31, n. 6, p. 952-963, 2012. 


\section{APÊNDICES}

\section{Apêndice A - Questionário aplicado na pesquisa de campo}

Olá, você está convidado a participar de projeto de pesquisa realizado por mestrando de pós-graduação em Administração da Faculdade de Economia e Administração (FEA) da Universidade de São Paulo (USP). Para tanto, pedimos que responda a perguntas de simples respostas, as quais tomarão de 5 a 7 minutos (aproximadamente) de seu tempo. Sua participação neste estudo é totalmente voluntária e isenta de qualquer risco. Muito obrigado por seu tempo e auxílio! Para iniciar sua pesquisa, clique no botão CONTINUE logo abaixo.

Você é o/a principal responsável pela escolha das marcas de produtos que utiliza diariamente? (Selecione apenas uma resposta)
1. Sim

2. Não

Nas próximas telas, você verá uma estória. Por favor, leia-a com detalhes e, quando estiver confortável, prossiga com a pesquisa clicando no botão "Continue", posicionado logo abaixo do vídeo:

\section{APRESENTAÇÃO DOS ESTÍMULOS DE ACORDO COM A CELA DE TESTE}

Pensando na estória que você acabou de ler, aponte o quanto você concorda ou discorda com cada uma das seguintes afirmativas.

Para isso, quanto mais você concordar com a afirmação, mais próxima de 7 deve ser a sua resposta e, quanto mais você discordar da afirmarção, mais próxima de 1 deve ser a sua resposta. (Selecione apenas uma resposta por afirmativa)

\begin{tabular}{|c|c|c|c|c|c|c|c|}
\hline & 1 & 2 & 3 & 4 & 5 & 6 & 7 \\
\hline $\begin{array}{c}\text { A geladeira que João pretende comprar é } \\
\text { uma boa opção para ele }\end{array}$ & $\square$ & $\square$ & $\square$ & $\square$ & $\square$ & $\square$ & $\square$ \\
\hline $\begin{array}{c}\text { João definitivamente deve comprar a } \\
\text { geladeira sobre a qual ouviu falar }\end{array}$ & $\square$ & $\square$ & $\square$ & $\square$ & $\square$ & $\square$ & $\square$ \\
\hline
\end{tabular}

Ainda pensando na história que você leu, como você descreveria a decisão que João deve tomar? (Selecione apenas uma resposta)

1. Algo que ele tem pouco tempo para decidir. Precisa escolher com urgência.

2. Algo que ele tem tempo para decidir. Não precisa escolher com urgência.

Qual das afirmativas abaixo melhor descreve como você decidiria pela compra de uma geladeira? (Selecione apenas uma resposta)

1. Escolheria qualquer uma, sem fazer qualquer comparação entre as opções disponíveis

2. Escolheria a melhor opção possível, após comparar todas as opções disponíveis

3. Escolheria uma opção específica, pois apenas uma opção de geladeira atende às minhas necessidades

Brastemp é uma marca conhecida? (Selecione apenas uma resposta)

1. Sim

2. Não

Brastemp é uma marca líder entre as geladeiras? (Selecione apenas uma resposta)

1. Sim

2. Não

Qual é a marca de sua geladeira atual?

1. Bosch

2. Brastemp 

3. Britânia
4. Cadence
5. Consul
6. Continental
7. DAKO
8. Electrolux
9. Esmaltec
10. GE
11. Gelopar
12. LG
13. Multilaser
14. Panasonic
15. Prosdócimo
16. Samsung
17. Smeg
18. Suggar
19. Outra marca

Qual é o seu grau de satisfação com sua geladeira atual? (Selecione apenas uma resposta)
1. Extremamente Satisfeito
2. Muito Satisfeito
3. Satisfeito
4. Insatisfeito
5. Muito Insatisfeito
6. Extremamente Insatisfeito

Você é:

1. Homem

2. Mulher

Assinale em que faixa se encontra a sua idade:
1. 20 a 24 anos
2. 25 a 30 anos
3. 31 a 40 anos
4. Acima de 40 anos

Complete com sua idade exata:

Qual é o seu estado civil? (Selecione apenas uma resposta)

1. Solteiro (a)

2. Casado (a)/ União Estável

3. Divorciado (a)/ Separado (a)

4. Viúvo (a)

Incluindo você, quantas pessoas moram em sua residência? (Selecione apenas uma resposta)

1. Apenas uma. Eu moro sozinho (a)

2. Duas pessoas

3. Três pessoas

4. Quatro pessoas

5. Cinco ou mais pessoas

Você possui filhos? (Selecione apenas uma resposta)

1. Sim

2. Não

Seus filhos moram na mesma residência que você? (Selecione apenas uma resposta)

1. Sim

2. Não 
Qual é a sua atual situação de trabalho? (Selecione apenas uma resposta)

1. Não estou trabalhando

2. Trabalho em meio período (até 20 horas semanais)

3. Trabalho em tempo integral (40 horas semanais ou mais)

Quantos dos seguintes itens você possui em sua residência? Assinale as quantidades utilizando a escala abaixo: (Selecione apenas uma resposta por item)

Atenção: "TV preta e branca" não entra para a contagem e "Geladeira Duplex" entra para a contagem de "Geladeira" e "Freezer" separadamente, ou seja, você deve assinalar um ponto para cada um dos itens.

\begin{tabular}{|c|c|c|c|c|c|}
\hline & 0 & 1 & 2 & 3 & 4 ou mais \\
\hline Banheiros & $\square$ & $\square$ & $\square$ & ل & \\
\hline Empregados domésticos (que vem diariamente) & $\square$ & $\square$ & $\square$ & $\square$ & \\
\hline Automóveis/ Carros & $\square$ & $\square$ & $\square$ & $\square$ & $\square$ \\
\hline Microcomputador (notebooks, netbooks, desktops) & $\square$ & $\square$ & $\square$ & $\square$ & ב \\
\hline Máquina lava-louças & $\square$ & $\square$ & 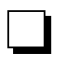 & & \\
\hline Geladeira & $\square$ & $\square$ & $\square$ & $\square$ & \\
\hline Freezer (aparelho independente ou parte da geladeira duplex) & $\square$ & $\square$ & $\square$ & $\square$ & \\
\hline Máquina de Lavar & $\square$ & $\square$ & $\square$ & $\square$ & $\square$ \\
\hline Aparelho de DVD & $\square$ & $\square$ & $\square$ & $\square$ & $\square$ \\
\hline Microondas & $\square$ & $\square$ & $\square$ & $\square$ & $\square$ \\
\hline Motocicleta & $\square$ & $\square$ & $\square$ & $\square$ & 1 \\
\hline Máquina secadora de roupas & $\square$ & $\square$ & $\square$ & $\square$ & $\square$ \\
\hline
\end{tabular}

Qual é o grau de instrução do chefe de sua família, ou seja, da pessoa que é a principal responsável pelo pagamento das despesas de sua casa? (Selecione apenas uma resposta)

1. Analfabeto ou até $3^{\mathrm{a}}$ série do primário/ fundamental

2. Até a $4^{\mathrm{a}}$ série do primário/ fundamental completo

3. Primário/ Fundamental completo ou Ensino Médio incompleto

4. Ensino Médio completo ou Ensino Superior incompleto

5. Ensino Superior ou Pós-graduação completo

Sua casa possui água encanada? (Selecione apenas uma resposta)

1. Sim

2. Não

Sua casa está localizada em rua pavimentada? (Selecione apenas uma resposta)

1. Sim

2. Não 
Apêndice B - Estímulos que compuseram as estórias apresentadas nas celas de teste

a) Sequência de estímulos para situação de decisão URGENTE
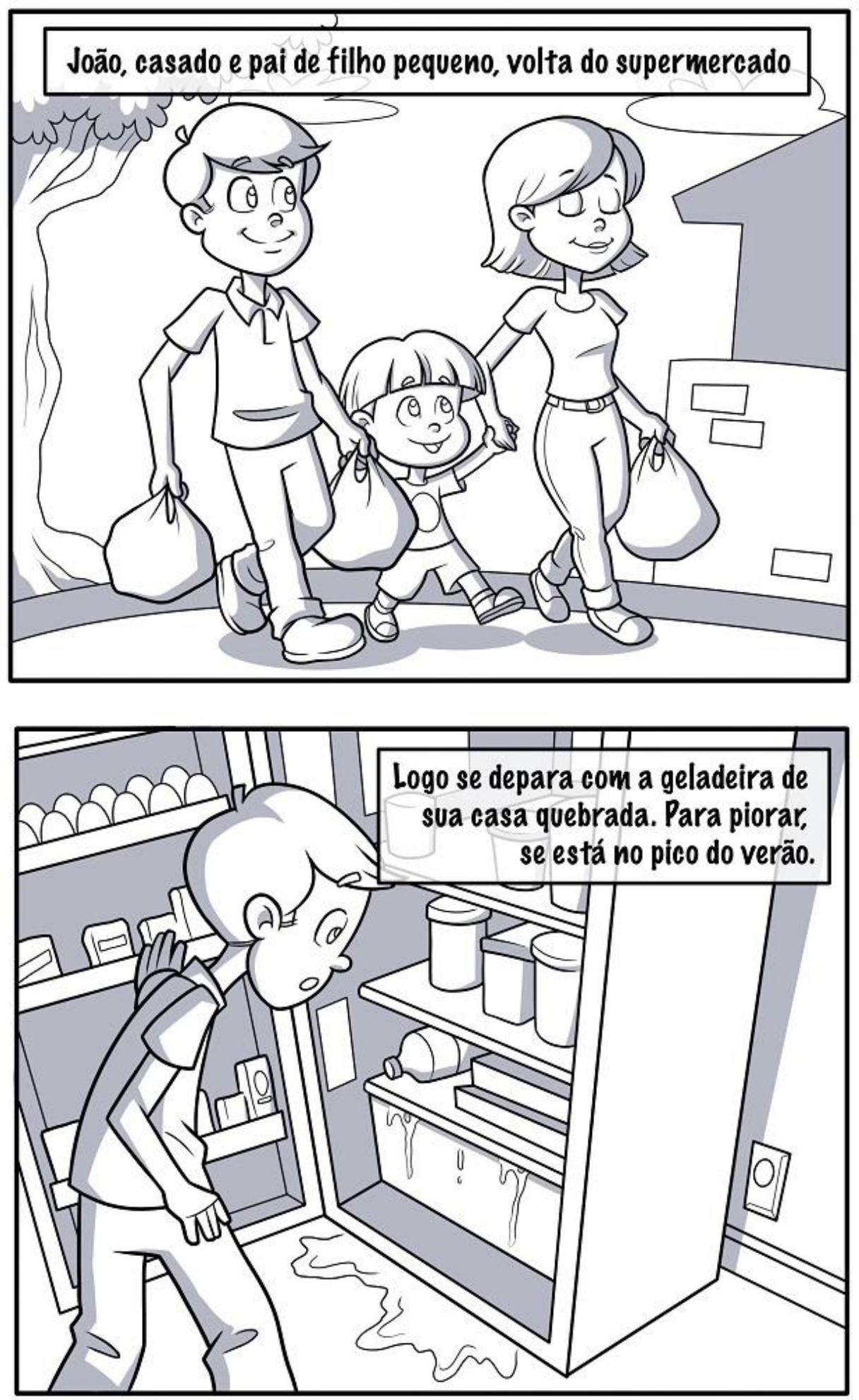


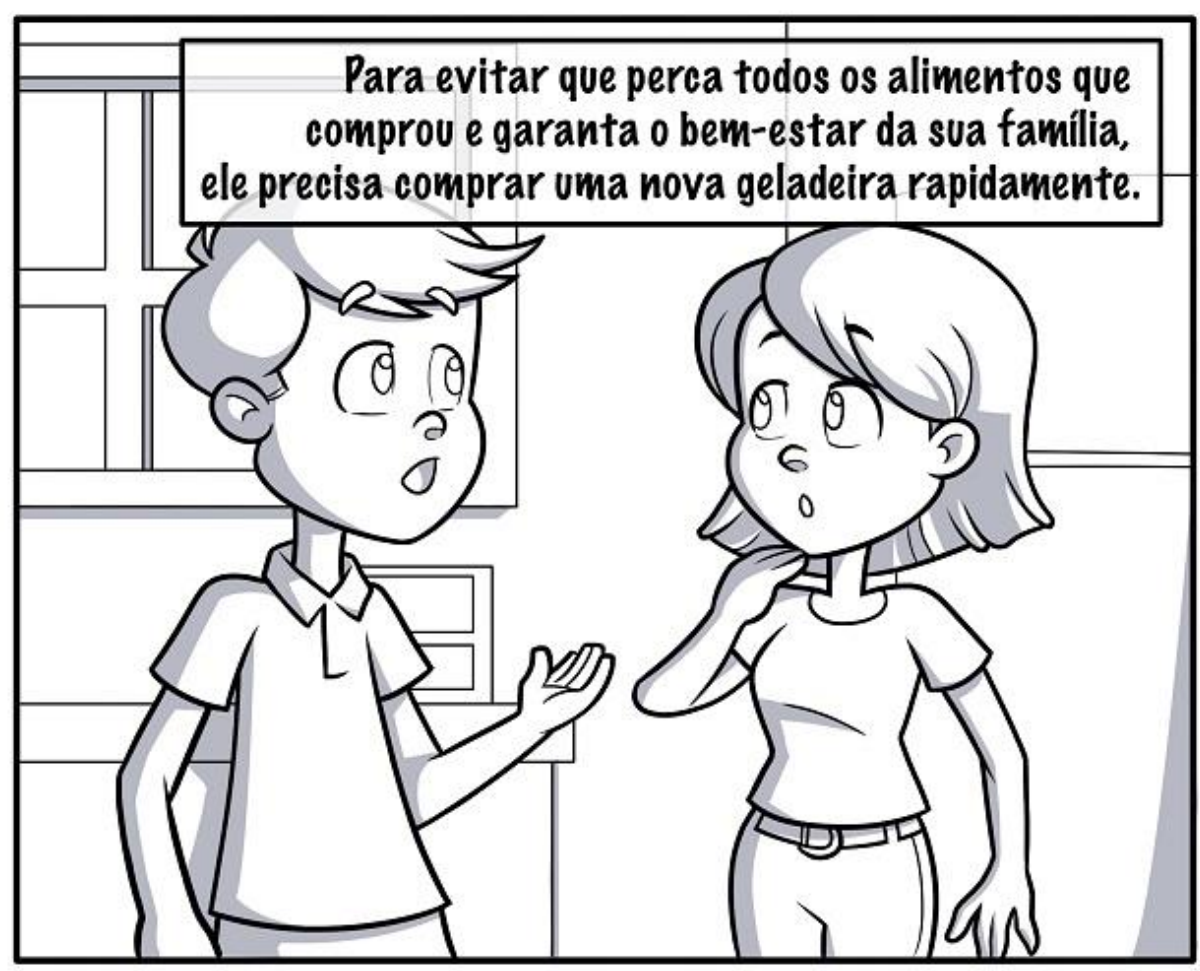

b) Sequência de estímulos para situação de decisão PLANEJADA

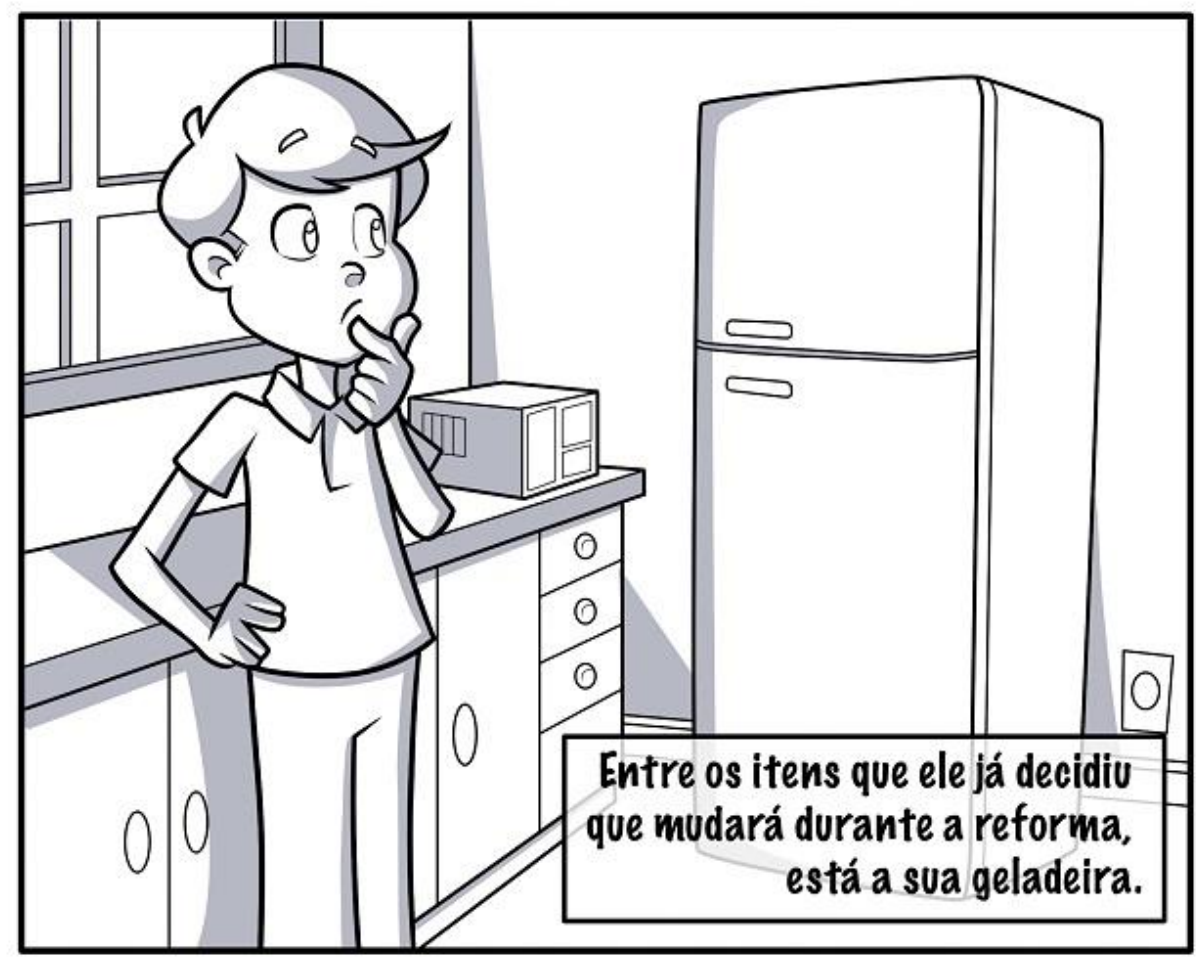



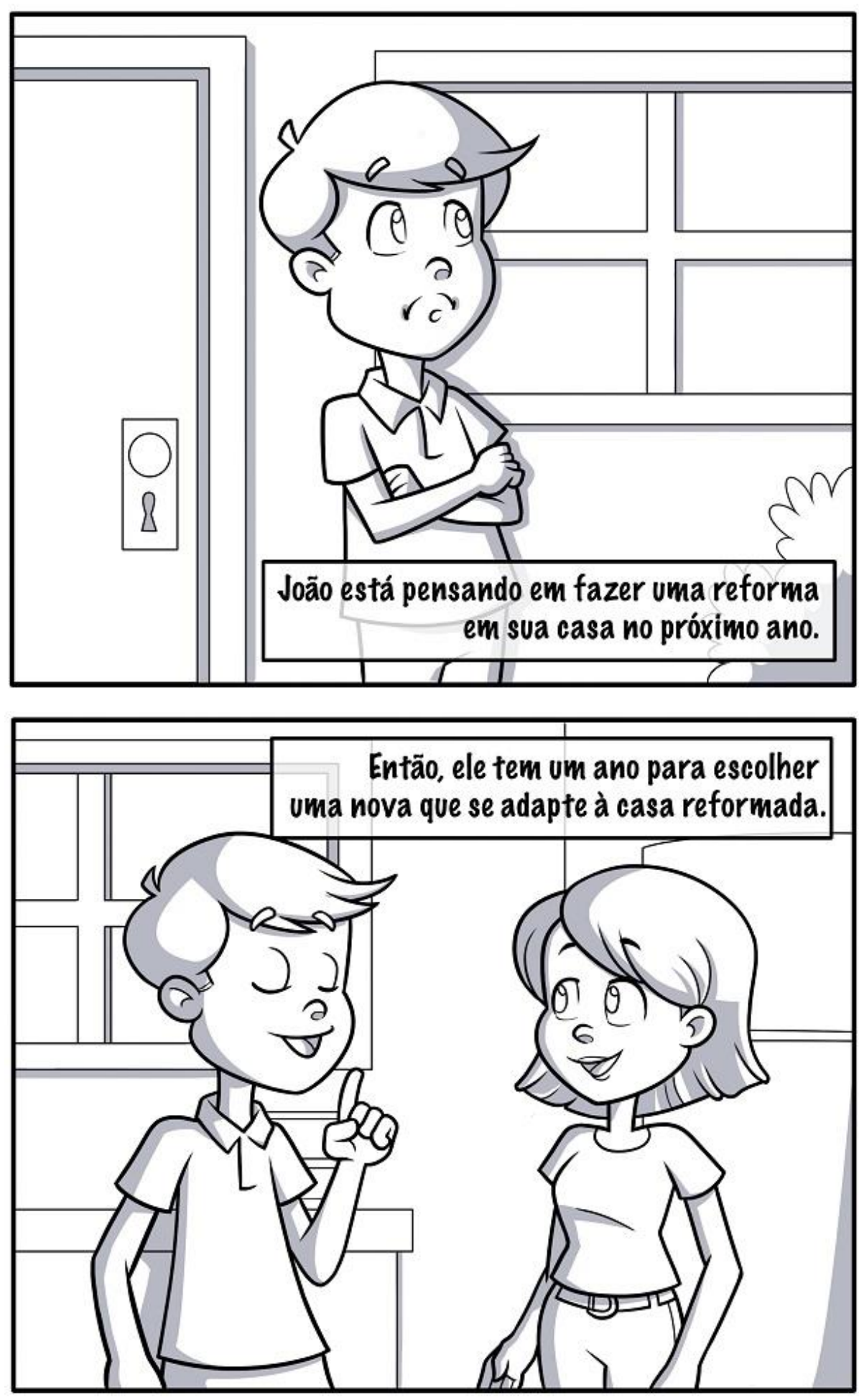
c) Estímulo para Marca Madura

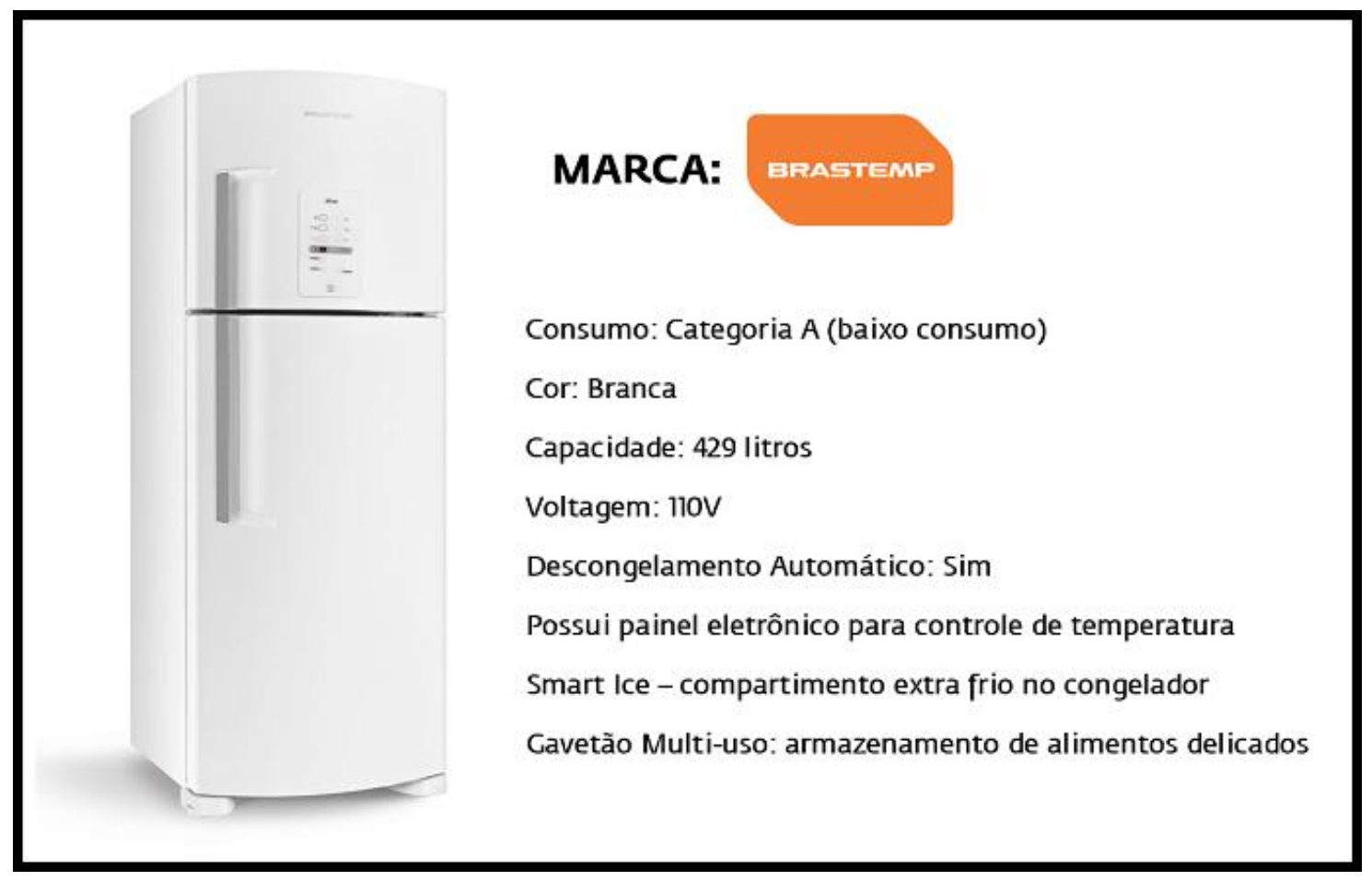

d) Estímulo para Marca Nova

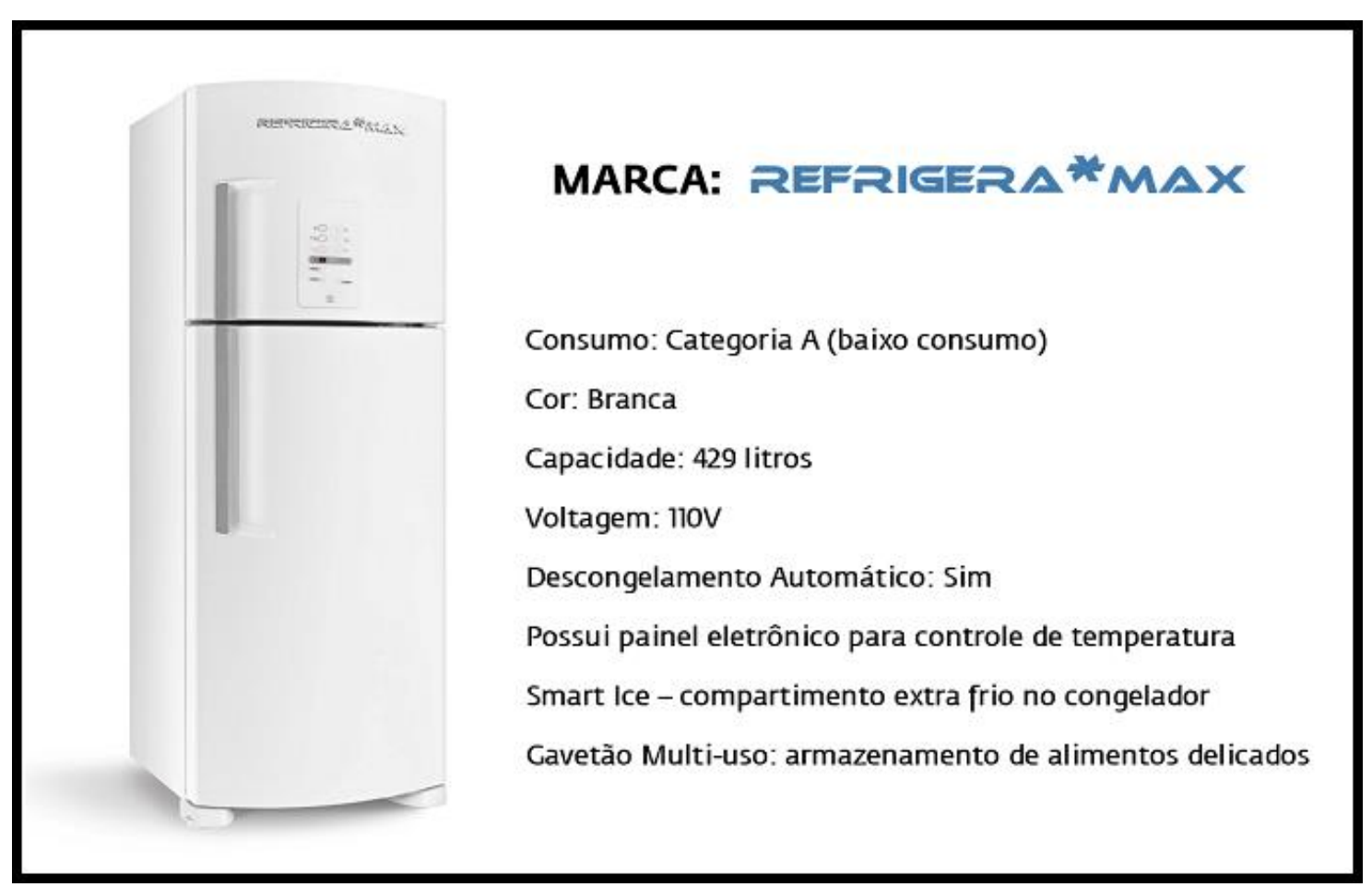


e) Estímulo para "boca a boca" positivo

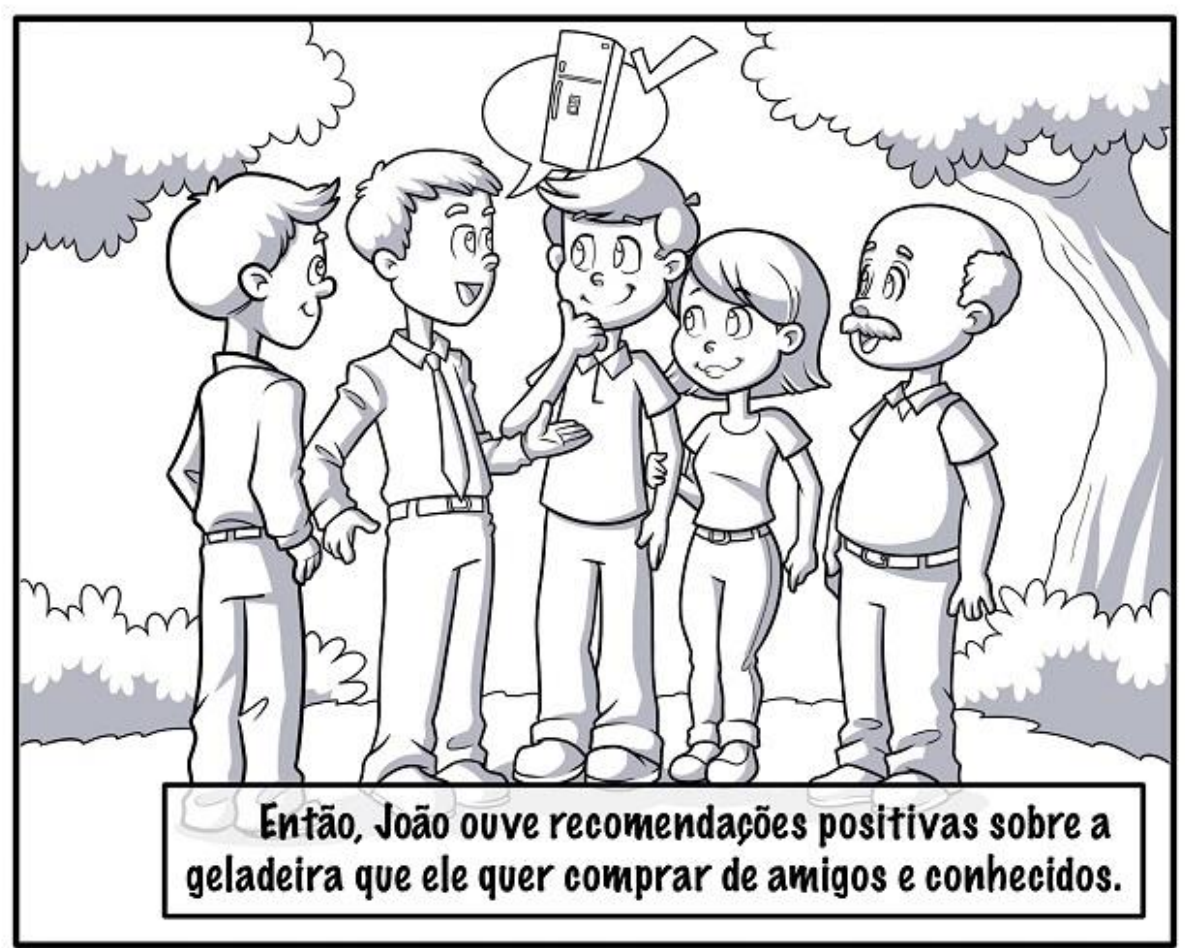

f) Estímulo para "boca a boca" negativo

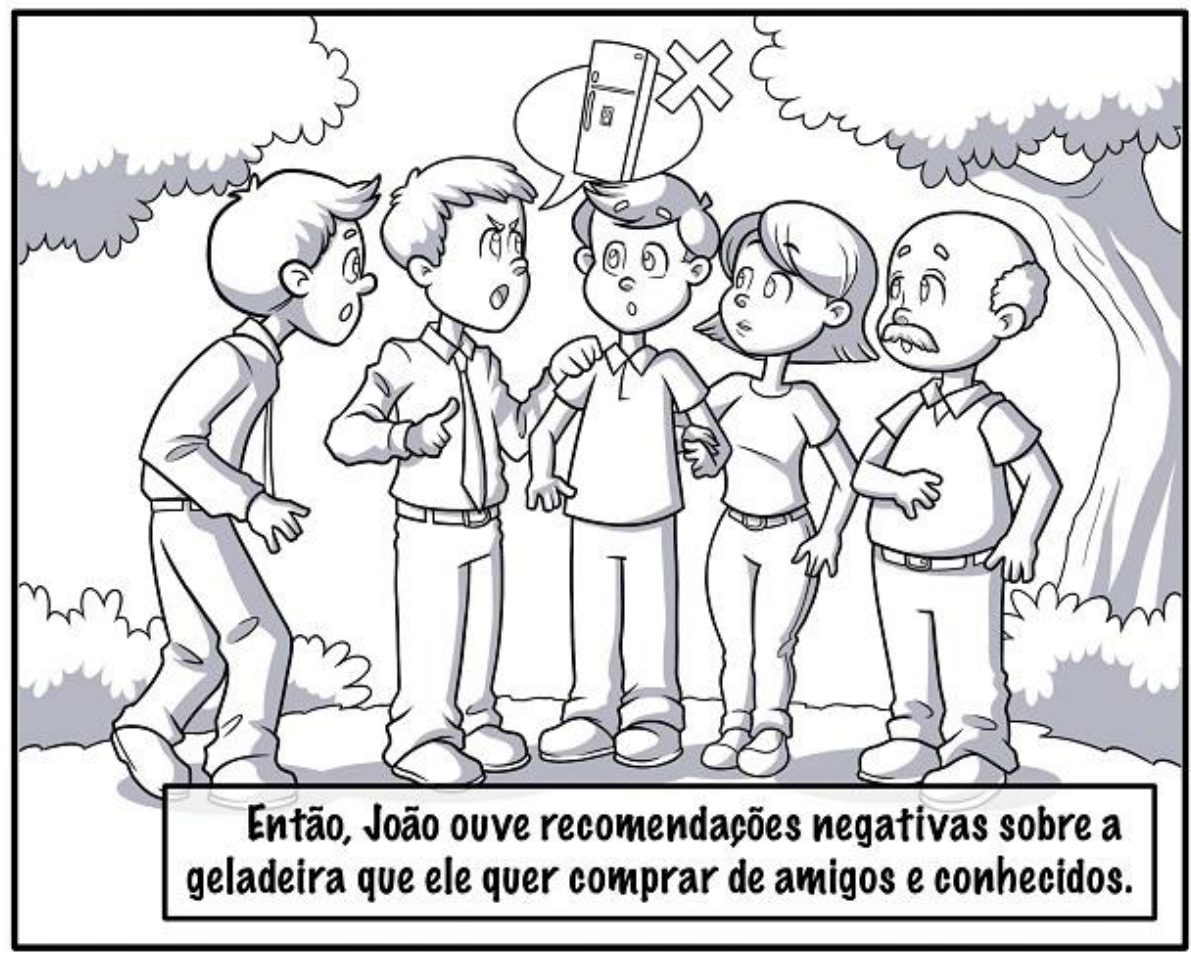


